\title{
Drop Test Results for the Combustion Engineering Model No. ABB-2901 Fuel Pellet Shipping Package
}

R. Hafner, G. Mok, and L. Hagler

\section{June 1, 2002}

U.S. Department of Energy

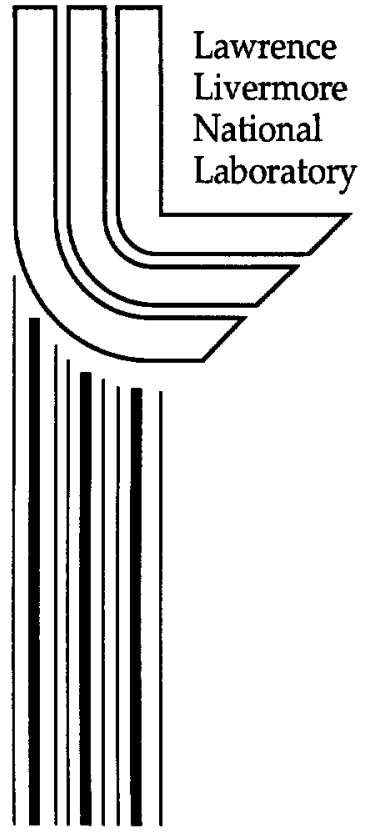




\section{DISCLAIMER}

This document was prepared as an account of work sponsored by an agency of the United States Government. Neither the United States Government nor the University of California nor any of their employees, makes any warranty, express or implied, or assumes any legal liability or responsibility for the accuracy, completeness, or usefulness of any information, apparatus, product, or process disclosed, or represents that its use would not infringe privately owned rights. Reference herein to any specific commercial product, process, or service by trade name, trademark, manufacturer, or otherwise, does not necessarily constitute or imply its endorsement, recommendation, or favoring by the United States Government or the University of California. The views and opinions of authors expressed herein do not necessarily state or reflect those of the United States Government or the University of California, and shall not be used for advertising or product endorsement purposes.

This work was performed under the auspices of the U.S. Department of Energy by the University of California, Lawrence Livermore National Laboratory under Contract No. W-7405-Eng-48.

This report has been reproduced directly from the best available copy.

Available electronically at http://www.doc.gov/bridge

Available for a processing fee to U.S. Department of Energy And its contractors in paper from

U.S. Department of Energy

Office of Scientific and Technical Information

P.O. Box 62

Oak Ridge, TN 37831-0062

Telephone: (865) 576-8401

Facsimile: (865) 576-5728

E-mail: reports@adonis.osti.gov

Available for the sale to the public from

U.S. Department of Commerce

National Technical Information Service

5285 Port Royal Road

Springfield, VA 22161

Telephone: (800) 553-6847

Facsimile: (703) 605-6900

E-mail: orders@ntis.fedworld.gov

Online ordering: http://www.ntis.gov/ordering.htm

OR

Lawrence Livermore National Laboratory

Technical Information Department's Digital Library

http://www.llnl.gov/tid/Library.html 


\section{Executive Summary}

The U.S. Nuclear Regulatory Commission (USNRC) contracted with the Packaging Review Group (PRG) at Lawrence Livermore National Laboratory (LLNL) to conduct a single, 30-ft shallow-angle drop test on the Combustion Engineering ABB-2901 drum-type shipping package. The purpose of the test was to determine if bolted-ring drum closures could fail during shallowangle drops.

The PRG at LLNL planned the test (see Appendix A of this report), and Defense Technologies Engineering Division (DTED) personnel from LLNL's Site-300 Test Group executed the plan. The test was conducted in November 2001 using the drop-tower facility at LLNL's Site 300. Two representatives from Westinghouse Electric Company in Columbia, South Carolina (WEC-SC), two USNRC staff members, and three PRG members from LLNL witnessed the preliminary test runs and the final test.

The single test clearly demonstrated the vulnerability of the bolted-ring drum closure to shallowangle drops - the test package's drum closure was easily and totally separated from the drum package.

The results of the preliminary test runs and the $30-\mathrm{ft}$ shallow-angle drop test offer valuable qualitative understandings of the shallow-angle impact.

- A drum package with a bolted-ring closure may be vulnerable to closure failure by the shallow-angle drop, even if results of the steep-angle drop demonstrate that the package is resistant to similar damage.

- Although there exist other mechanisms, the shallow-angle drop produces closure failure mainly by buckling the drum lid and separating the drum lid and body, which the bolted ring cannot prevent.

- Since the closure failure by the shallow-angle drop is generated mainly by structural instabilities of a highly discontinuous joint, the phenomenon can be rather unpredictable. Thus, a larger-than-normal margin of safety is recommended for the design of such packages.

- The structural integrity of the bolted-ring drum closure design depends on a number of factors. To ensure that the drum closure survives the shallow-angle drop, the following general qualitative rules should be observed:

- The drum closure components should be quality products made of ductile materials, and the torque value for tightening the bolted ring should be included in the SAR and operating procedures to ensure quality.

- The package should not be too heavy.

- The package internal structure should be impact-absorbent and resistant to disintegration and collapse under high compressive load. However, a strong internal structure may defeat the purpose of protecting the containment vessel from damage during a free drop. 
- If not previously tested, drum packages with bolted-ring drum closures should be drop-tested at shallow angles. Due to the unpredictable nature of the behavior, the demonstration should be completed by test and on a case-by-case basis. The test plan should take into account the behavior's sensitivity to the details of the package design and the impact condition.

- Because the shallow-angle drop can open the drum closure, organizations using these types of drum packages should assess the consequences of exposing the radioactive contents in the containment vessel to unconsidered external elements or conditions. 


\section{Table of Contents}

1.0 Introduction

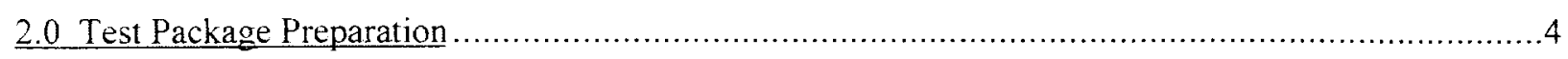

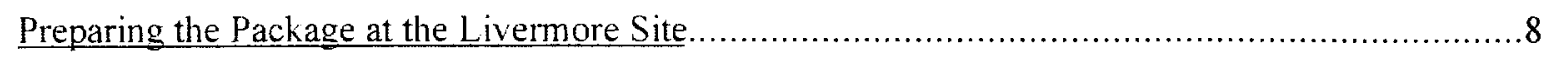

3.0 Test Setup and Preliminary Test Runs...................................................................... 15

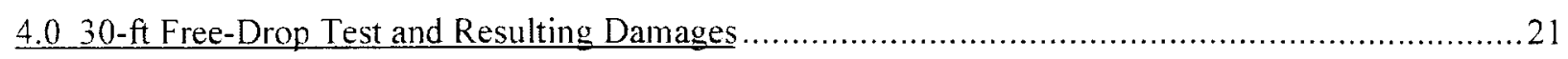

4.1 Drum lid and closure ring ............................................................................. 23

4.2 Round plywood boards between the lid and the containment box ...................................24

4.3 Hardboards and plywood rings at the impact end .................................................. 25

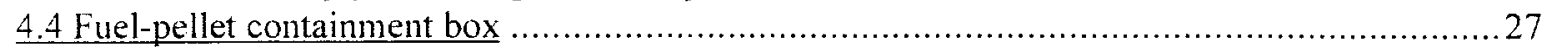

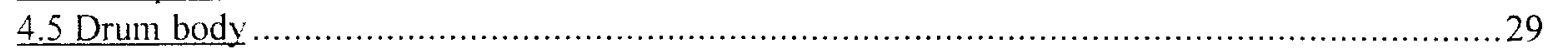

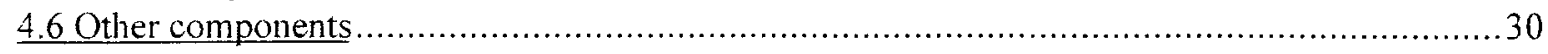

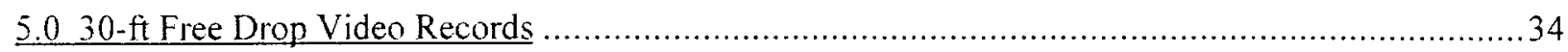

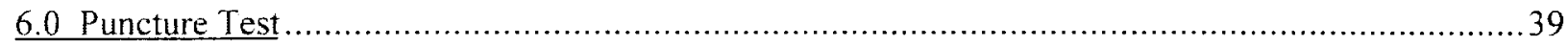

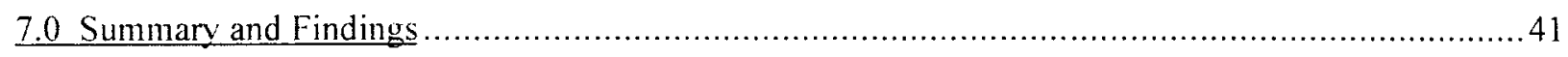

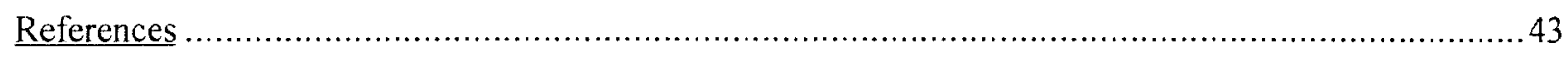

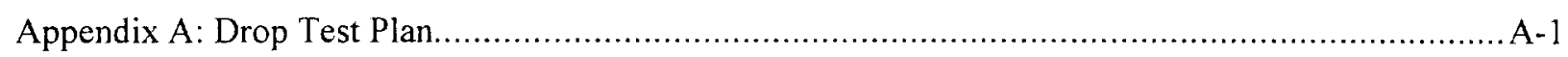

\section{List of Figures}

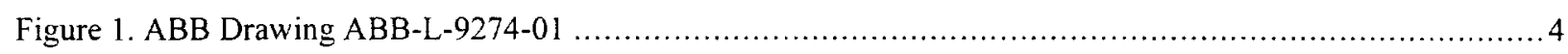

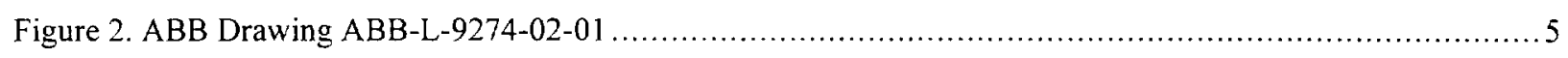

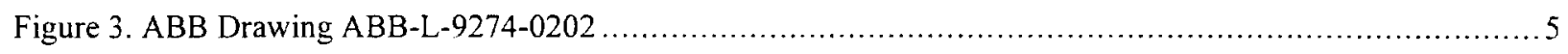

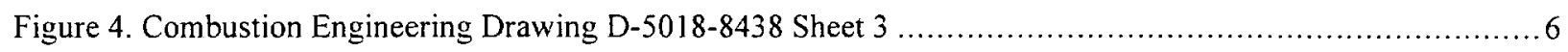

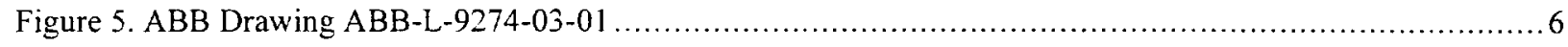

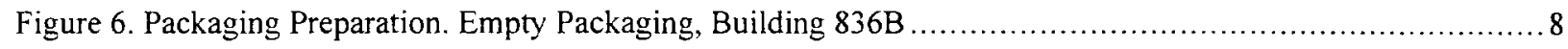

Figure 7. Packaging Prep and Weighing. Empty Package, Bldg. 836B ............................................

Figure 8. Packaging Preparation, Pellet Tray Removal (I), Bldg. 836B ...........................................

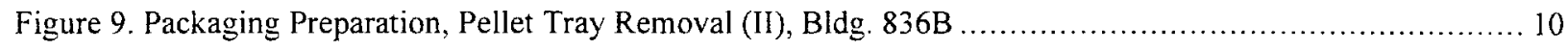

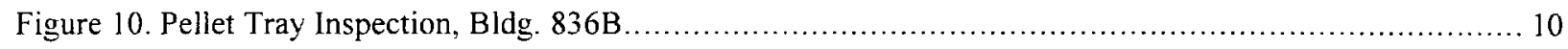

Figure 11. Pellet Tray Loading and Weighing (I), Bldg. 836C ................................................ 11

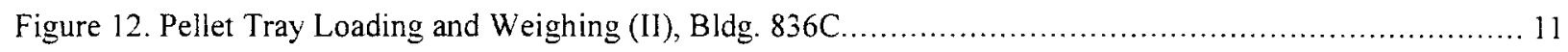

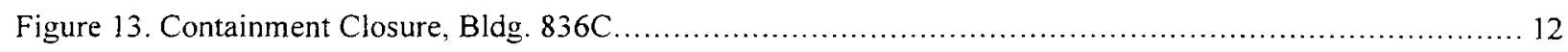

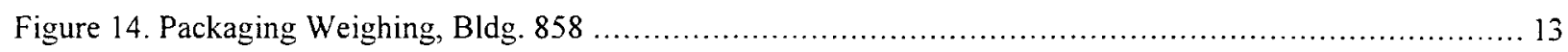

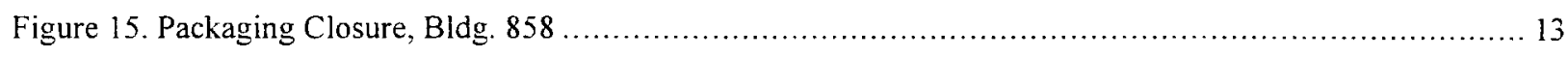

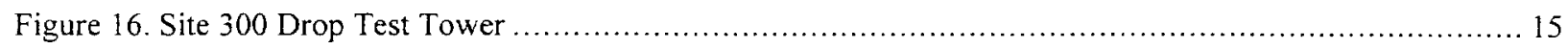


Drop Test Results

for the ABB-2901 Package

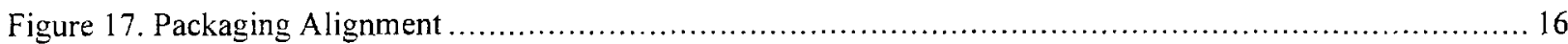

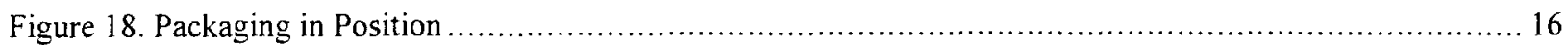

Figure 19. Distances from the cameras to the center of the test pad, and from the center of the test pad to the center of the grid boards

Figure 20. Damage to Lid, Closure Ring and Drum Along Side of Damage to Previously Dropped 35-Gallon,

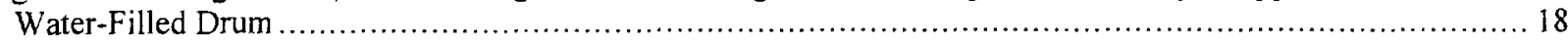

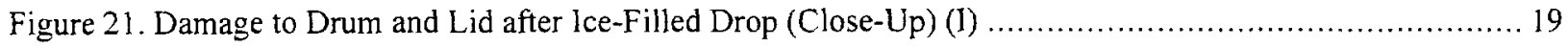

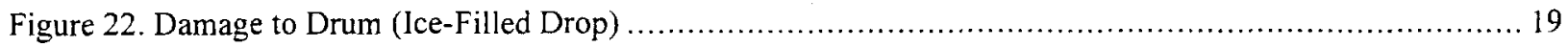

Figure 23. Close-Up of Ice Section from Bottom of Drum w/Quarter for Relative Size ............................ 20

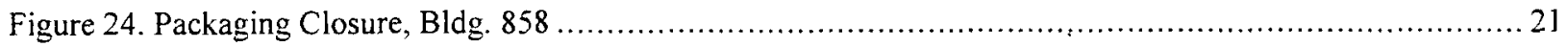

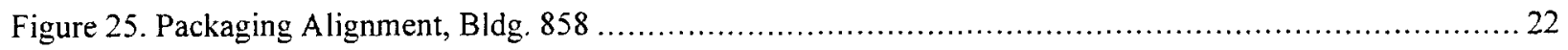

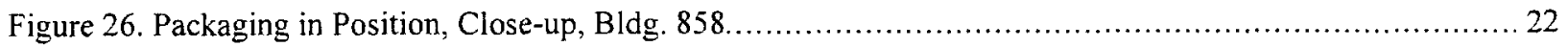

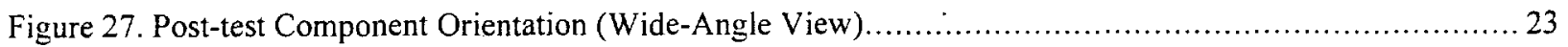

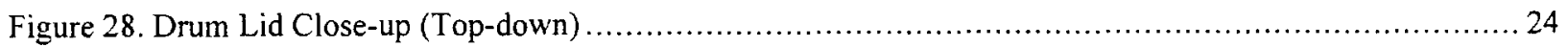

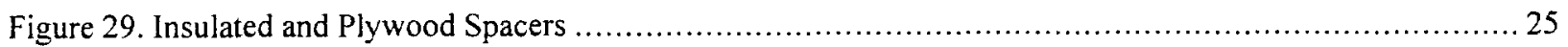

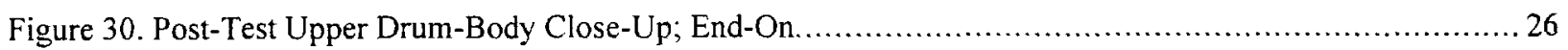

Figure 31. Lower 1" Inner Compartment Plywood Spacer ................................................................... 26

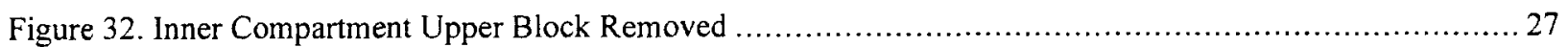

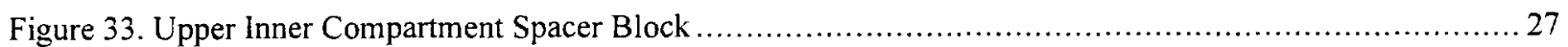

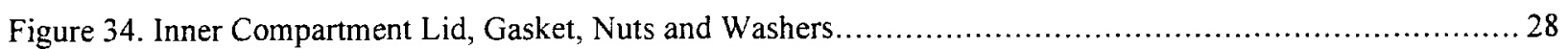

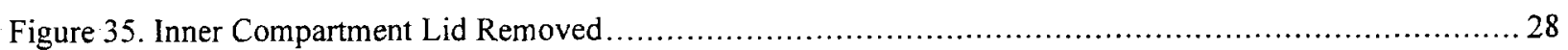

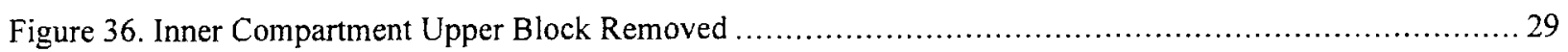

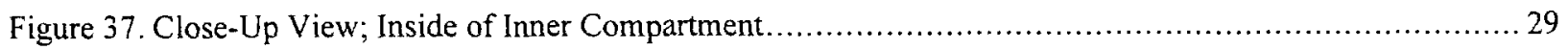

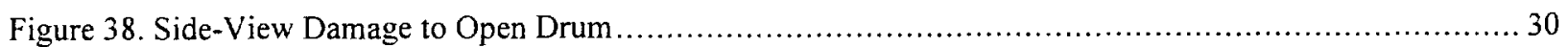

Figure 39. Upper, Inner Compartment Spacer Block, Pellet Trays; Pellet Tray Box, and Drum....................... 31

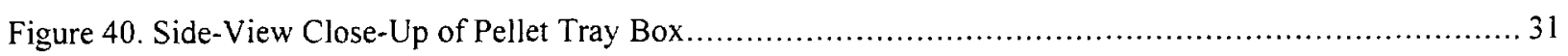

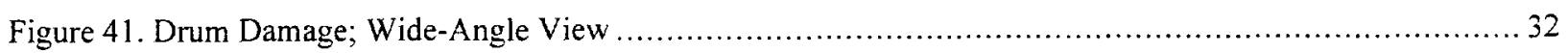

Figure 42. The lowest edge of the drum package was about to hit the unyielding target surface..................... 34

Figure 43. The lowest edge of the drum package had impacted the target. The impact had already caused some

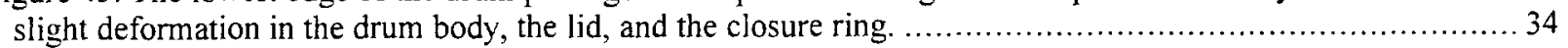

Figure 44. Large deformation of the package had occurred in the impact area. .................................... 35

Figure 45 . The drum-lid-and-ring assembly began to separate from the drum body . ............................. 35

Figure 46. The top edge of the drum body near the closure ring appeared to be pushed outward (or upward)....... 36

Figure 47. The top edges of the drum-lid-and-ring assembly and of the drum body started to separate............... 37

Figure 48. The impact end of the drum package appeared to have stopped deforming and started to rebound........ 37 
Drop Test Results

for the ABB-2901 Package

Figure 49. The frames between Frame +3 and this frame show bending vibrations of the drum-lid-and-ring assembly.

Figure 50. Drum Damage; Wide-Angle View 


\subsection{Introduction}

Steel cylindrical drums have been used for many years to transport radioactive materials. The radioactive material inserted into the drum cavity for shipping is usually restrained within its own container or containment vessel. For additional protection, the container is surrounded or supported by components made of impact-absorbent and/or thermal-insulation materials. The components are expected to protect the container and its radioactive contents under severe transportation conditions like free drops and fires.

Due to its simplicity and convenience, bolted-ring drum closures are commonly used to close many drum packages. Because the structural integrity of the drum and drum closure often play a significant role in determining the package's ability to maintain sub-criticality, shielding, and containment of the radioactive contents, regulations require that the complete drum package be tested for safety performance.

The structural integrity of the drum body is relatively simple to understand and analyze, whereas analyzing the integrity of the drum closure is not so simple.

Steep-angle drop tests. The common bolted-ring drum closure has been tested and shown to be resistant to damage under the regulatory $30-\mathrm{ft}$ free-drop condition. Frequently, only steep-angle drop tests are used to test drum packages because they are generally recognized to produce the largest impact forces. In most steep-angle drop tests, a drum package is dropped upside down (the open end of the drum) at a "steep angle," that is, with the drum axis so oriented that the center of gravity of the package is aligned vertically with the center of the impact area. The socalled "end-on," "top-down," and "center-of-gravity (c.g.)-over-corner" drops are examples of steep-angle drops.

Under loads, the integrity of the drum closure depends not only on the magnitude of the applied load but also on the direction of the load relative to the closure geometry. Indeed, the steep-angle drop can produce large deformations due to its greater force, but it tends to crush the drum closure components (the drum body, lid, and ring) together due to its impact direction. Thus, the drum closure seldom opens during steep-angle drops.

Shallow-angle drop tests. On the contrary, openings have occurred in shallow-angle drop tests. In the shallow-angle drop, the drum package is dropped upside down with its axis nearly parallel to the horizontal plane. The impact force of the shallow-angle drop is considerably smaller than that of the steep-angle drop, but its line of action lies almost in the plane of the drum lid. Thus, the impact force can easily cause the lid to buckle outward and move away from the drum body. While the shallow-angle drop does not have the great force of the steep-angle drop, it has the unique ability to drive the drum closure components apart.

The shallow-angle drop is frequently ignored in test plans for the bolted-ring drum package simply because the shallow-angle drop is not known to produce great impact forces.

Failures leading to the LLNL test. Few people are aware of the studies by Lewallen (1972) and Towell (1988) that recommended weight limits for preventing closure failures. In addition, several shallow-angle drop tests conducted by the Department of Energy at the Savannah River 
Site in Aiken, South Carolina (WSRC 2001), have demonstrated the complete opening of the drum closure. The most recent drum closure failure, a 9975 package during a 30-ft, $17.5^{\circ}$ shallow-angle drop in March 2000 (Hagler 2000), prompted Westinghouse Savannah River Corporation (WSRC) to replace the package's bolted-ring drum closure with a bolted-lid system.

The failure was brought to the attention of the U.S. Nuclear Regulatory Commission (USNRC) who contracted the Packaging Review Group (PRG) at Lawrence Livermore National Laboratory (LLNL) to conduct a single, 30 -ft shallow-angle drop test of a drum package. The purpose of the test was to determine if a bolted-ring closure could fail during a shallow-angle drop.

The LLNL shallow-angle test. The PRG at LLNL planned the test (see Appendix A of this report), and DTED personnel from LLNL's Site-300 Test Group executed the plan.

Westinghouse Electric Company at Columbia, South Carolina (WEC-SC) generously donated the empty test drum package. The test was conducted in November 2001 using the drop-tower facility at LLNL's Site 300.

The following personnel were in attendance to prepare, witness, and offer advice on the package during the preliminary test runs and the final shallow-angle drop test.

\begin{tabular}{|l|l|}
\hline Name & Organization \\
\hline Henry W. Lee & USNRC \\
\hline Ronald W. Parkhill & USNRC \\
\hline Paul F. McMahon & WEC-SC \\
\hline Brian E. Hempy & WEC-SC \\
\hline Ronald S. Hafner & LLNL PRG \\
\hline Lisle B. Hagler & LLNL PRG \\
\hline Gerald C. (Gerry) Mok & LLNL PRG \\
\hline Douglas K. Vogt & LLNL PRG \\
\hline Alan L. Brooks & LLNL Site 300 Test Engineer \\
\hline Leslie B. (Bruce) Clegg & LLNL Site 300 Test Group Technician \\
\hline Robert J. Daily & LLNL Site 300 Test Group Technician \\
\hline Mark W. Giles & Test Preparation \\
\hline Bruce J. Greenfield & Test Preparation \\
\hline Jesse M. Rivera & LLNL Site 300 Test Group Technician \\
\hline Ronald P. Samoian & LLNL Site 300 Test Group Engineer \\
\hline Richard J. Villafana & LLNL Site 300 Test Group Technician \\
\hline Thomas G. Woehrle & LLNL Site 300 Test Group Technician \\
\hline
\end{tabular}


This report documents the procedures and results for the preliminary test runs and the final shallow-angle drop test. Section 2.0 describes the design and preparation details of the test drum package. Section 3.0 outlines the test setup and preliminary-test-run results. Section 4.0 reviews the $30-\mathrm{ft}, 17.5^{\circ}$ shallow-angle drop test and damage to the test package. Section 5.0 analyzes the high-speed digital video record of the $30-\mathrm{ft}$ drop test. Section 6.0 summarizes the findings of this test program. Appendix A is the ABB-2901 Test Plan. Although the Test Plan included procedures for a puncture test to follow the $30-\mathrm{ft}$ shallow-angle drop test, the complete separation of the drum lid during the final drop test made the puncture test unnecessary. 


\subsection{Test Package Preparation}

The empty drum package supplied by WEC-SC is the Combustion Engineering Fuel Pellet Shipping Package, Model No. ABB-2901. The Safety Analysis Report (Combustion Engineering 1997) describes its design and safety performance. Five engineering drawings from the SAR are reproduced in Figures 1-5 to aid the following brief description of the structural design.

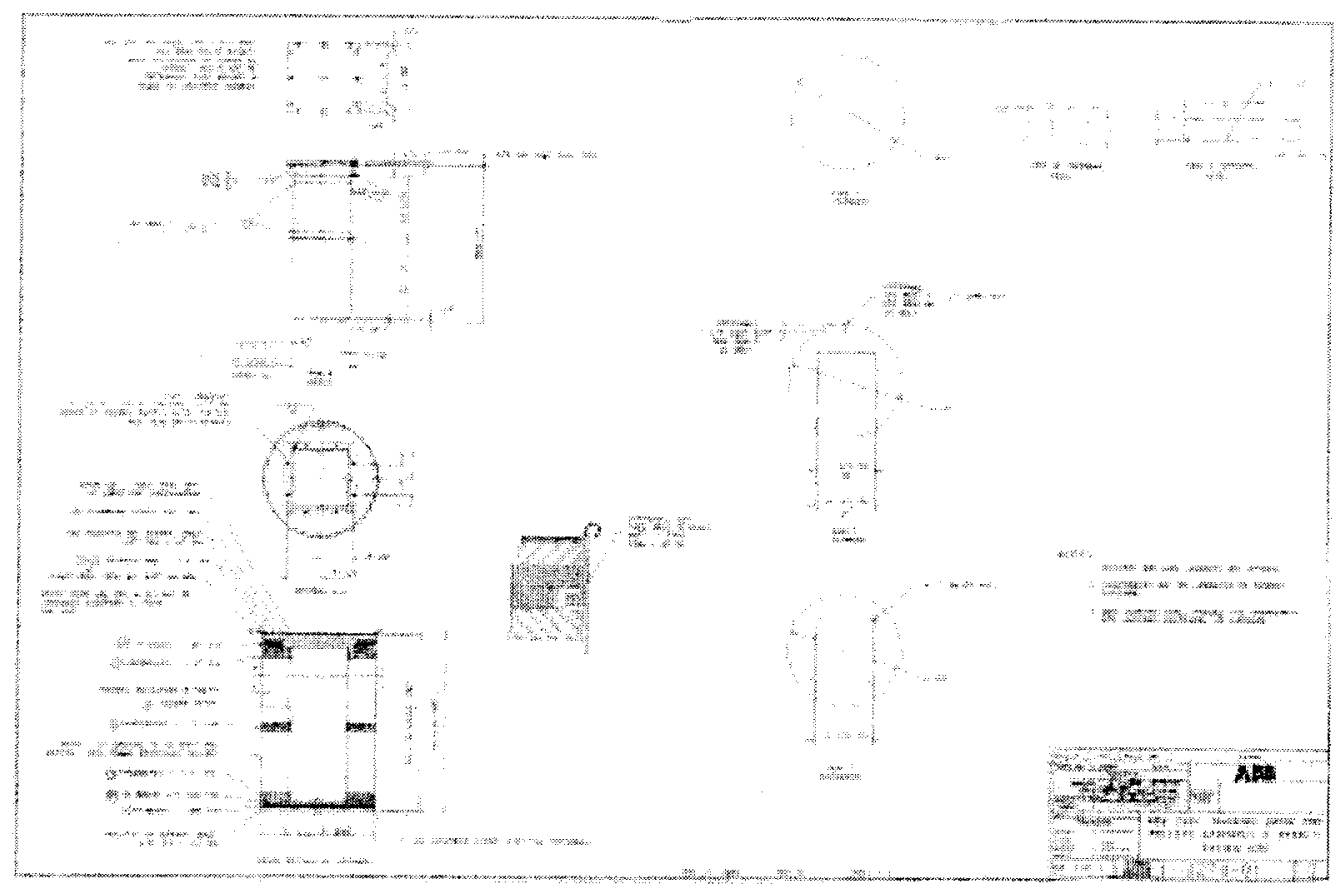

Figure 1. ABB Drawing ABB-L-9274-01 


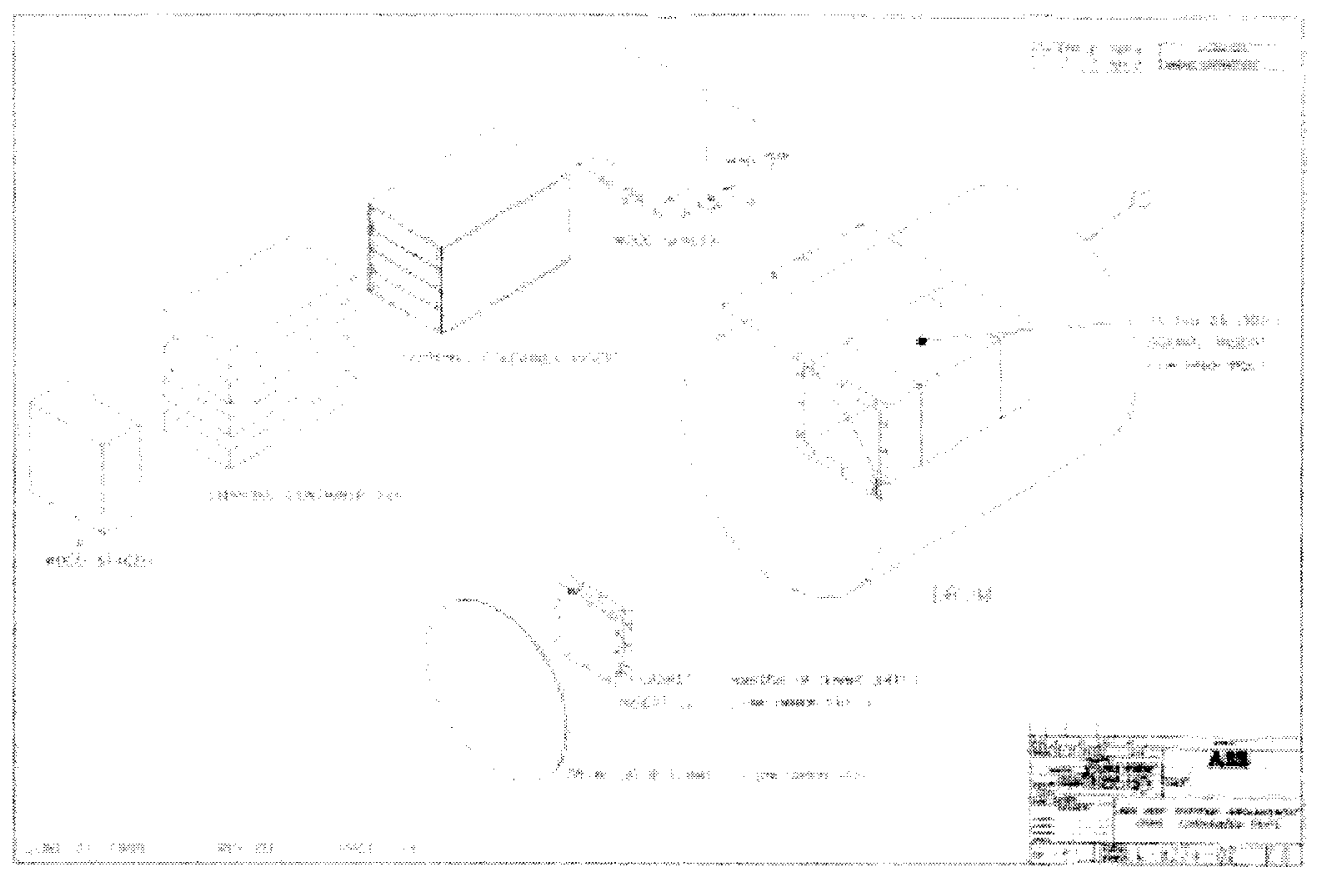

Figure 2. ABB Drawing ABB-L-9274-02-01

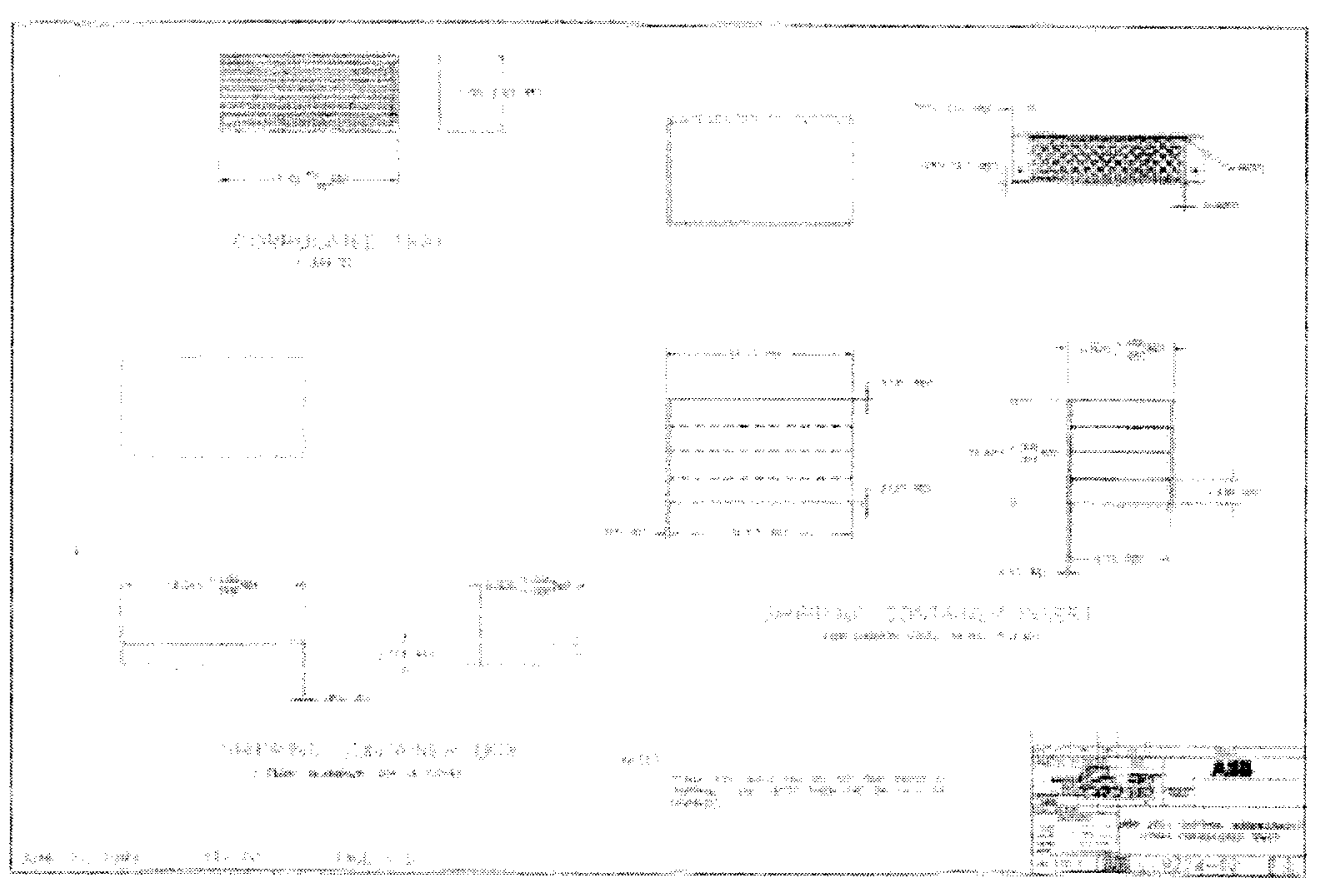

Figure 3. ABB Drawing ABB-L-9274-0202 


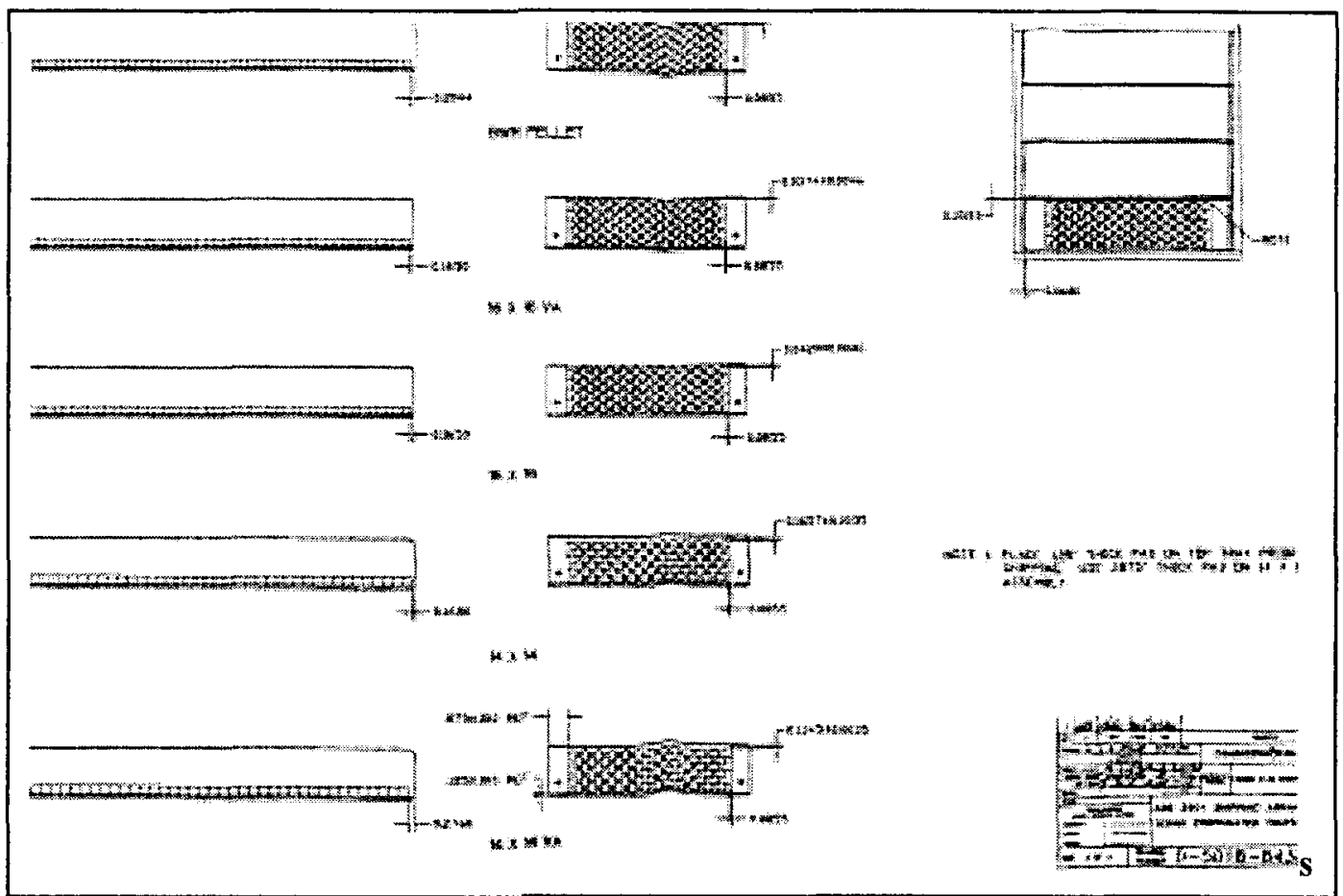

Figure 4. Combustion Engineering Drawing D-5018-8438 Sheet 3

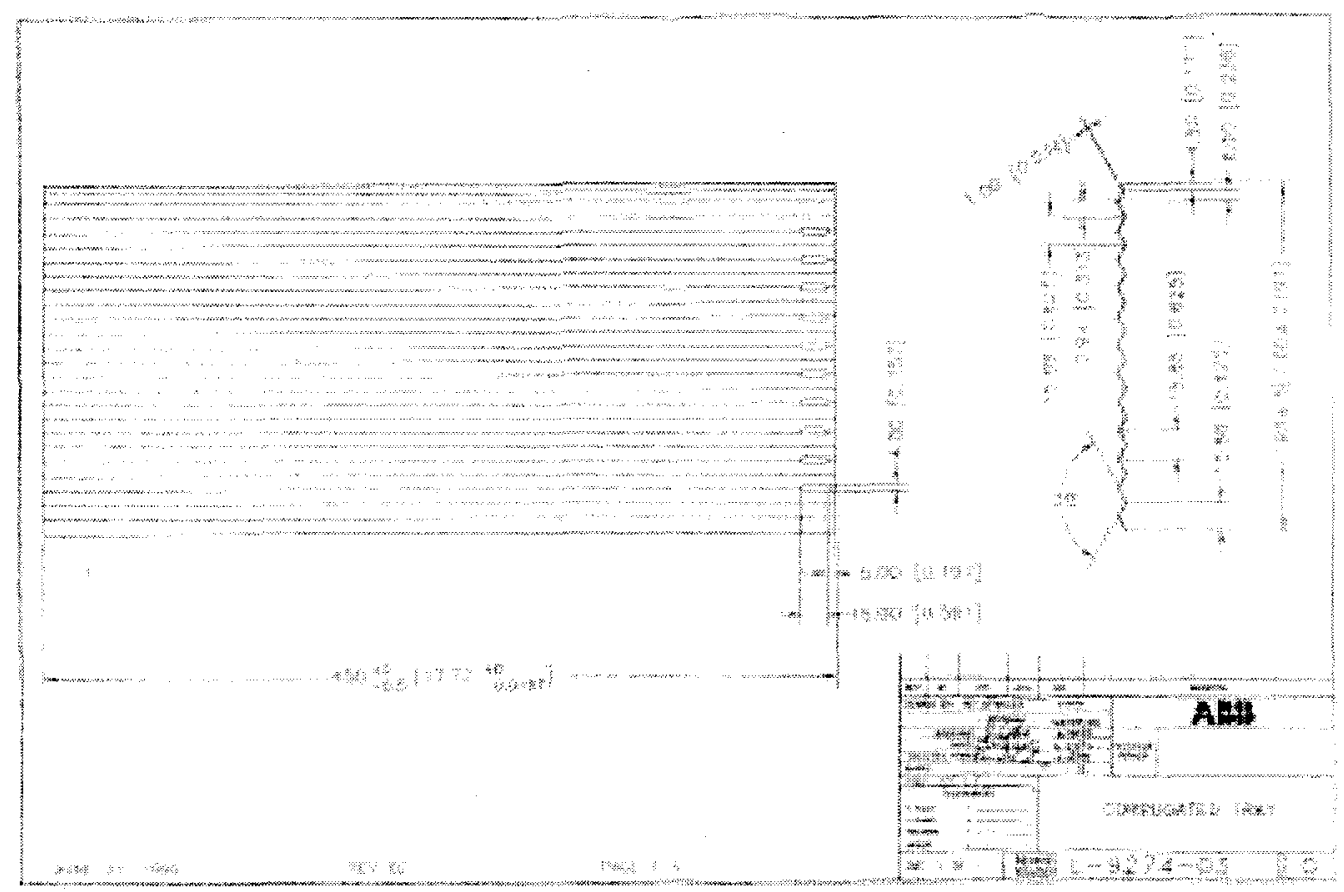

Figure 5. ABB Drawing ABB-L-9274-03-01

The cylindrical drum package, measured about two feet in diameter and three feet in height is a typical 55-gallon drum package. The open end of the thin-walled steel drum is closed using a flat circular steel lid and a bolted steel ring with a C-shaped cross-section. The bolted-ring closure device is common to many drum packages. To close the drum, the closure ring wraps around the 
drum opening and grips the rims of the opening and the lid with its $\mathrm{C}$-shaped cross-section. The ring is closed using a bolt, which passes through two lugs or nuts welded to the two ends of the open ring. The gripping pressure is adjusted by tightening or loosening the closure bolt.

Inside the drum cavity is a deep square steel box, used to contain the fuel pellets for shipment. The inner compartment (i.e., "containment box"), approximately $10 " \times 10 " \times 30$ " in size, is supported in the radial direction of the drum using hardboard and plywood rings that have a square hole at the center. The box is also supported in the axial direction using round solid plywood boards (without a hole). The open end of the box is closed with a square steel lid bolted to the box-opening flange using twelve $1 / 2 \_13 \mathrm{UNC}$ nuts threaded onto their corresponding studs, mounted on the flange. During shipment, fuel pellets are stored on corrugated trays inside four shallow rectangular storage boxes. The storage boxes are then inserted into the shipping container insert inside of the containment box. The storage boxes and insert are prevented from axial movements by two wood spacers located at the two ends of the containment box. The containment box with its contents is in turn prevented from sliding out of the drum by the front hardboard ring and a small steel internal tab tack-welded to the inner drum wall. Empty drumcavity space between the hardboard ring is filled with low-density thermal-insulation materials. The drum cavity top and bottom are covered with thermal-insulation sheets taped to one of the round solid plywood boards. 


\section{Preparing the Package at the Livermore Site}

WEC-SC shipped the empty drum package, in its normal tied-down position, to LLNL's Site 300. Three LLNL staff members, Ronald S. (Ron) Hafner, Lisle B. Hagler and Gerald C. (Gerry) Mok inspected the package in October 2001 and found its visible parts generally matching the descriptions in the Combustion Engineering drawings. The containment box was not removed for inspection due to blockage by the metal internal tab. However, the metal internal tab tackwelded to the inner drum wall (whose function it is to stop the containment box from sliding), appeared rather feeble considering the weight of the containment box and contents.

In November 2001, a team of technicians from LLNL's Site-300 Test Group, which included Leslie B. (Bruce) Clegg, Robert J. (Bob) Daily, Richard J. (Rich) Villafana, and Ronald P. (Ron) Samoian, lead test engineer, prepared the empty drum package for testing (see Figures 6 through 9). Additional contributors to earlier preparation work included Mark W. Giles and Bruce J. Greenfield. The two WEC-SC representatives, Paul F. McMahon and Brian E. Hempy, and two LLNL PRG staff members, Ron Hafner and Lisle Hagler, were present to witness the operations. The empty test drum weighed 471 pounds before the LLNL team inserted a predetermined amount of prefabricated steel plates into the four storage boxes in the test package to simulate the mass of fuel pellets (see Figures 10 through 12). Closure of the inner compartment was provided by tightening the twelve 1/2_13 UNC containment-box lid nuts to $30 \mathrm{ft}-\mathrm{lb}$ (see Figure 13).

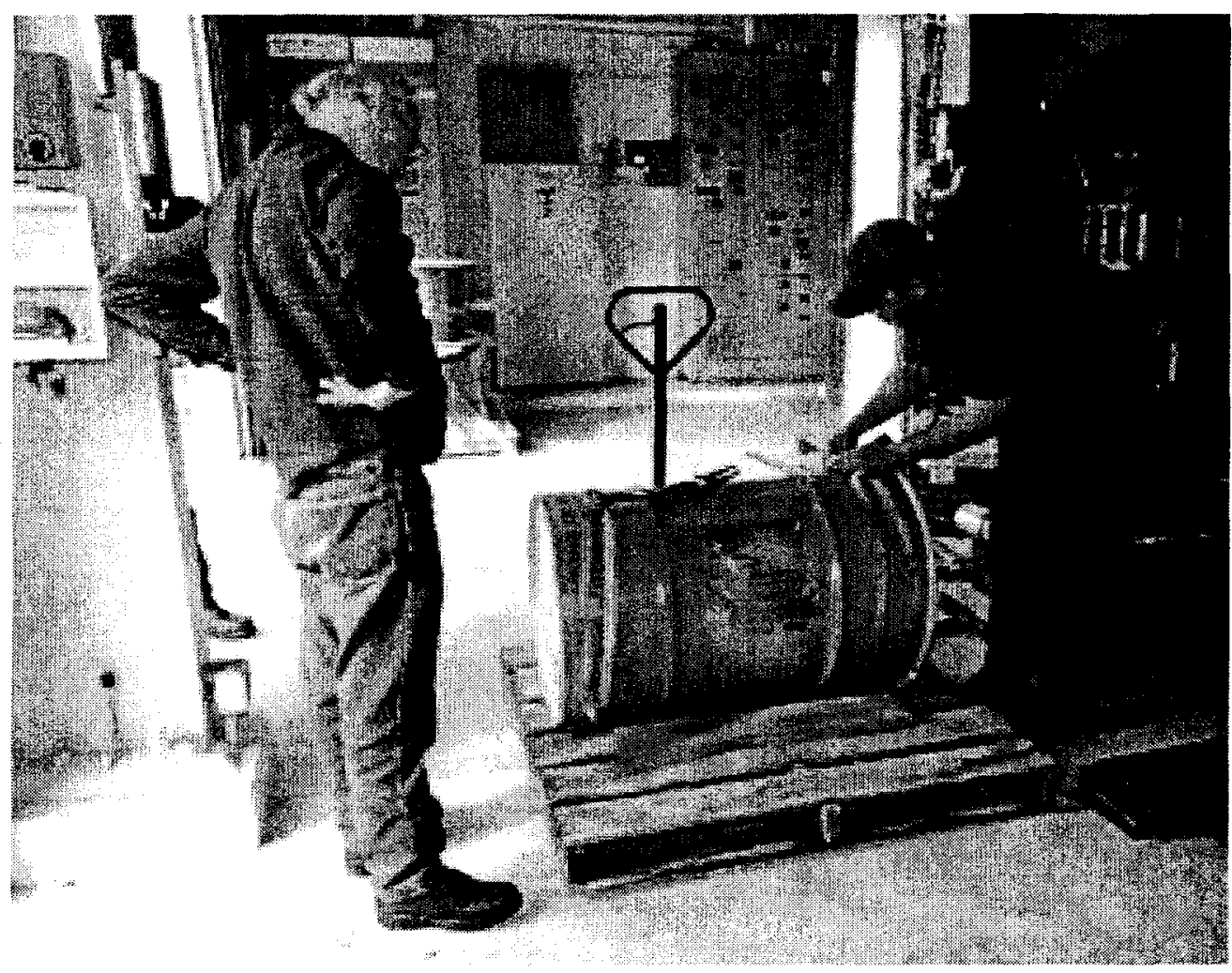

Figure 6. Packaging Preparation. Empty Packaging, Building 836B From left, Bruce Clegg (LLNL) and Rich Villafana (LLNL) 
Drop Test Results for the ABB-2901 Package

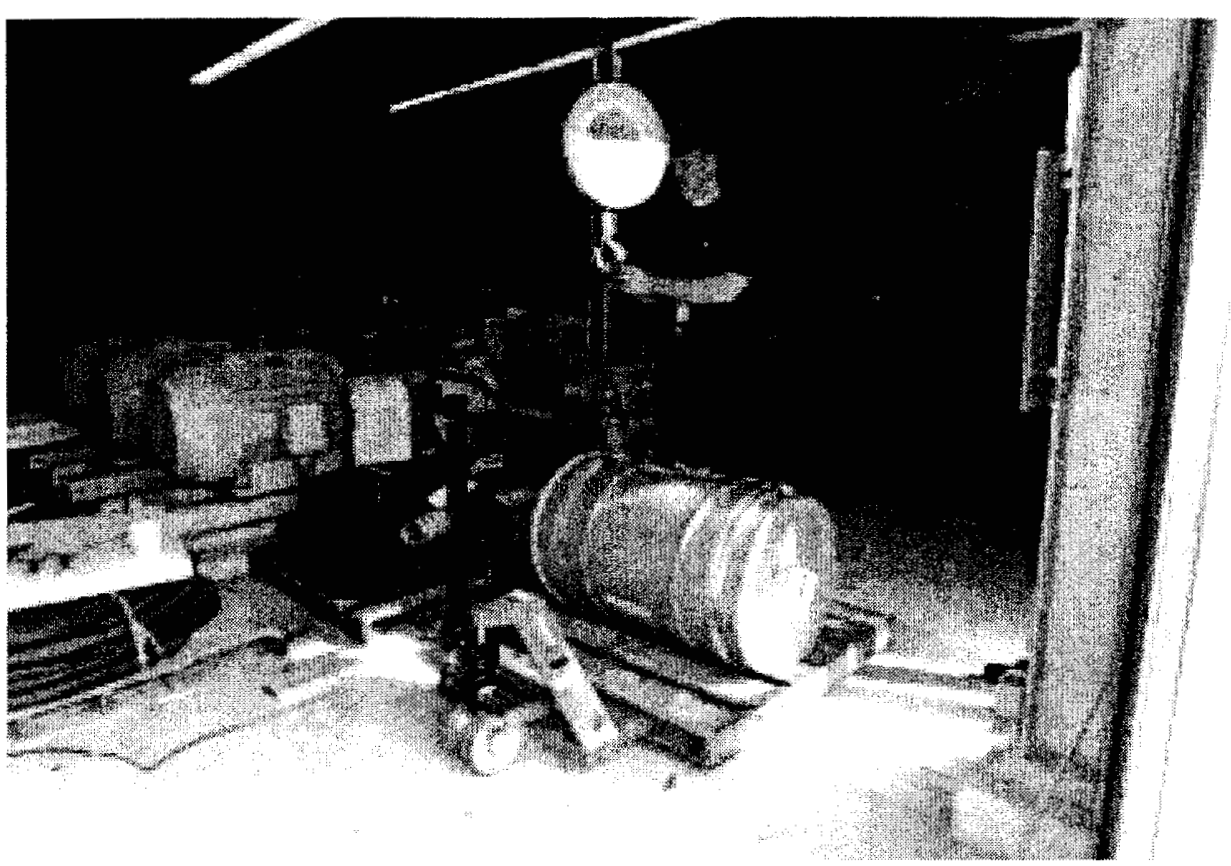

Figure 7. Packaging Prep and Weighing. Empty Package, Bldg. 836B Rich Villafana (LLNL)

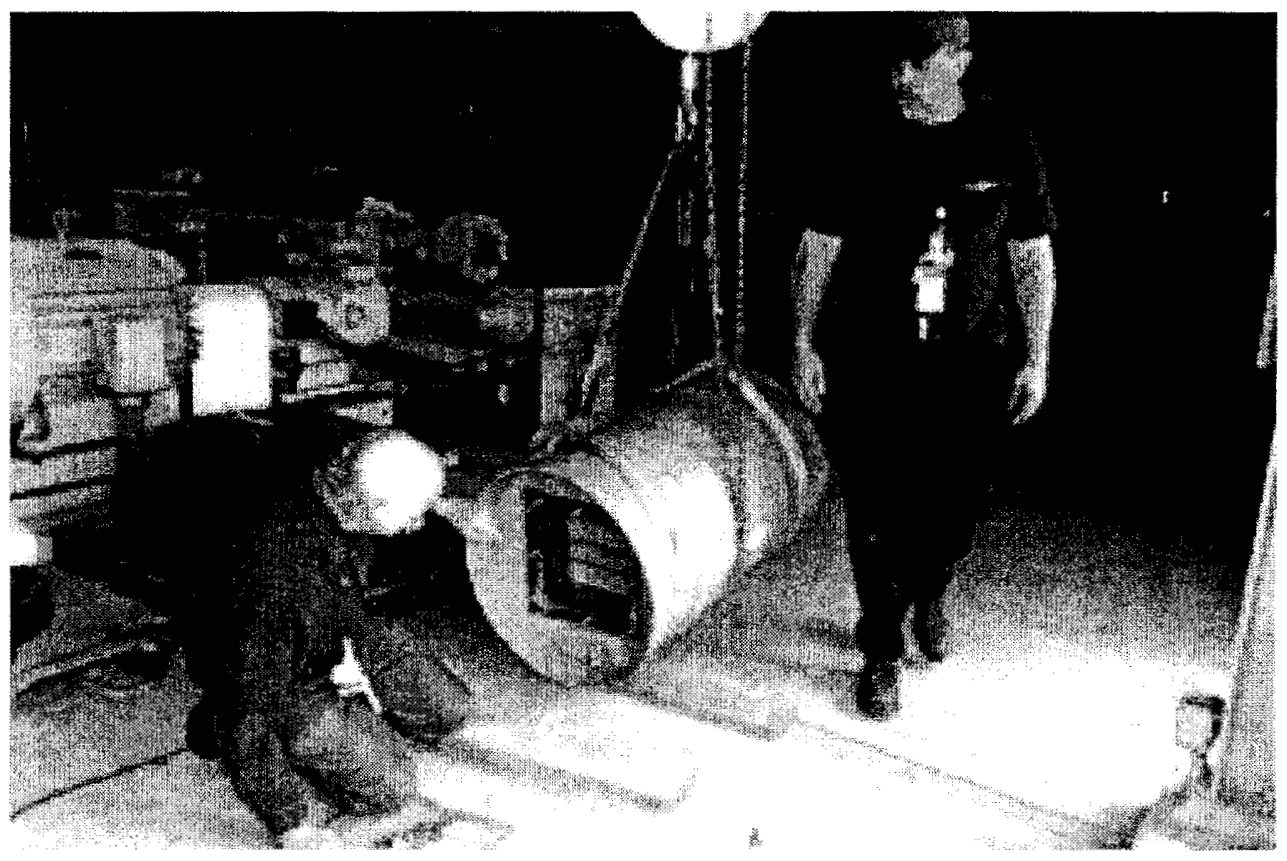

Figure 8. Packaging Preparation, Pellet Tray Removal (I), Bldg. 836B

From left, Bruce Clegg (LLNL) and Rich Villafana (LLNL) 
Drop Test Results

for the ABB-2901 Package

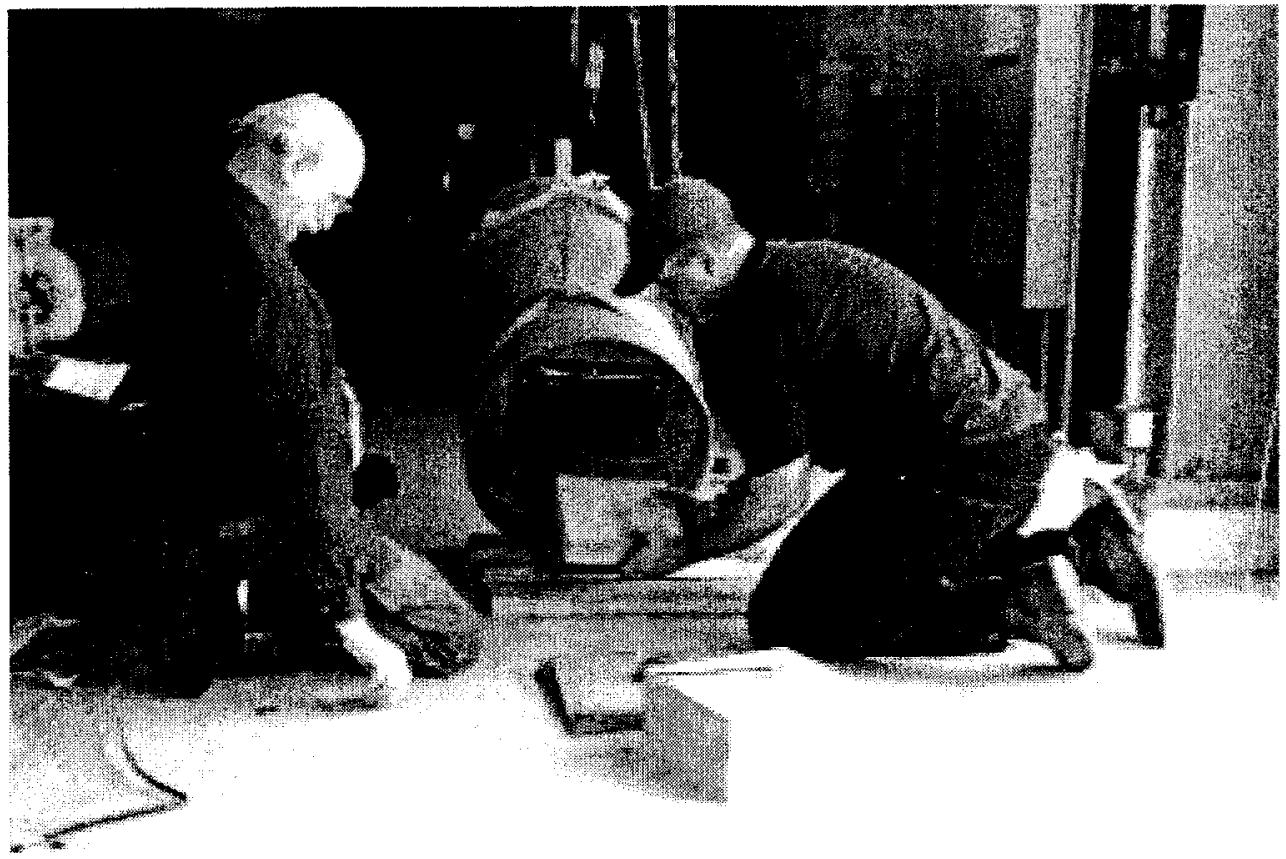

Figure 9. Packaging Preparation, Pellet Tray Removal (II), Bldg. 836B

From left, Bruce Clegg (LLNL) and Rich Villafana (LLNL)

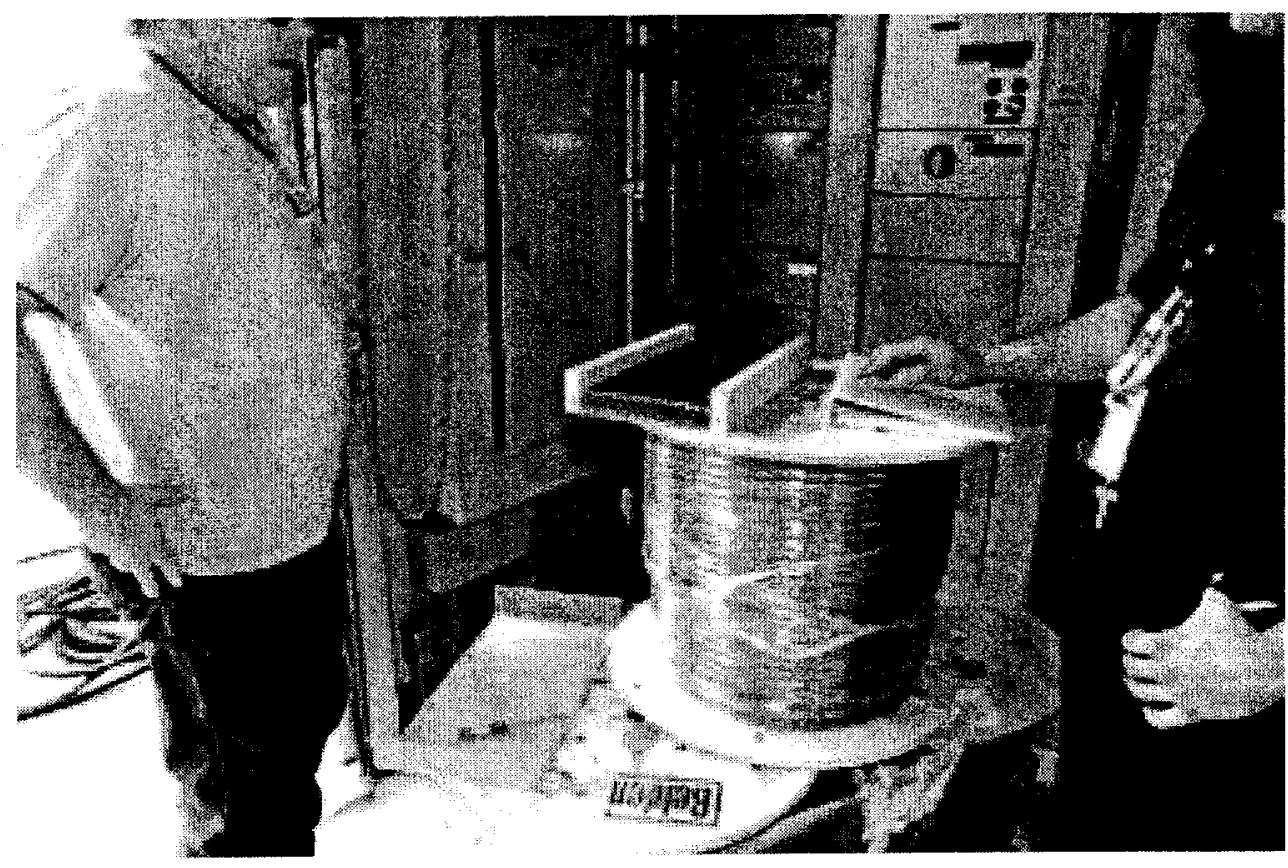

Figure 10. Pellet Tray Inspection, Bldg. 836B

From left, Bob Daily (LLNL) and Rich Villafana (LLNL) 
Drop Test Results for the ABB-2901 Package

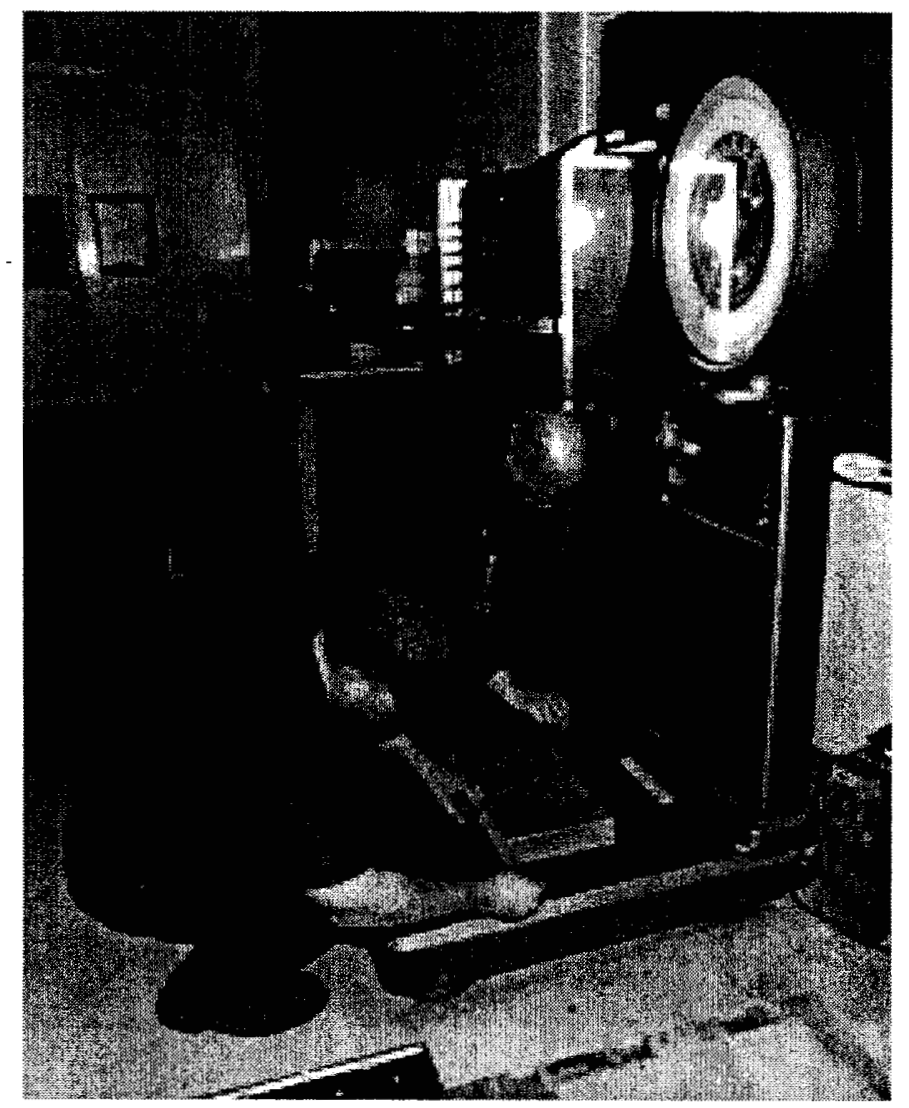

Figure 11. Pellet Tray Loading and Weighing (I), BIdg. 836C From left, Rich Villafana (LLNL) and Bruce Clegg (LLNL)

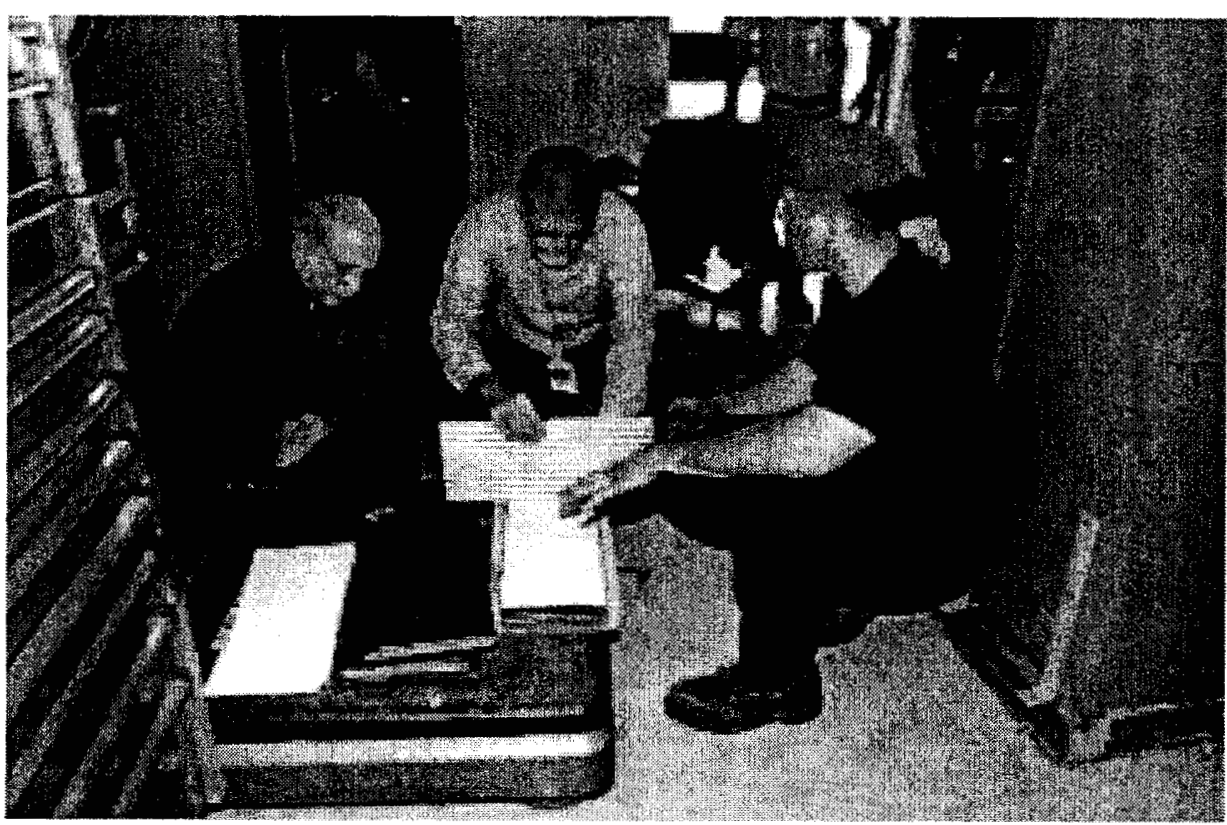

Figure 12. Pellet Tray Loading and Weighing (II), Bldg. 836C 
Foreground: Bruce Clegg (LLNL), Ron Samoian (LLNL), and Rich Villafana (LLNL). Background: Paul McMahon (WEC-SC), Ron Hafner (LLNL), Lisle Hagler (LLNL), and Brian Hempy (WEC-SC)

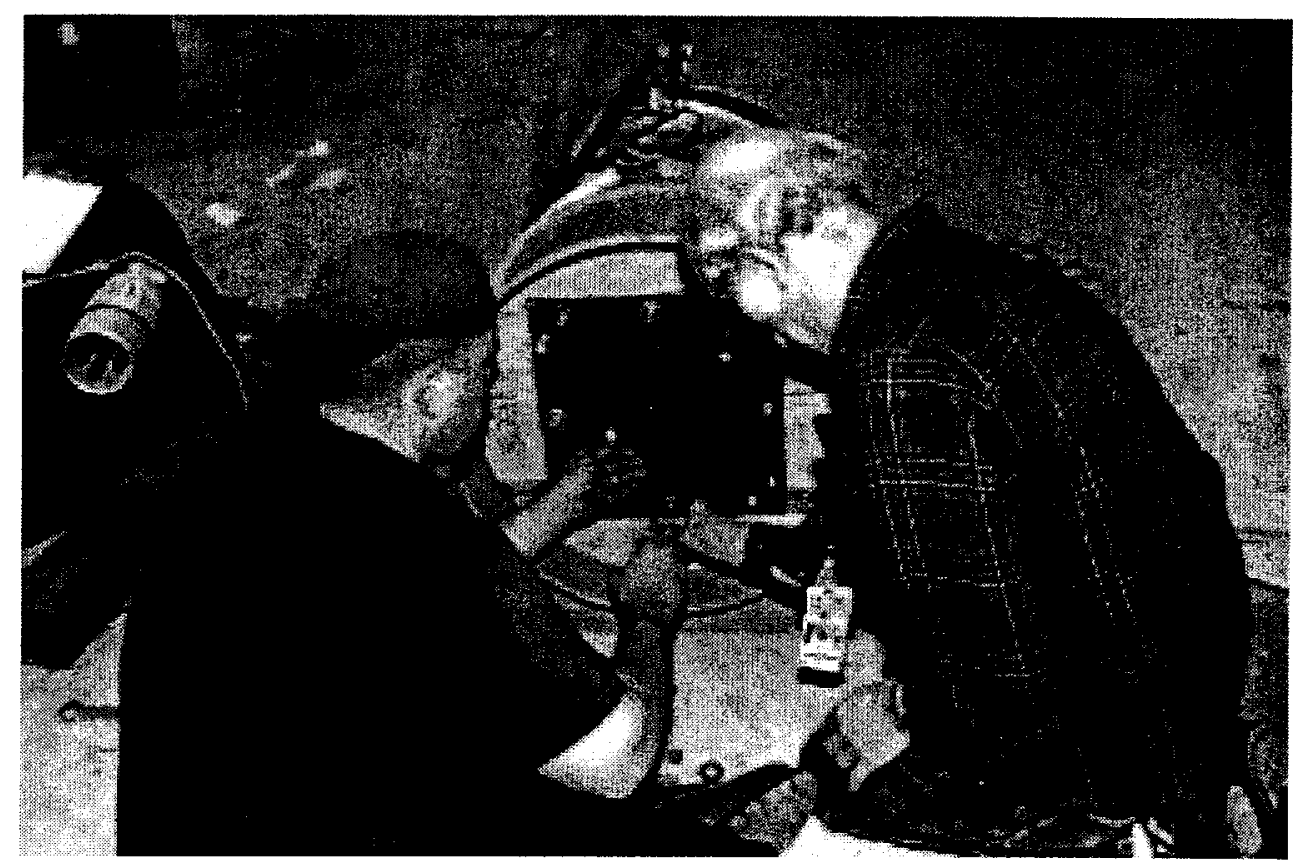

Figure 13. Containment Closure, Bldg. 836C From left, Rich Villafana (LLNL) and Bruce Clegg (LLNL)

The fully loaded test package weighed 655 pounds (Figure 14), which is just below the licensed maximum total weight of the package of 660 pounds. When closing the drum after loading, a defect in the threads of the closure bolt stripped the threads in the tightening lug of the drumclosure ring, such that it could not hold the specified tightening torque of $75 \mathrm{ft}-\mathrm{lbs}$. Thus the actual final weighing of the test package was not performed until shortly before the $30-\mathrm{ft}$ drop test on November 15, when the LLNL team closed the drum with a replacement ring specially delivered from WEC-SC (Figure 15).

Note: The WEC-SC representatives specified the value of $30 \mathrm{ft}-\mathrm{lbs}$ for the closure nuts of the containment-box lid and the value of $75 \mathrm{ft}$-lbs for the drum closure ring bolt, since neither was specified in the SAR. 
Drop Test Results for the ABB-2901 Package

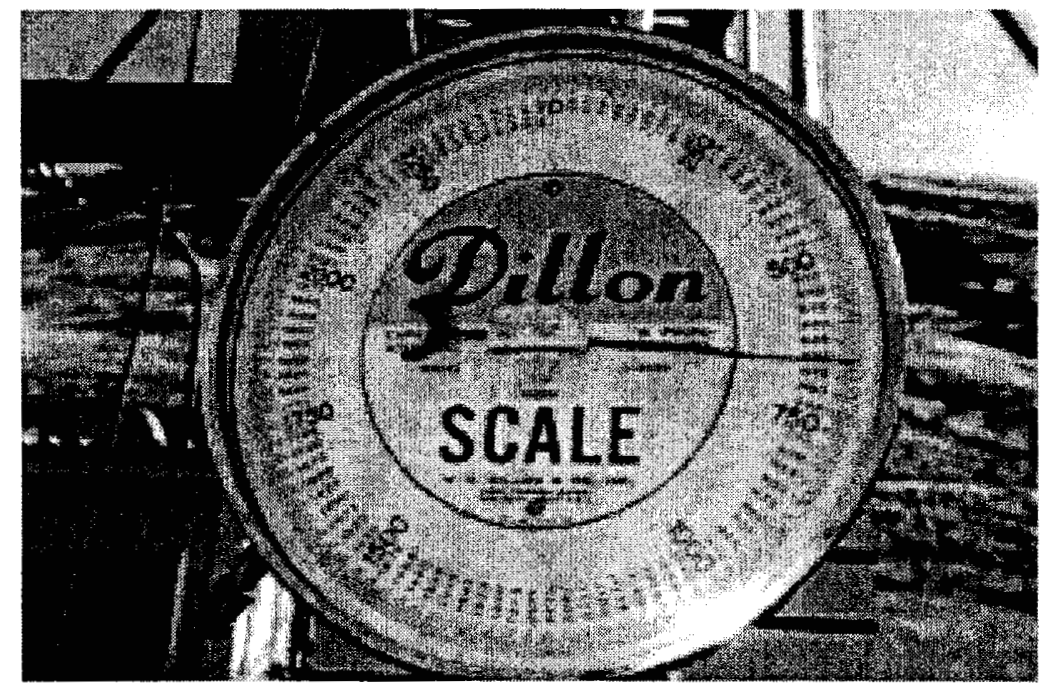

Figure 14. Packaging Weighing, Bldg. 858

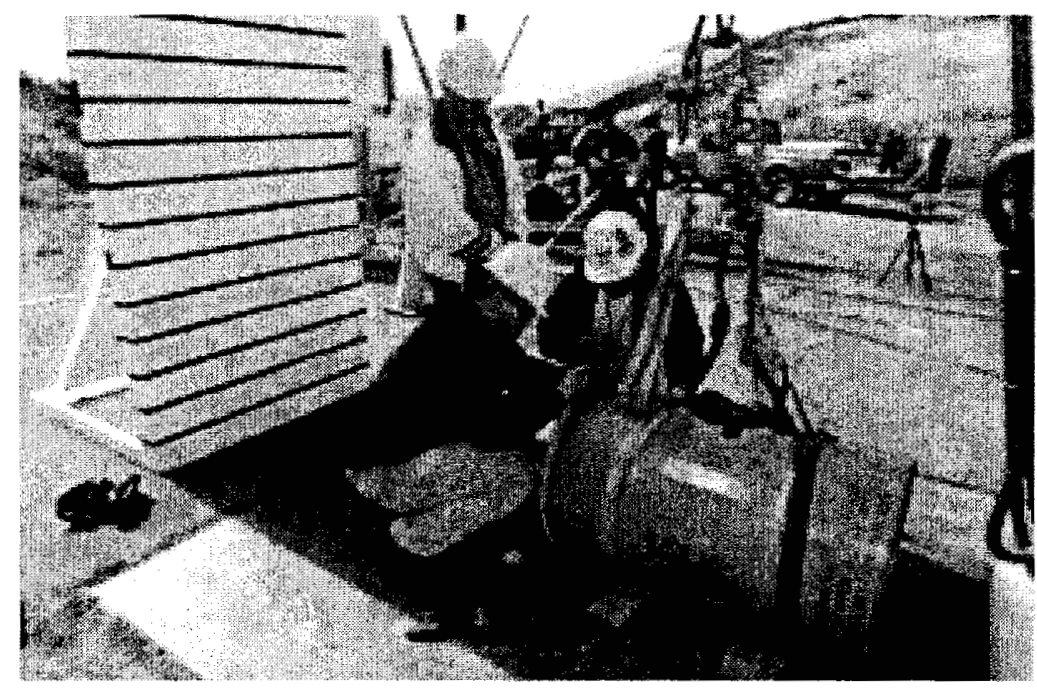

Figure 15. Packaging Closure, Bldg. 858

Foreground: Paul McMahon (WEC-SC) (standing), Rich Villafana (LLNL), and Tom Woehrle (LLNL) Background: Lisle Hagler (LLNL), Bruce Clegg (LLNL), Ron Parkhill (USNRC), Ron Hafner (LLNL), Brian Hempy (WEC-SC), and Alan Brooks (LLNL) 
Drop Test Results

for the ABB-2901 Package 


\subsection{Test Setup and Preliminary Test Runs}

The Drop Tower Facility at LLNL's Site-300 was used to perform the 30 - $\mathrm{ft}$ drop test. The Facility was initially designed for drop testing heavy weapons-related packagings weighing up to $6,000 \mathrm{lbs}$, and is used to perform both guided and unguided (free) drops from heights up to $100 \mathrm{ft}$. The Facility has a ten-foot square unyielding surface built, from top to bottom, with (1) a top steel plate 3-9/16" thick over (2) a 1" grout layer over (3) a $2 \mathrm{ft}$-thick reinforced concrete pad over (4) a square, concrete tank back-filled with gravel approximately $5 \mathrm{ft}$ deep. The Facility is more than adequate for the $30-\mathrm{ft}$ drop test. Figure 16 shows a distant view of the facility.

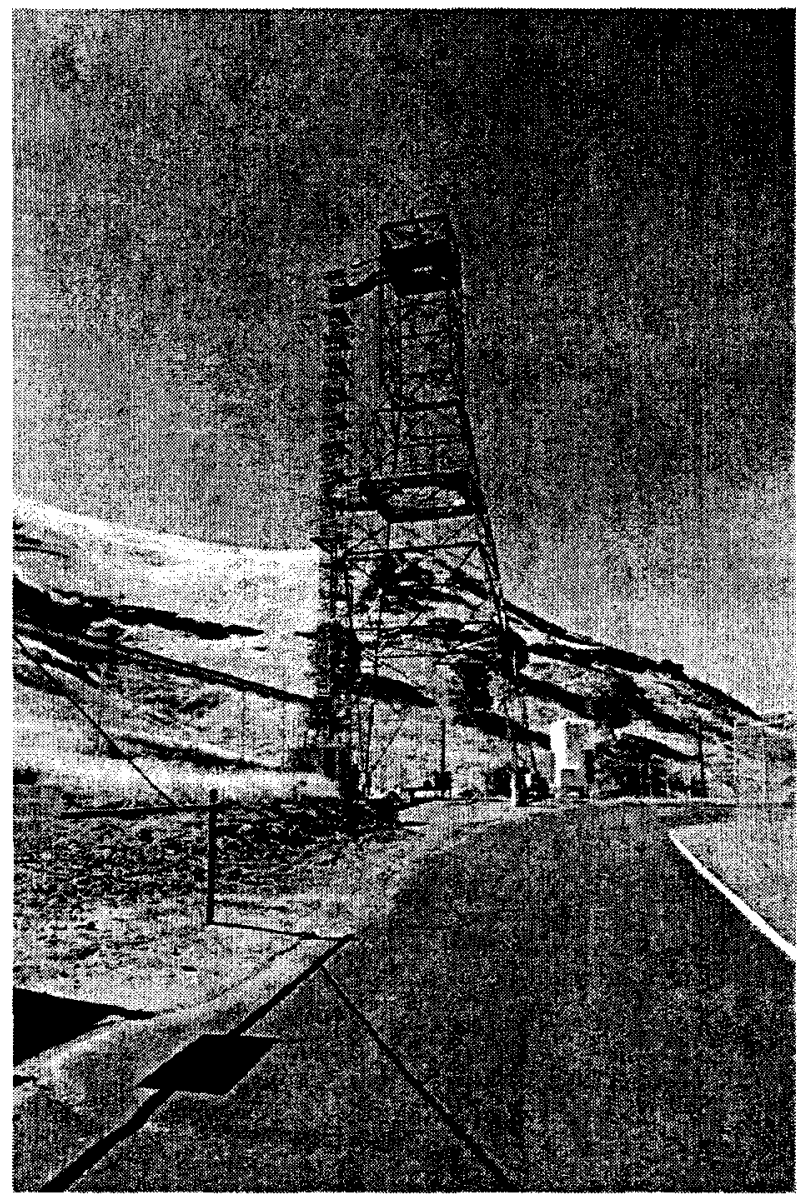

Figure 16. Site 300 Drop Test Tower

To ensure a free drop, the steel ropes used for guided drops were removed and pulled back prior to the setup for the $30-\mathrm{ft}$ drop test. A single sling was used to suspend the package so that the effect of the release operation on the drop orientation could be minimized. For the $30-\mathrm{ft} 17.5^{\circ}$ shallow-angle drop, the package was positioned and suspended according Figures A-1 and A-2 of the Test Plan (see Appendix A). The position of the closure-ring lug shown in Figure A-2 for the test was changed from the original plan. The original plan called for the lug to be located 90 degrees, as opposed to the current 180 degrees, from the impact point. Figure 17 shows the $17.5^{\circ}$ drop angle being set using a prefabricated wooden wedge. The $30-\mathrm{ft}$ drop height was determined using a pre-measured plumb line. A pneumatic device released the suspension sling with the package. An attached long rope stopped the falling suspension sling before it caught up with the 
Drop Test Results

for the ABB-2901 Package

impacting package. Figure 18 shows the actual test package suspended in the tower ready for the $30-\mathrm{ft}$ drop.

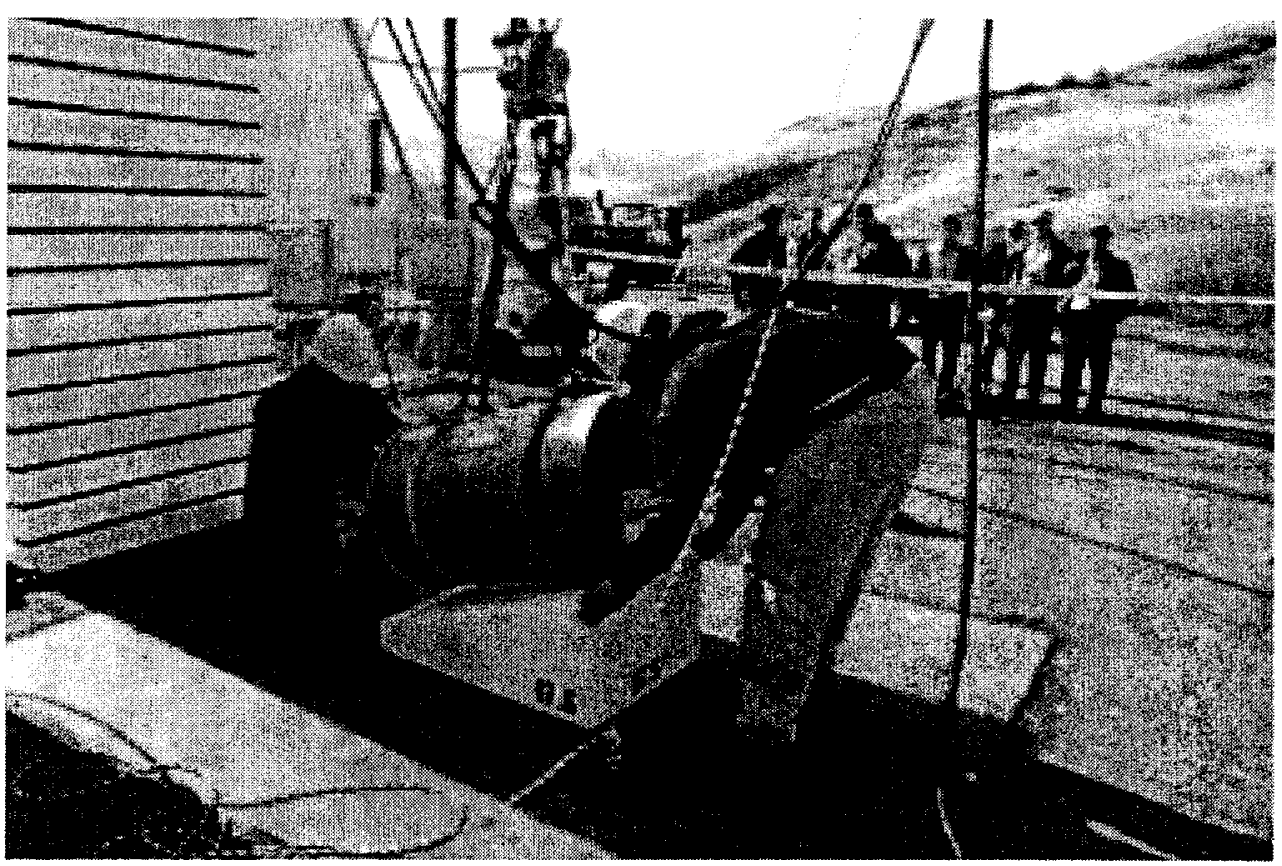

Figure 17. Packaging Alignment

Foreground: Alan Brooks (LLNL) and Rich Villafana (LLNL)

Background: Brian Hempy (WEC-SC), Paul McMahon (WEC-SC), Lisle Hagler (LLNL),

Gerry Mok (LLNL), Ron Hafner (LLNL), Ron Parkhill (USNRC), and Henry Lee (USNRC)

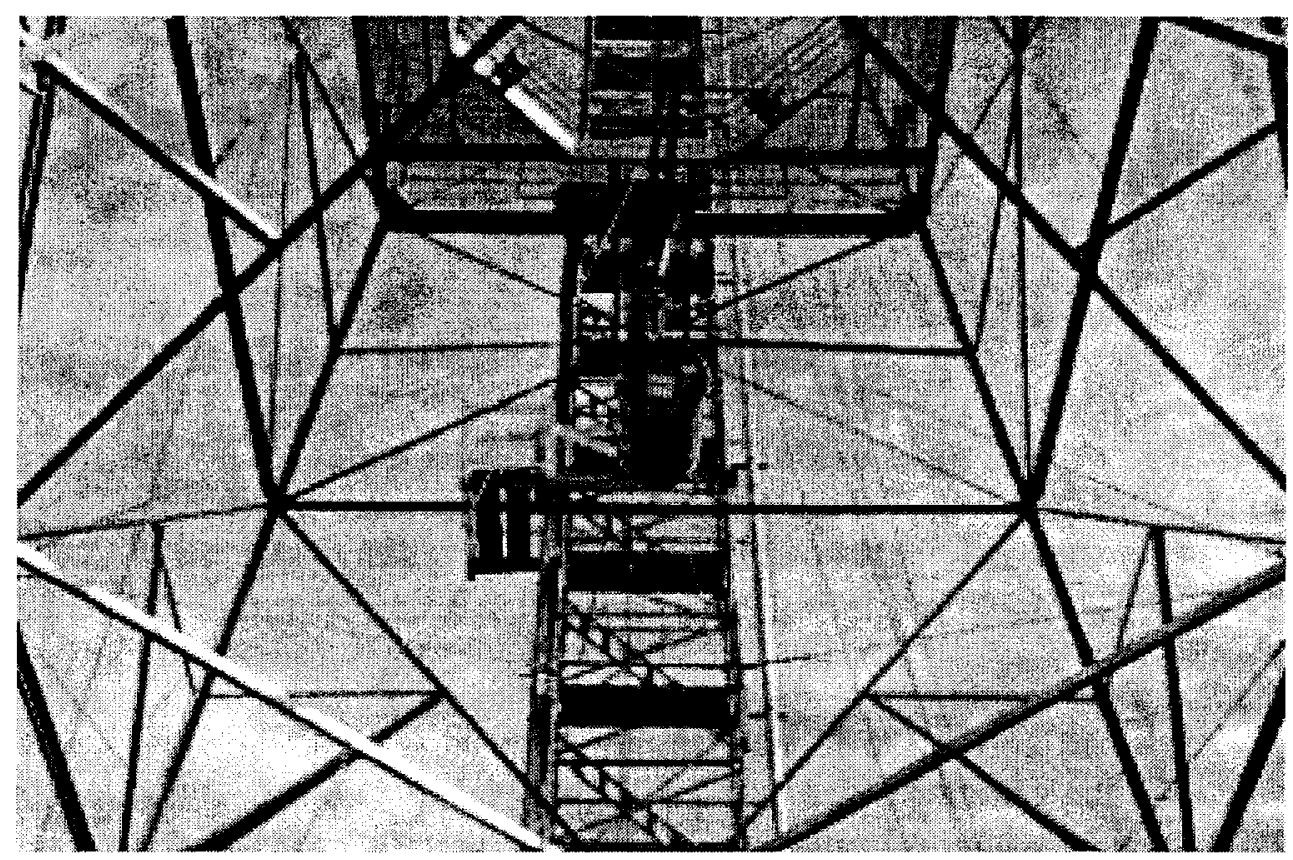

Figure 18. Packaging in Position 
Two high-speed (500 frames per second) digital video cameras were setup to record the motion of the impacting package. One camera was set to record the side view, and the other to record the top (lid) view of the impacting package. Two grid boards were erected around the intended impact area on the opposite side of the cameras to provide a plain background for the video photography. The boards had six-inch-wide and six-inch-apart black horizontal lines to provide a length scale for the video records. The distances from the cameras to the center of the test pad,

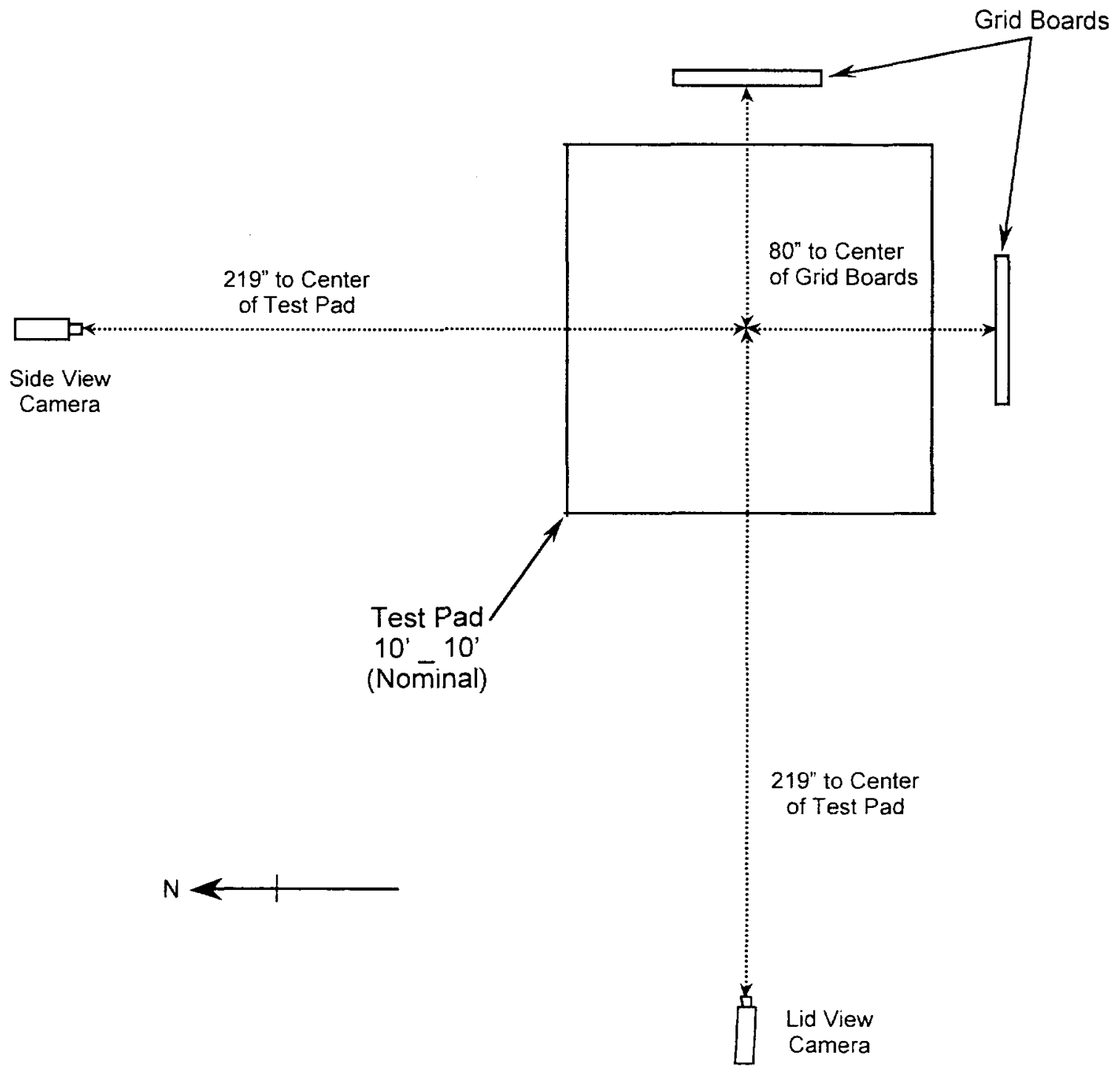

and from the center of the test pad to the center of the grid boards, are shown in Figure 19.

Figure 19. Distances from the cameras to the center of the test pad, and from the center of the test pad to the center of the grid boards 
For the puncture test, the LLNL test team fabricated a puncture bar according to the standards set forth in 10 CFR Part 71. The bar was about 40" long, and was joined to its own base plate with four welded triangular gussets. (Although the intent was to bolt the puncture bar base plate to the unyielding target surface for the puncture test, the puncture bar test was deemed to be unnecessary after the initial failure of the package.)

On the morning of November 14, the LLNL test team conducted two preliminary test runs of the 30 -ft shallow-angle drop using two common 55-gallon drums as the test package. One of the drums was filled with water and the other with solid ice. The solid-ice test drum package was produced by placing a 55-gallon drum of water overnight in an environmental test chamber. A thermocouple placed at the center of the drum cavity confirmed the formation of solid ice there. As generally expected, the water-filled drum failed miserably. Figure 20 shows the severely deformed drum components. The high hydrodynamic pressure generated by the impact apparently had caused the large deformations. Being pushed outward, the drum body and lid deformed naturally in the horizontal directions, which offered the least resistance.

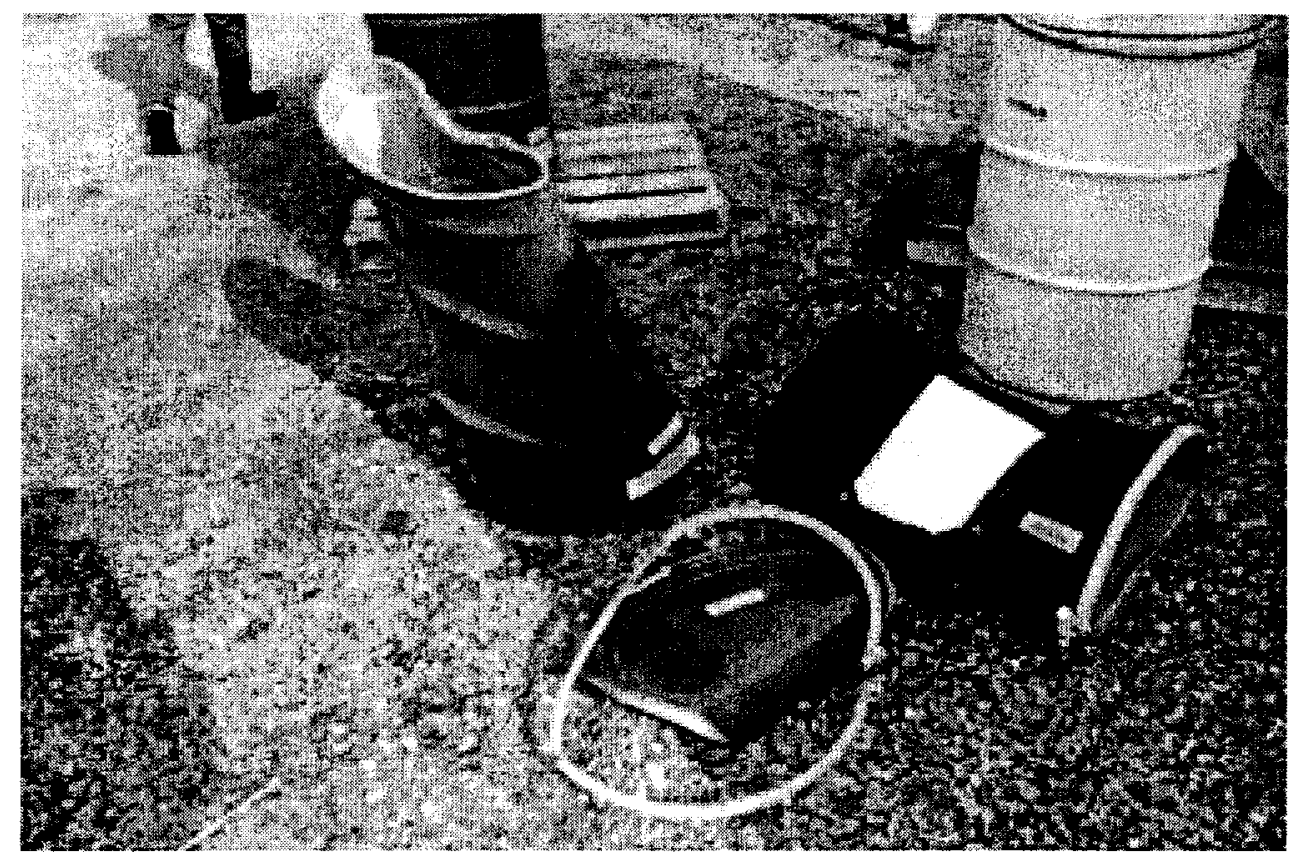

Figure 20. Damage to Lid, Closure Ring and Drum Along Side of Damage to Previously Dropped 35-Gallon, Water-Filled Drum

Figures 21 through 23 show the results of the $30-\mathrm{ft}$ drop of the solid-ice drum. 


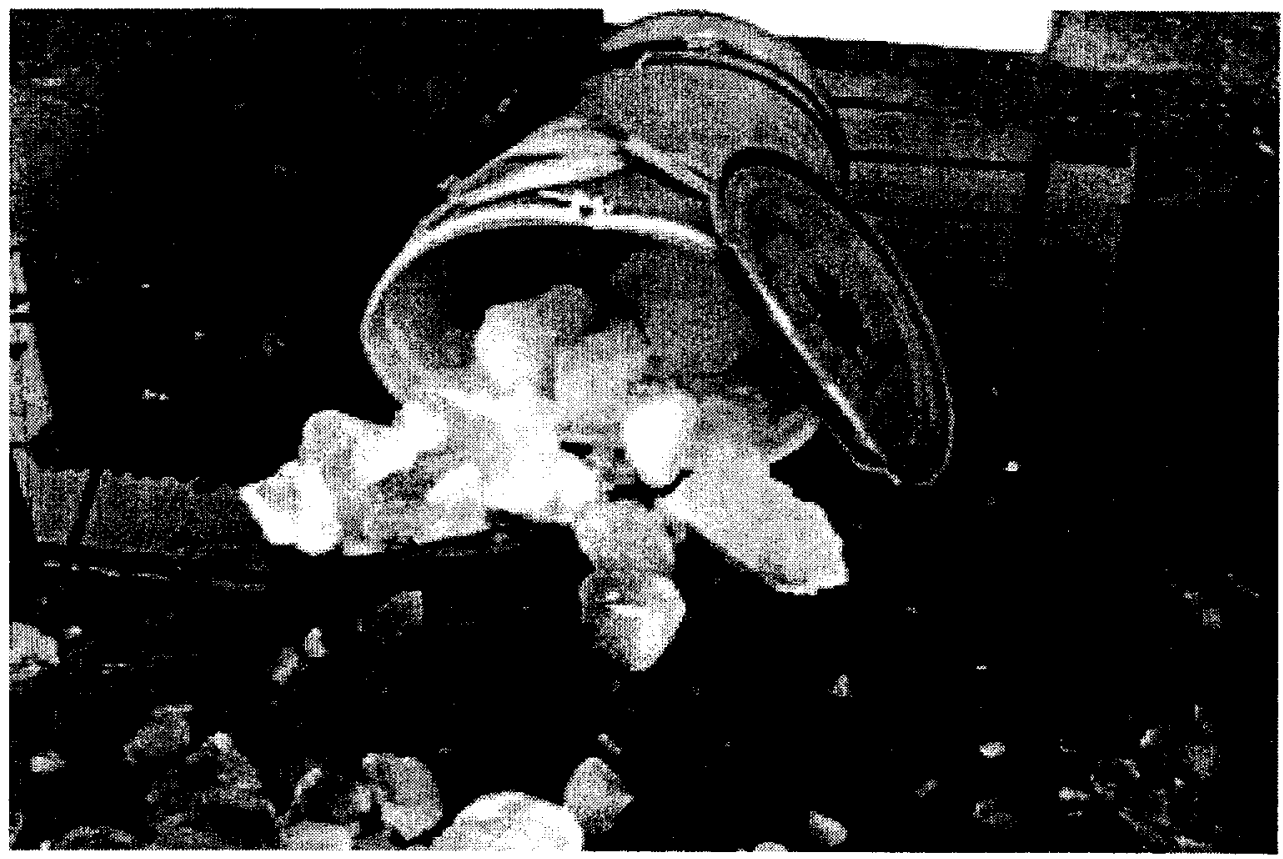

Figure 21. Damage to Drum and Lid after Ice-Filled Drop (Close-Up) (I)

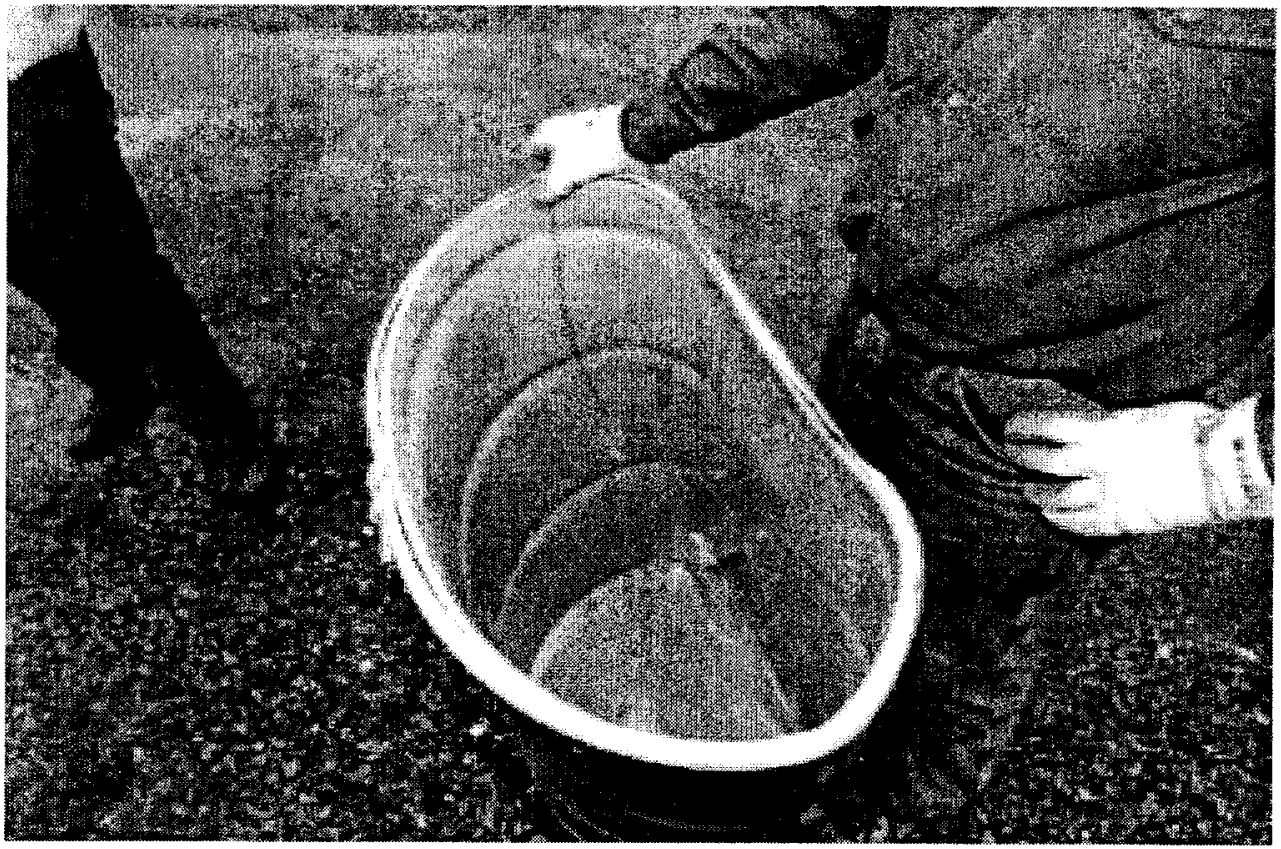

Figure 22. Damage to Drum (Ice-Filled Drop) Rich Villafana (LLNL) and Jesse Rivera (LLNL)

At first glance, the solid-ice drum did not appear to fare much better than the water-filled drum. Closer examination, however, revealed that the ice in the solid-ice drum was not a true solid, i.e., there were numerous radial fracture surfaces in the ice from the outside of the drum to the inside, and there was a basketball- to beach-ball-sized volume of liquid water inside the ice, near the 
bottom of the drum (see Figures 24 through 28). Without analyzing the results of this preliminary test run in detail, it appeared that the ice behaved more like liquid water than expected because the drum and its closure did not maintain its integrity under the high-impact forces.

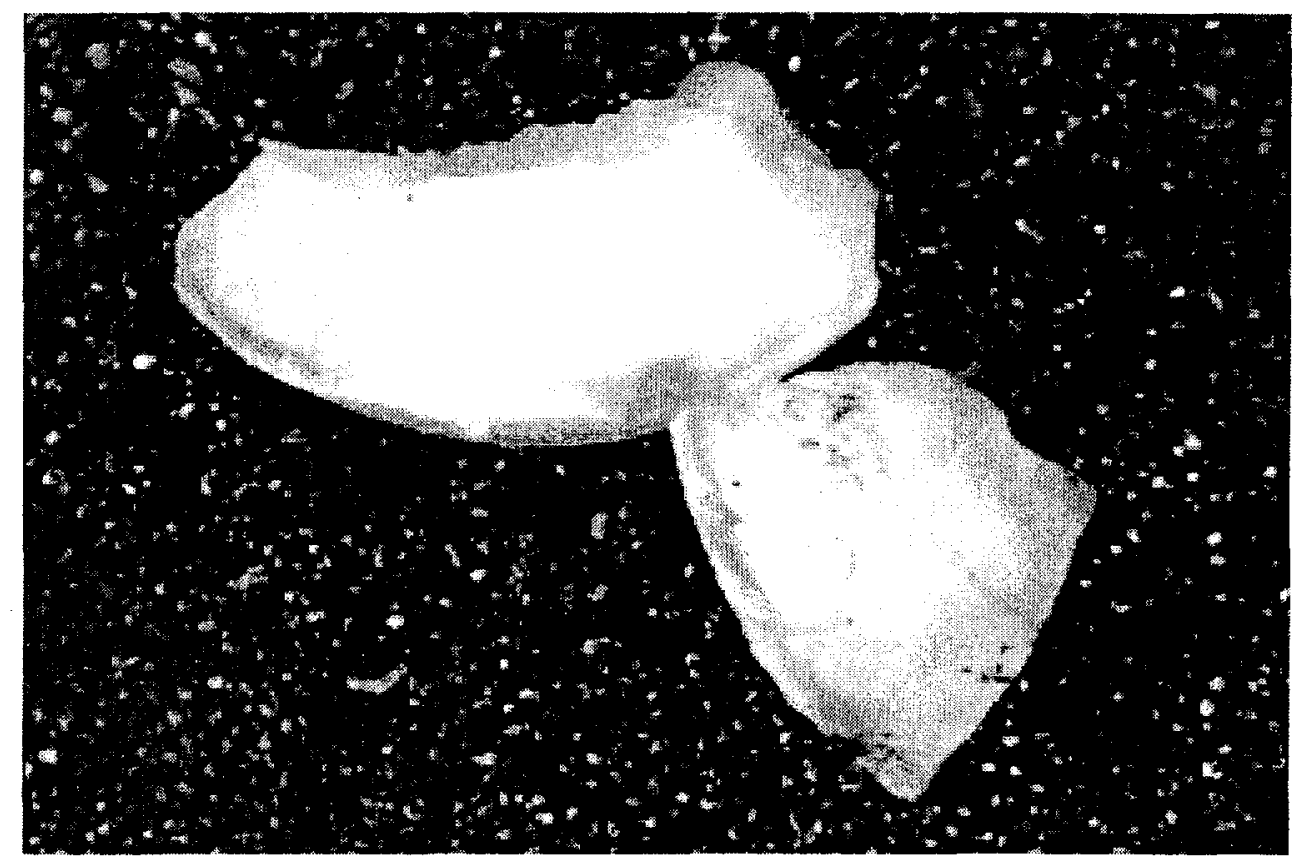

Figure 23. Close-Up of Ice Section from Bottom of Drum w/Quarter for Relative Size

The results of the preliminary test runs clearly demonstrated that the integrity of a drum closure depends heavily on the structural integrity of the internal components of the drum. Ronald W. (Ron) Parkhill and Henry W. Lee from USNRC, Paul McMahon and Brian Hempy from WEC-SC, Ron Hafner, Lisle Hagler, Gerry Mok, and Douglas K. (Doug) Vogt from LLNL witnessed the preliminary test run with the solid-ice package.

The LLNL Site 300 Test Group technicians assigned to this task included Bruce Clegg, Jesse M. Rivera, Rich Villafana, and Thomas G. (Tom) Woehrle. Alan L. Brooks was assigned as the lead test engineer for the preliminary test runs and the actual package drop test. 


\subsection{0-ft Free-Drop Test and Resulting Damages}

The 30-ft free drop of the test package was conducted on the morning of November 15, 2001. The weather conditions were nearly perfect: winds light and variable, light overcast, and temperatures around $70^{\circ} \mathrm{F}$. Except for Doug Vogt of LLNL, the same group of LLNL, USNRC, and WEC-SC personnel who witnessed the preliminary test runs the day before was present for the final drop test (see Figure 17).

After the test team fitted the test drum with the replacement closure ring from WEC-SC, the ring-closure bolt was tightened to the recommended torque value of $75 \mathrm{ft}-\mathrm{lb}$, which Paul McMahon of WEC-SC had specified on November 13th. The test package was then properly positioned, suspended, and lifted to a height of 30 feet from the surface of the unyielding target. (Details of the operation are described in Section 3.0. See also Figures 24 through 26.) The package was dropped, and the test was completed, without any apparent difficulties with the operating procedures or the test hardware. The drum, however, failed with the lid enclosure ring completely separated from the drum.

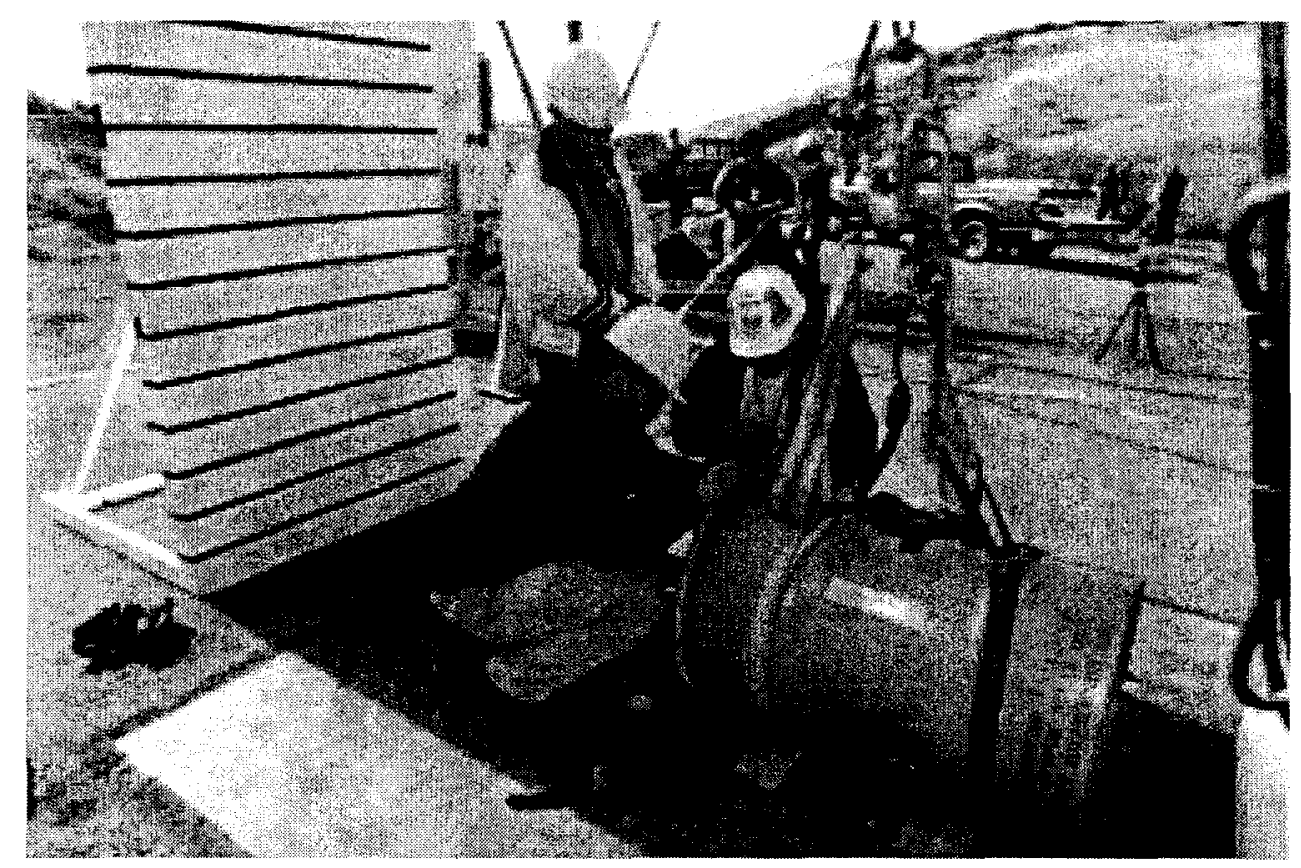

Figure 24. Packaging Closure, Bldg. 858

Foreground: Paul McMahon (WEC-SC) (Standing), Rich Villafana (LLNL), and Tom Woehrle (LLNL)

Background: Lisle Hagler (LLNL), Bruce Clegg (LLNL), Ron Parkhill (USNRC), Ron Hafner (LLNL), Brian Hempy (WEC-SC) and Alan Brooks (LLNL) 
Drop Test Results

for the ABB-2901 Package

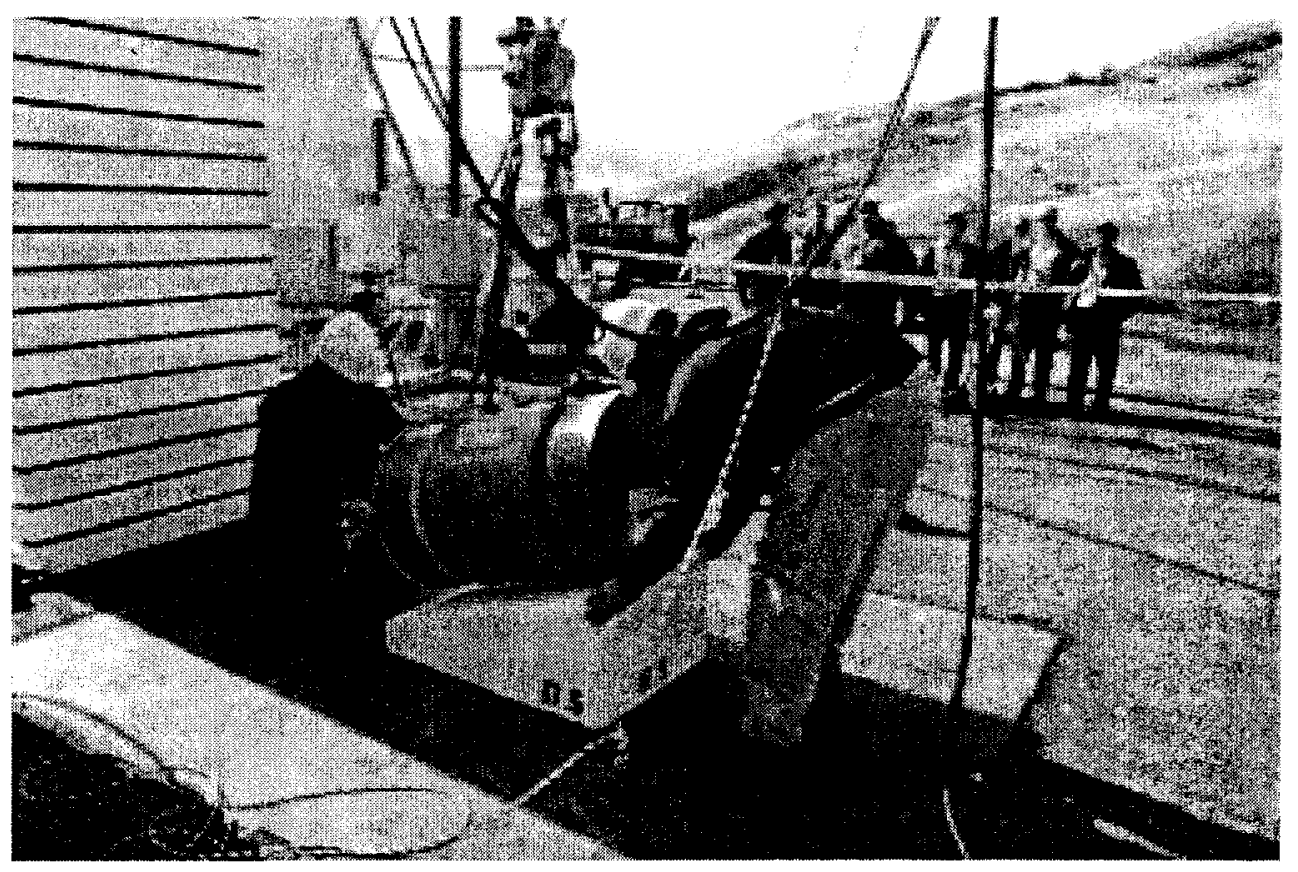

Figure 25. Packaging Alignment, Bldg. 858

Foreground: Alan Brooks (LLNL), Rich Villafana (LLNL)

Background: Brian Hempy (WEC-SC), Paul McMahon (WEC-SC), Lisle Hagler (LLNL), Gerry Mok (LLNL), Ron Hafner (LLNL), Ron Parkhill (USNRC), Henry Lee (USNRC)

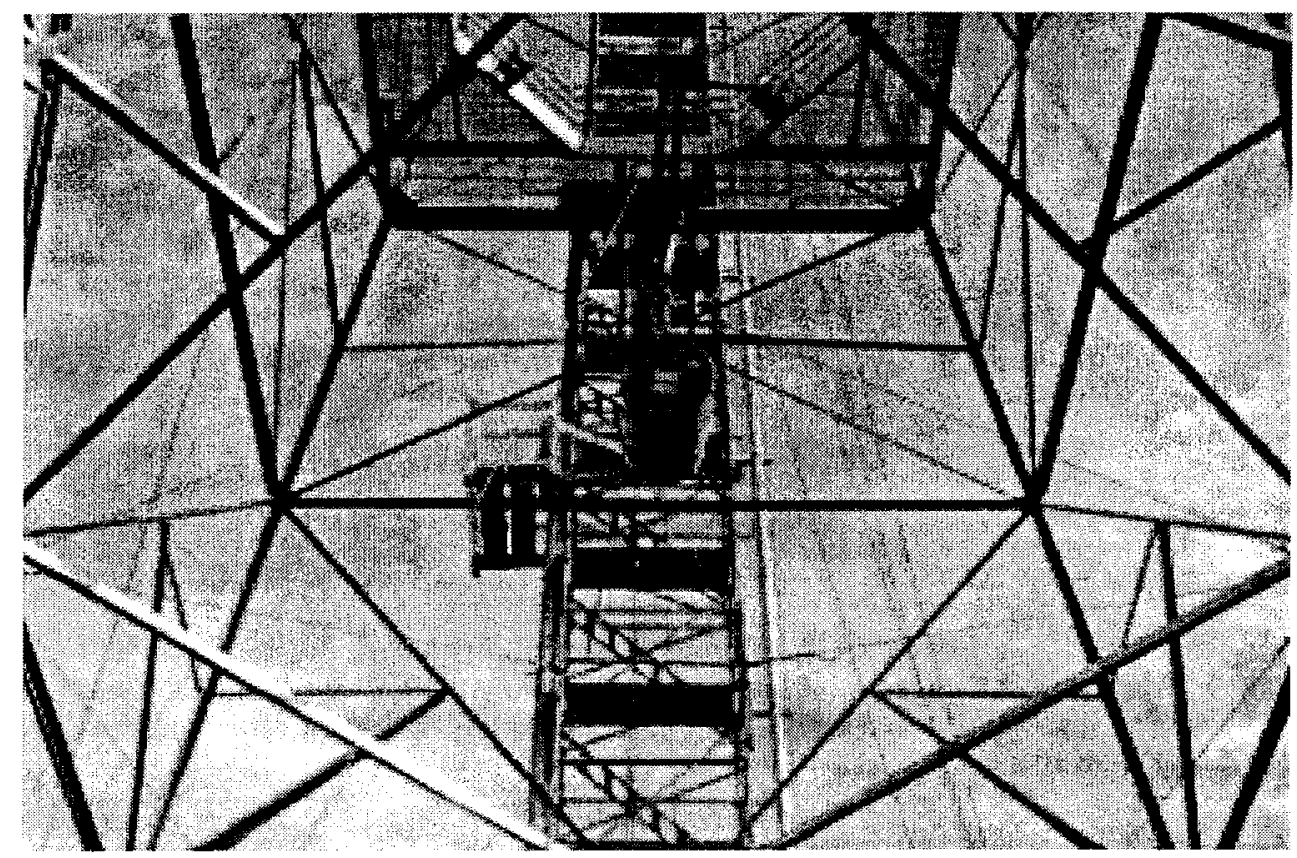

Figure 26. Packaging in Position, Close-up, Bldg. 858

Figure 27 shows the final position of all drum components after the drop. Figures 28 through 41 show the details of the damage suffered by the drum components. 


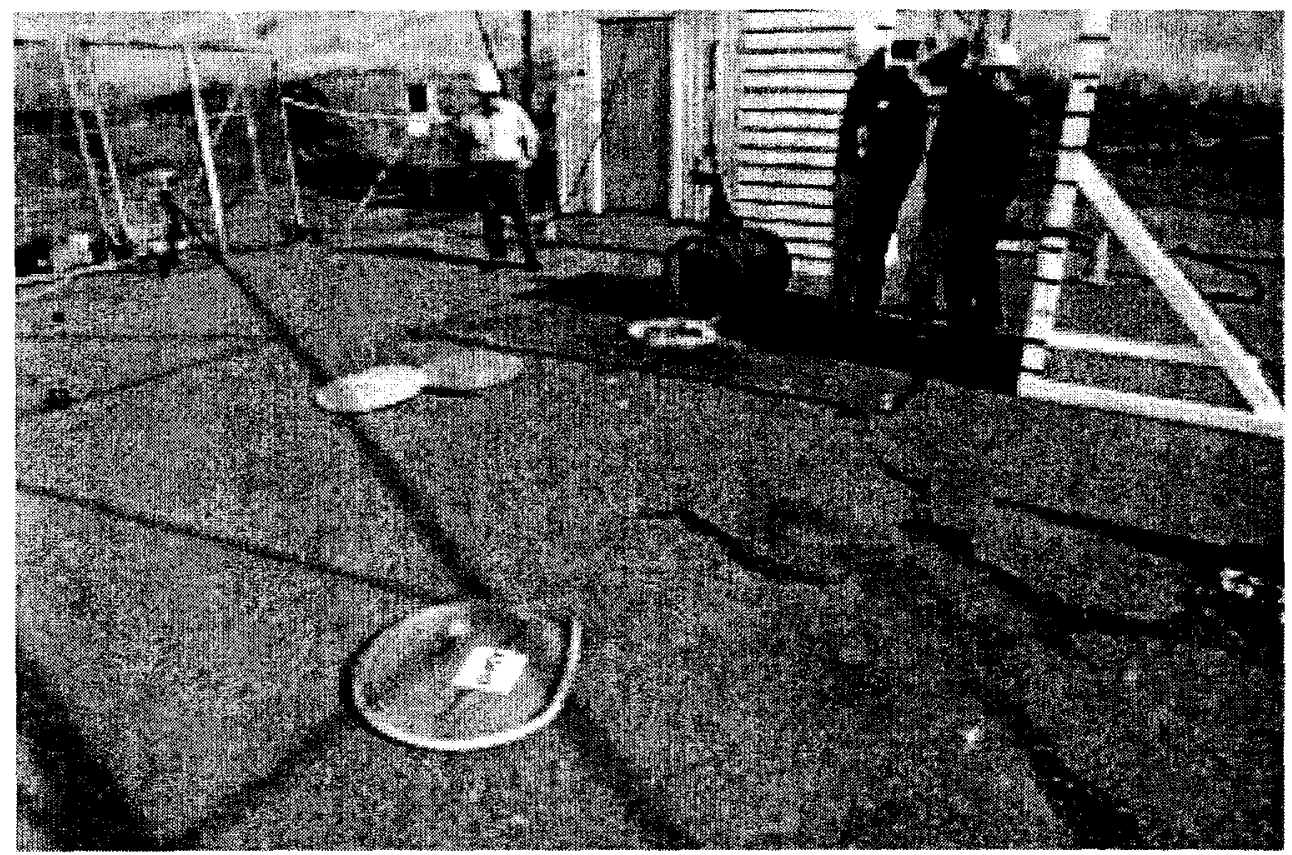

Figure 27. Post-test Component Orientation (Wide-Angle View)

From left, Jesse Rivera (LLNL), Rich Villafana (LLNL), Tom Woehrle (LLNL), and Bruce Clegg (LLNL)

The following subsections include a description of each component and an analysis of the damage sustained during the shallow-angle drop test.

\subsection{Drum lid and closure ring}

The lid and ring flew off together during the test and remained together after the test. They showed minimal out-of-plane deformation, i.e., they remained a planar structure. This indicates that the large buckling deformation of the lid-and-ring assembly that led to the separation of the assembly from the drum body was basically elastic. The assembly showed only large in-plane permanent deformation in the impact area. The impact produced an approximately 12-in.-long straight edge of the lid-and-ring assembly. The lid adjusted itself to this large in-plane deformation with minor out-of-plane local buckling, while the ring accommodated the large deformation by in-plane bending. 


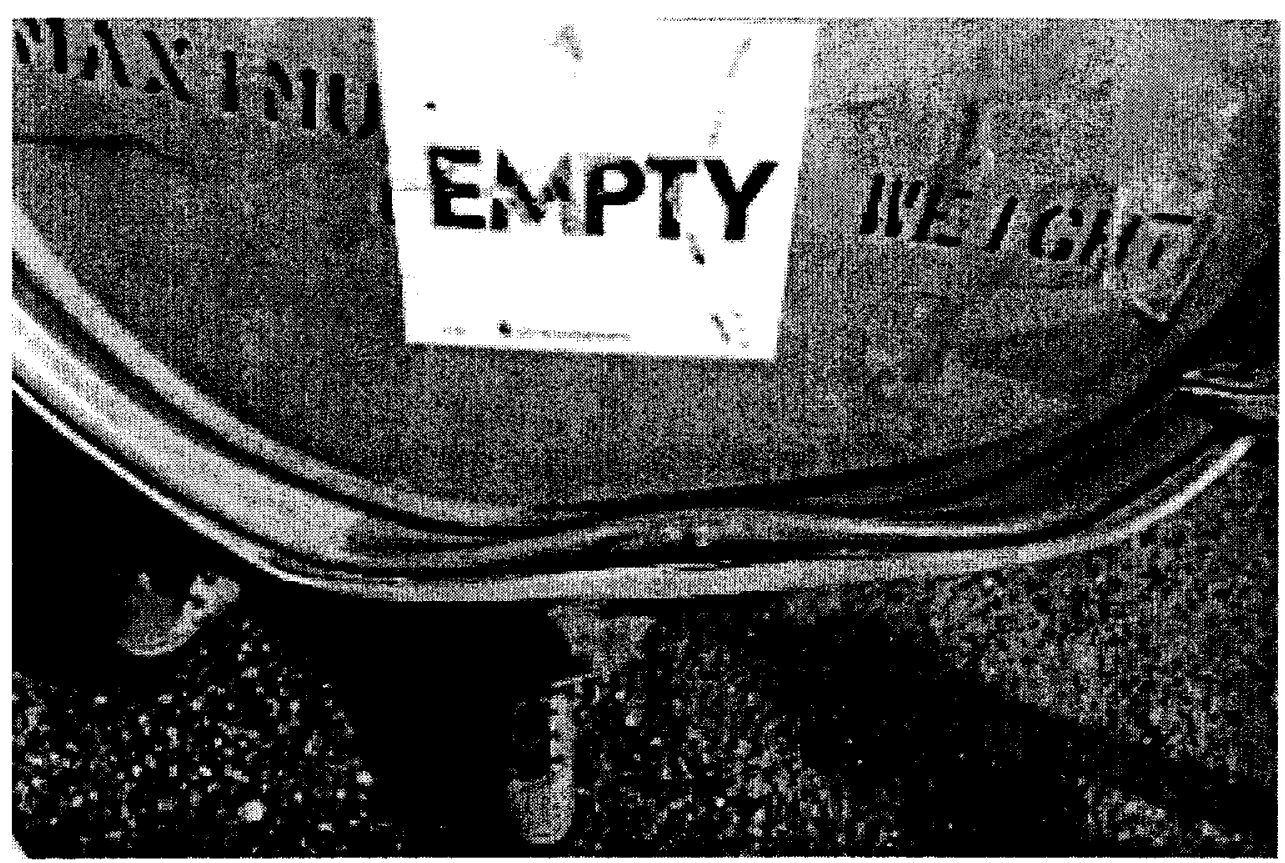

Figure 28. Drum Lid Close-up (Top-down)

\subsection{Round plywood boards between the lid and the containment box}

The two round solid plywood boards (one covered with a thermal insulation sheet), which occupied the space between the drum lid and the fuel-pellet containment box, suffered much less damage than their neighbors. This fact suggests that the boards had not borne or transmitted significant loads. Thus, their ejection from the impacting package consumed very little of the impact energy. Consequently, they were not able to contribute much to the ejection of the lidand-ring assembly. 


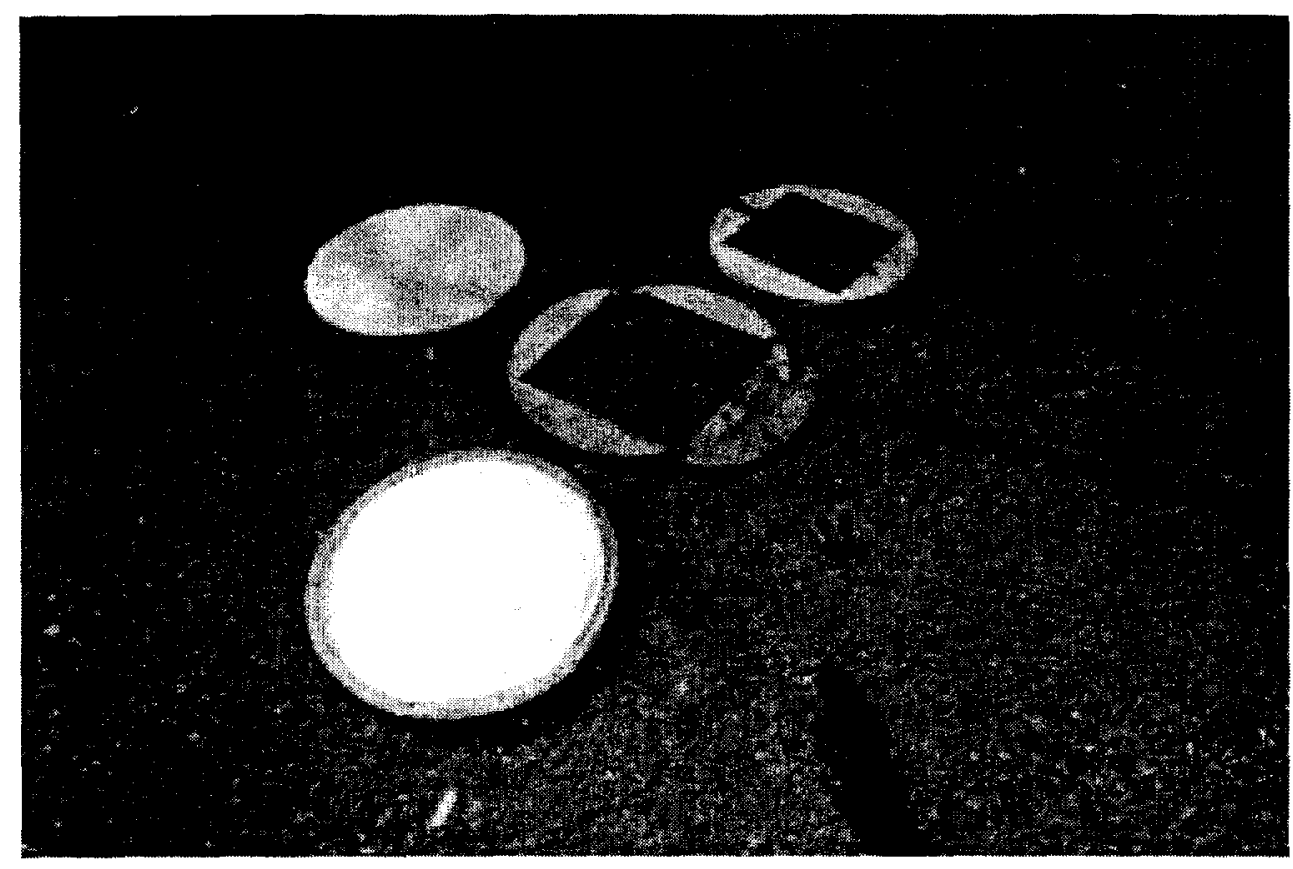

Figure 29. Insulated and Plywood Spacers

\subsection{Hardboards and plywood rings at the impact end}

Except for the plywood ring at the front, the hardboard and plywood rings around the impact end of the fuel-pellet containment box were fractured and crushed in the bottom area underneath the box. The severity of the damage suggests that the bottoms of the rings were in the major load path of the impact. The collapse of the rings allowed the impact to easily produce a large buckling deformation in the drum-lid-and-closure ring assembly. Had the rings been stronger, or had the test package been positioned to hit the ground at a corner of the containment box, the ejection of the lid-and-ring assembly might not have occurred so easily. 
Drop Test Results

for the ABB-2901 Package

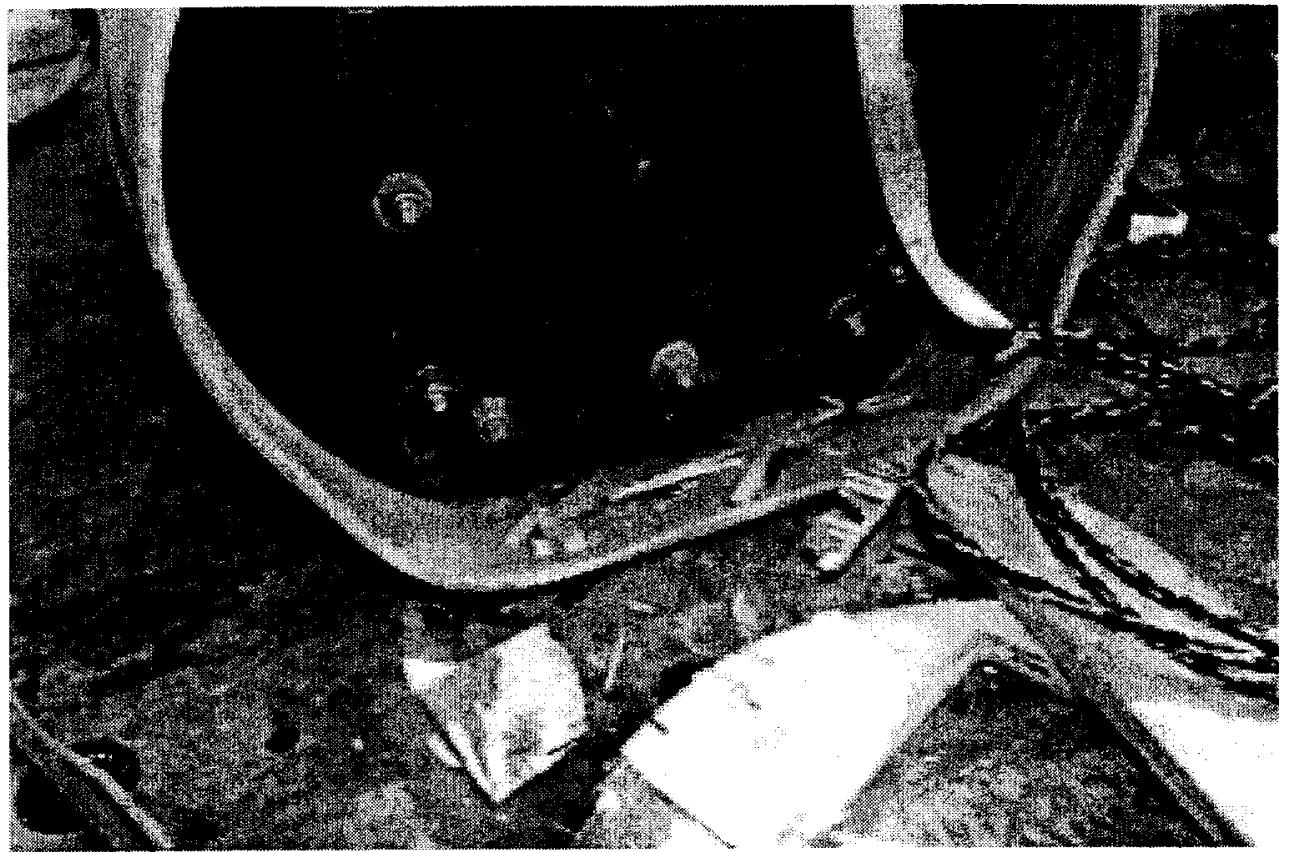

Figure 30. Post-Test Upper Drum-Body Close-Up; End-On

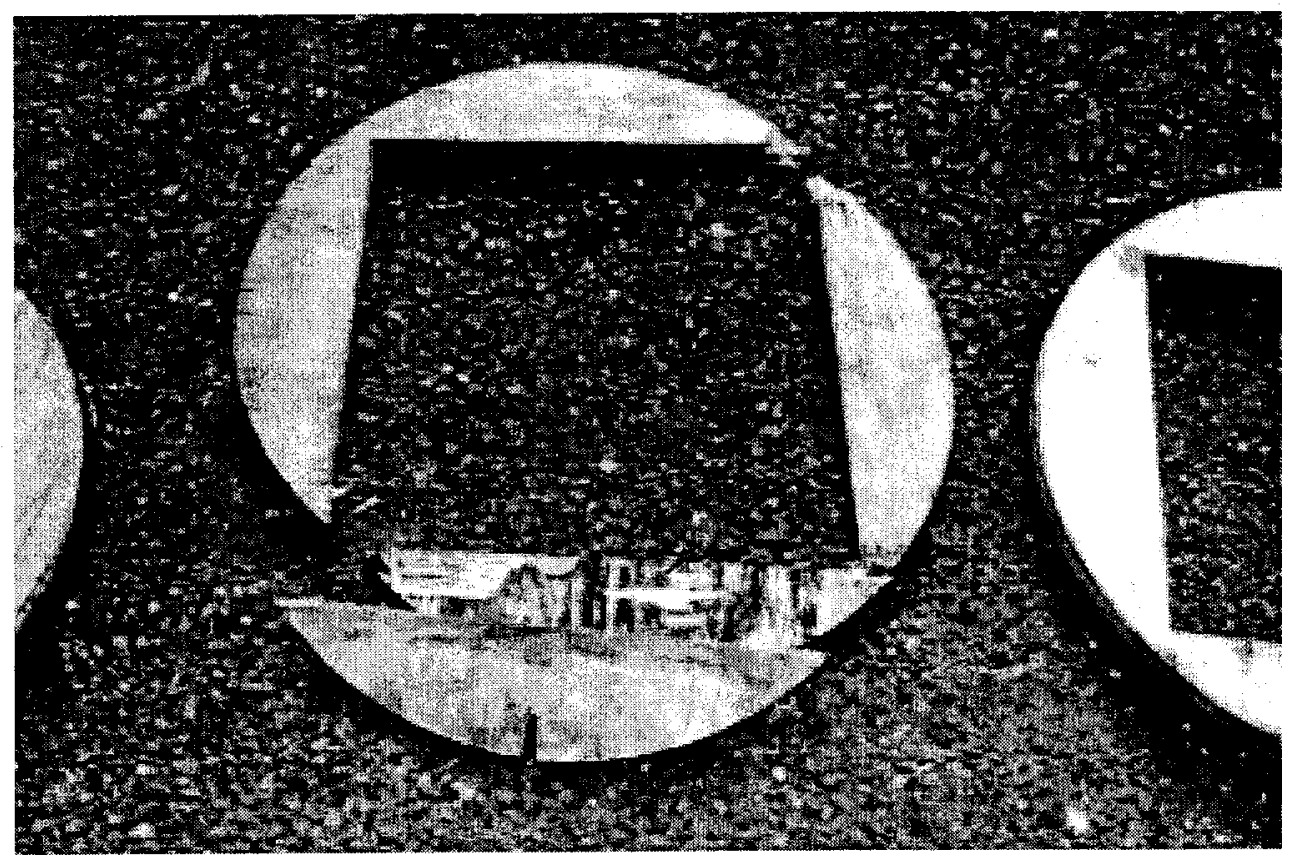

Figure 31. Lower 1" Inner Compartment Plywood Spacer 


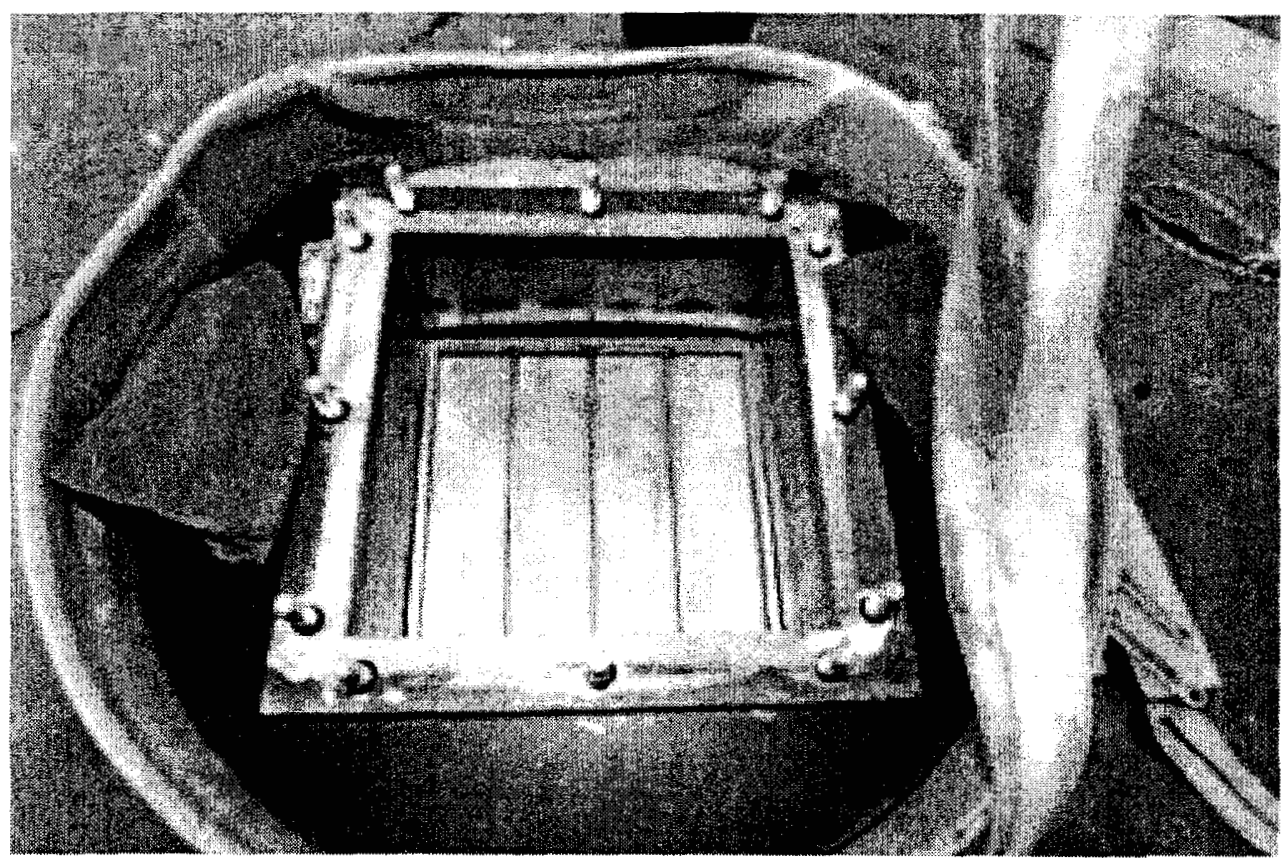

Figure 32. Inner Compartment Upper Block Removed

\subsection{Fuel-pellet containment box}

The fuel-pellet containment box had only minor damage at the impact end. The presence of the solid square wood block inside the box opening at the impact end might have helped limit the extent of the damage. A technician noticed that some of the closure bolts in the box-opening flange were slightly displaced off the centerline of their base holes. A slight deflection of the impacting side of the box was visible. The deflection could be easily felt by touch.

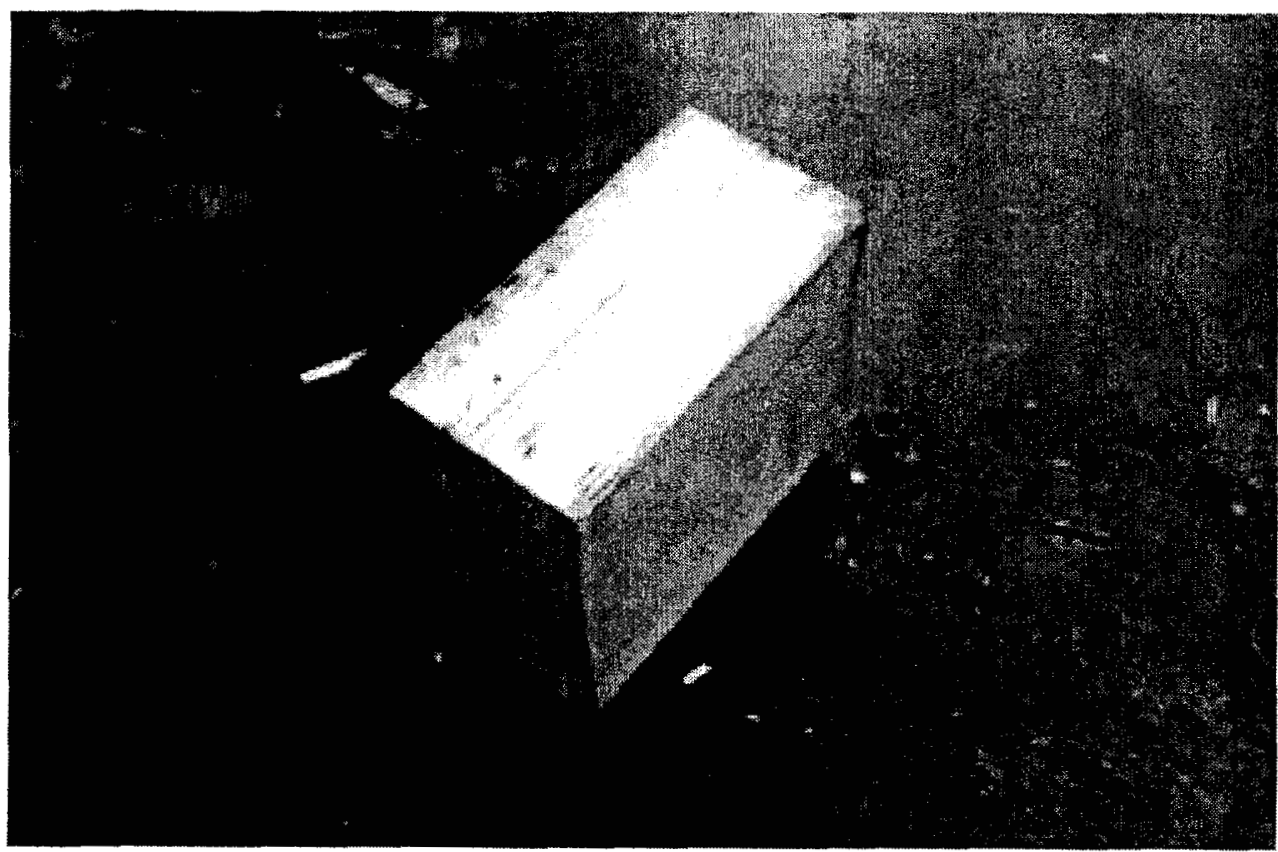

Figure 33. Upper Inner Compartment Spacer Block 
Drop Test Results

for the ABB-2901 Package

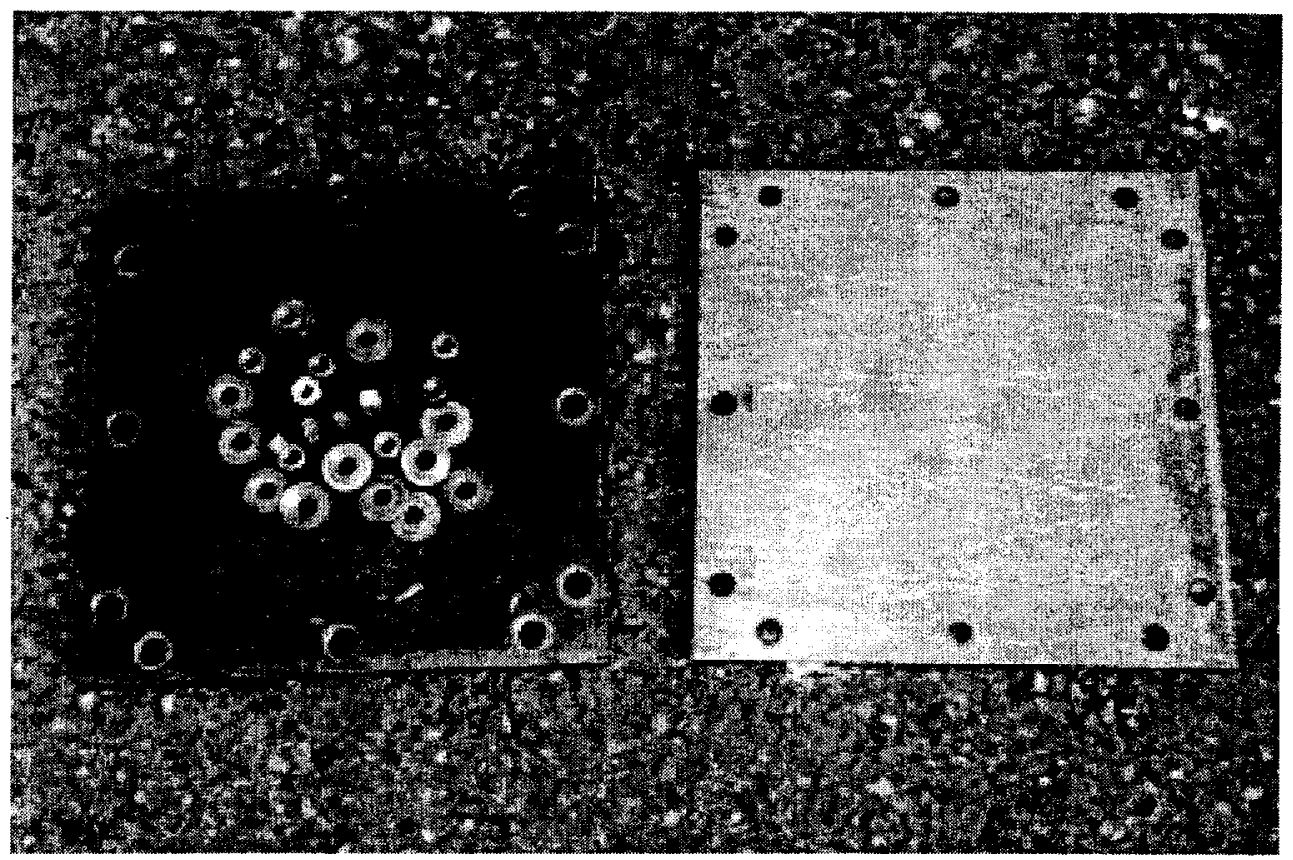

Figure 34. Inner Compartment Lid, Gasket, Nuts and Washers

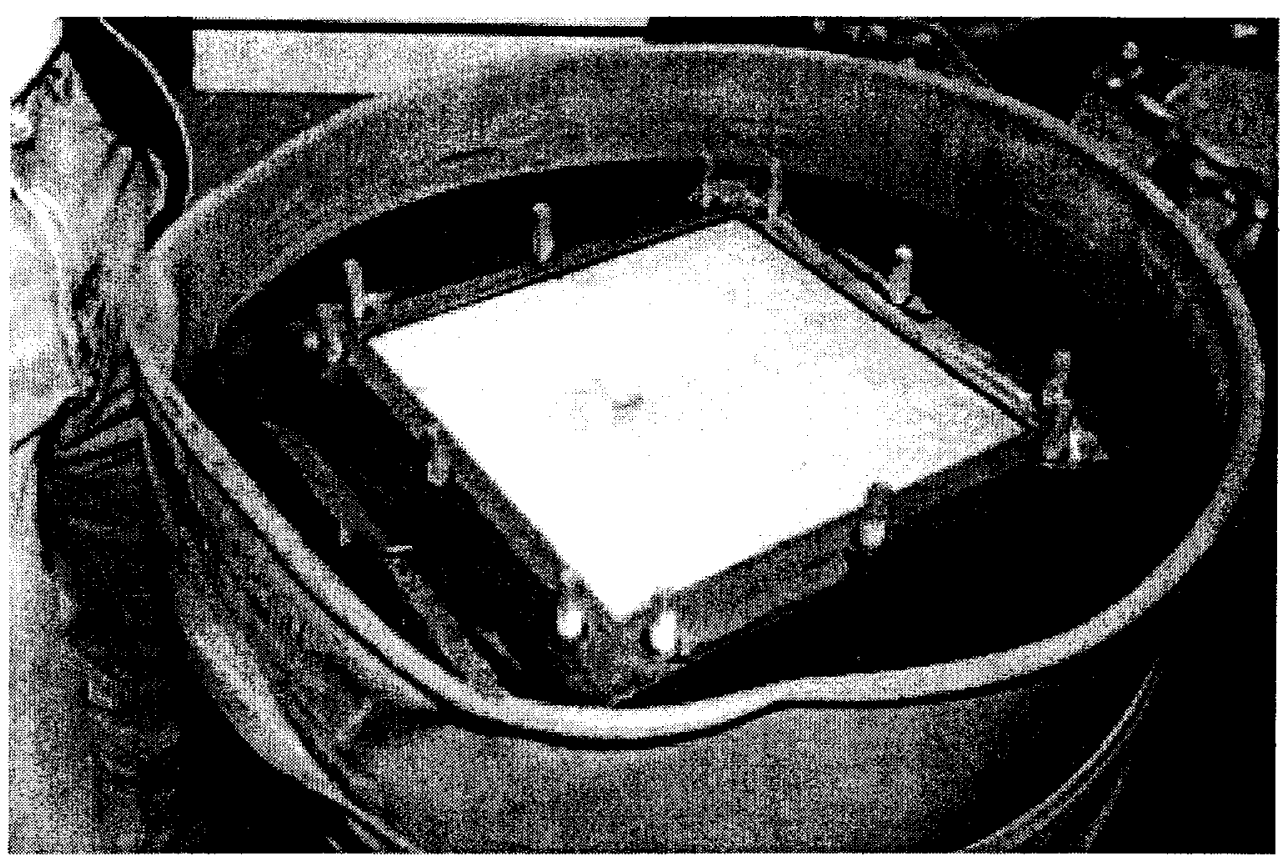

Figure 35. Inner Compartment Lid Removed 


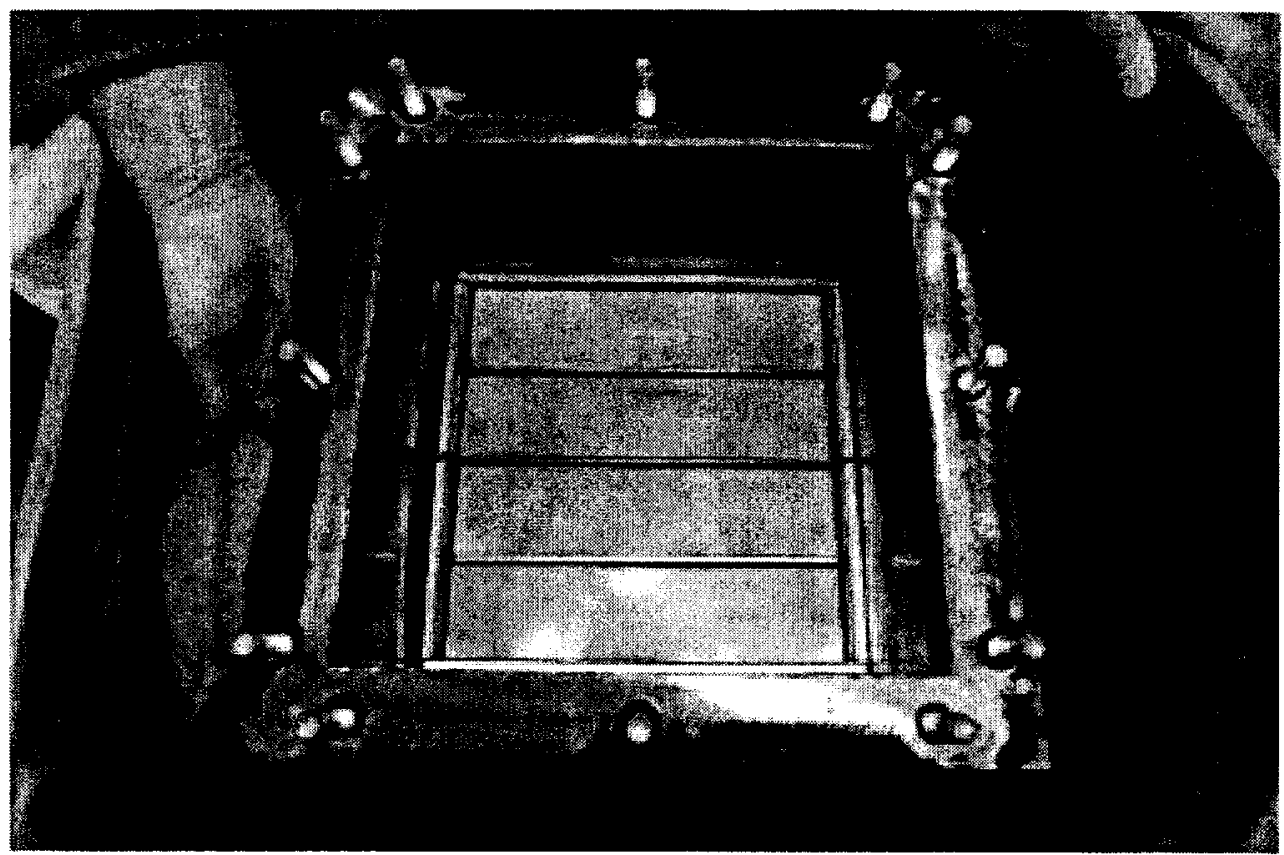

Figure 36. Inner Compartment Upper Block Removed

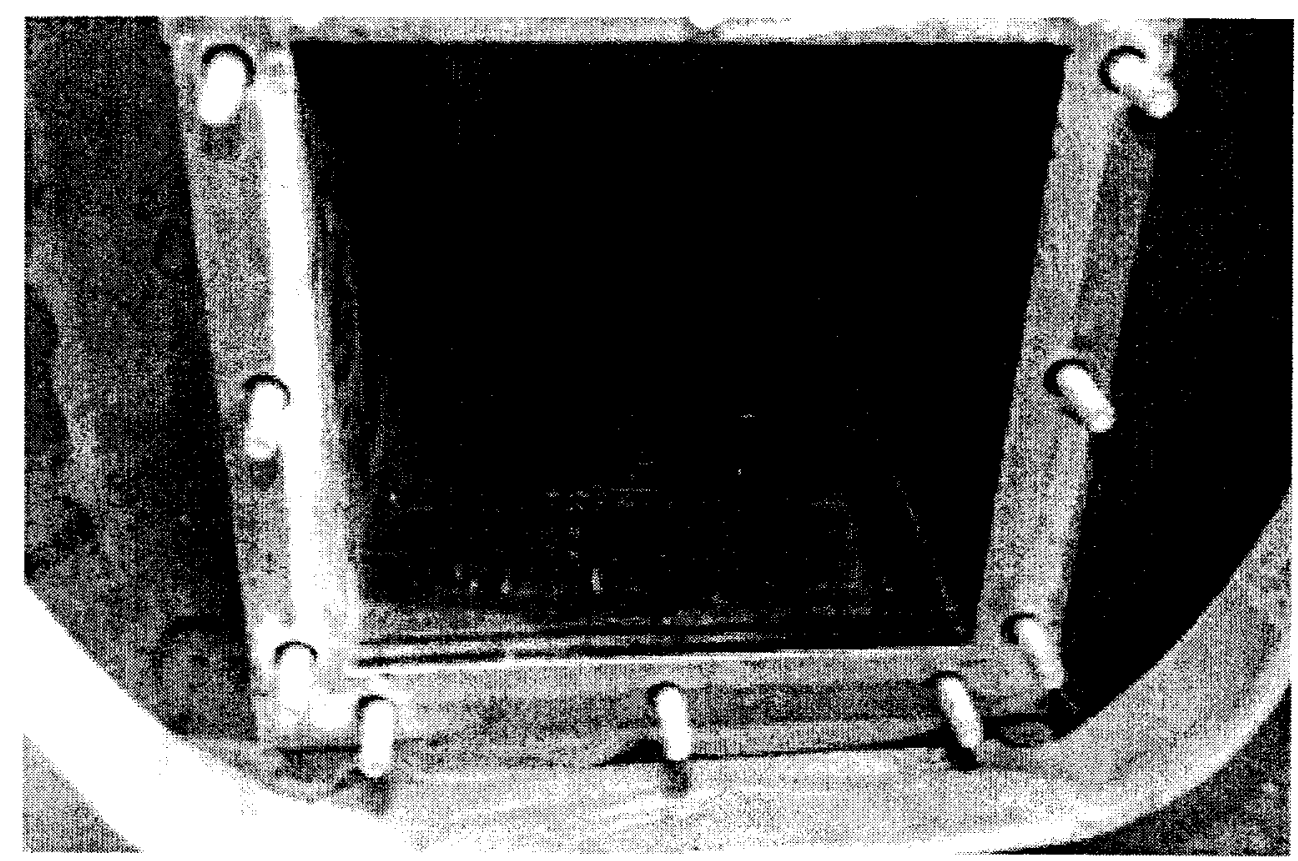

Figure 37. Close-Up View; Inside of Inner Compartment

\subsection{Drum body}

Similar to the lid-and-ring assembly, the round drum opening was flattened in the impact area. In addition, the round opening appeared slightly oval in the horizontal direction. This deformation was probably due to the compressive action of the vertical impact force rather than the bursting 
Drop Test Results

for the ABB-2901 Package

action of disintegrated contents, as in the case of the water-filled drum in the preliminary test runs.

The slight local buckling deformation of the drum opening near the impact area indicated the high intensity of the compressive action.

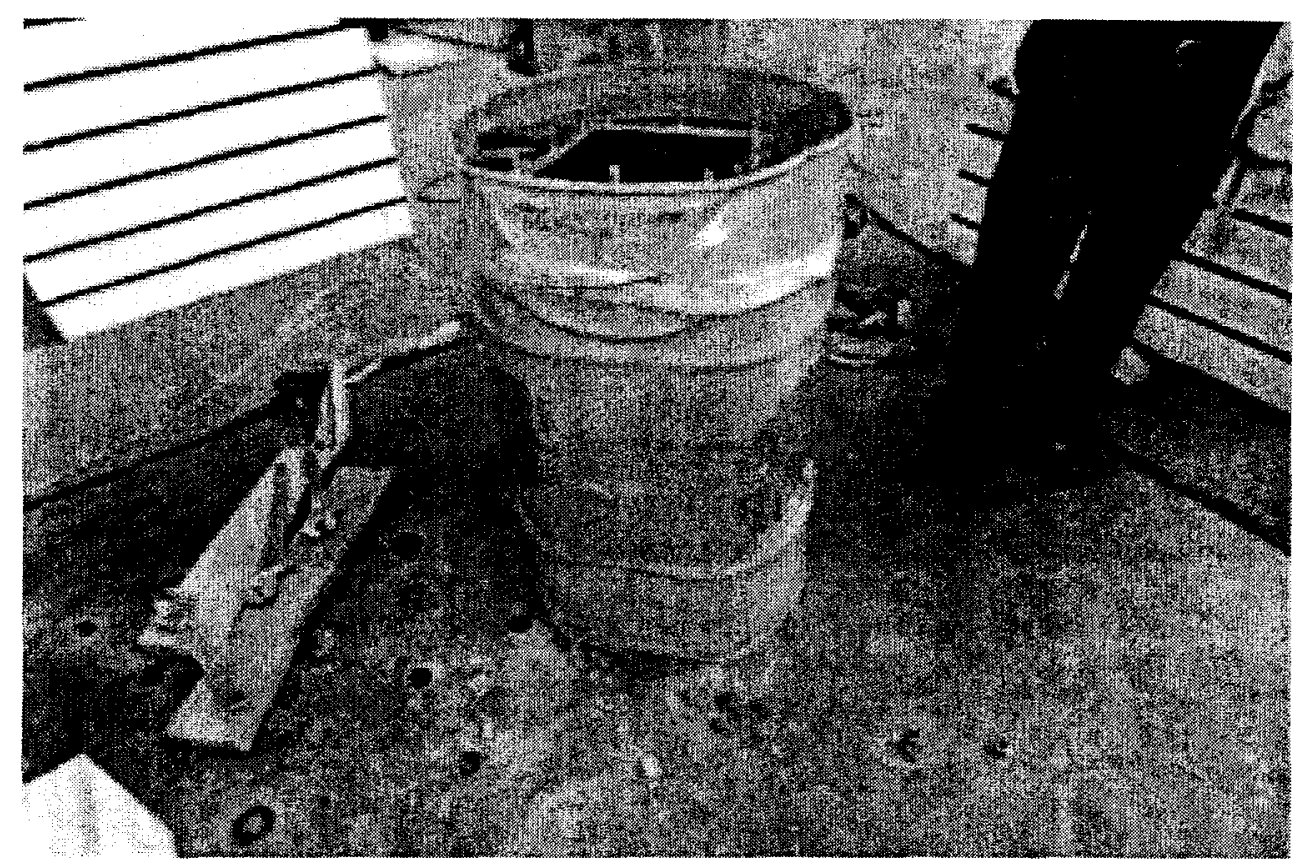

Figure 38. Side-View Damage to Open Drum

\subsection{Other components}

The internal tab tack-welded to the inner drum body to prevent the containment box from sliding out of the drum cavity became ineffective due to the destruction of the hardboard ring, with which the internal tab was supposed to engage. In Figure 41, the test team turned the damaged drum upside down to demonstrate that the containment box could easily come out of the drum cavity by its own weight. A technician also noticed a crack in the corner welds of the shipping container insert, which was not visible prior to the test. 
Drop Test Results for the ABB-2901 Package

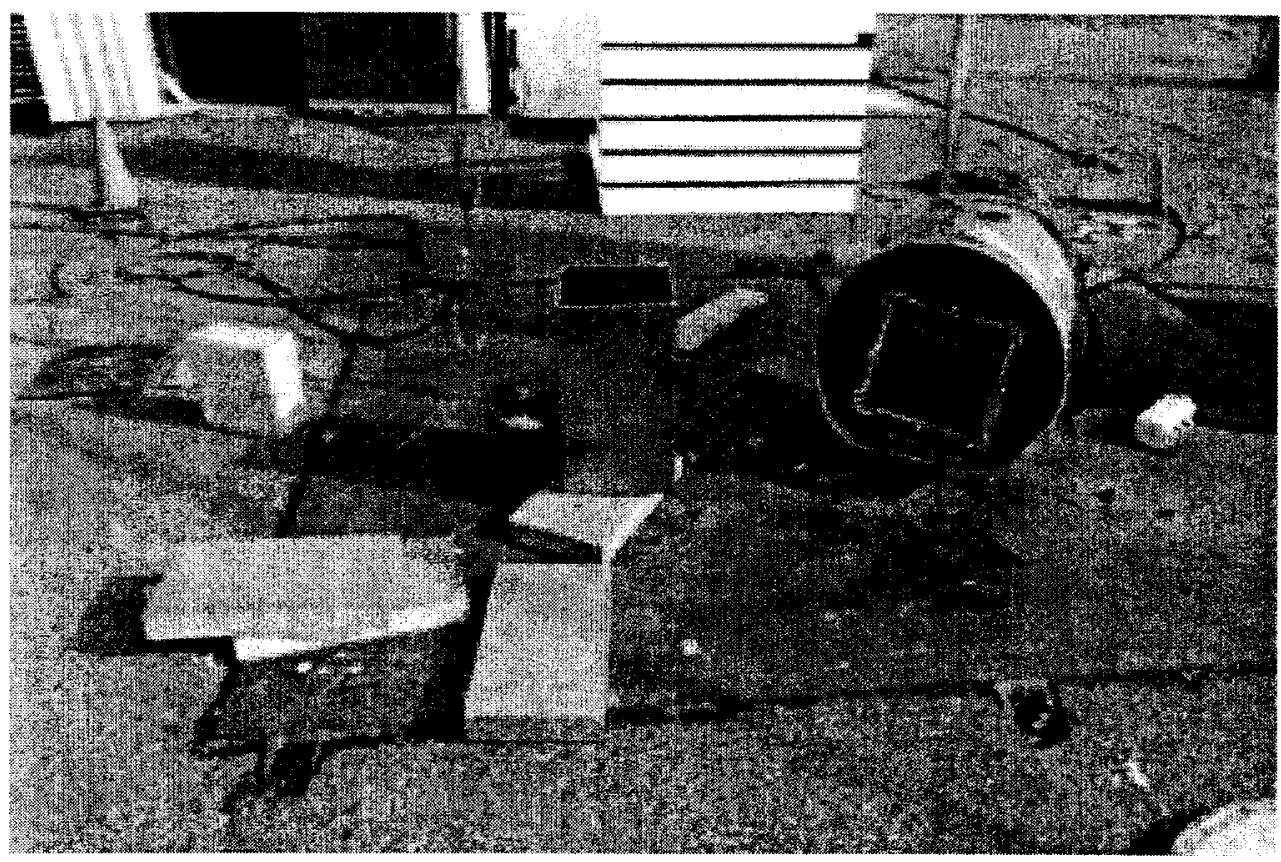

Figure 39. Upper, Inner Compartment Spacer Block, Pellet Trays; Pellet Tray Box, and Drum

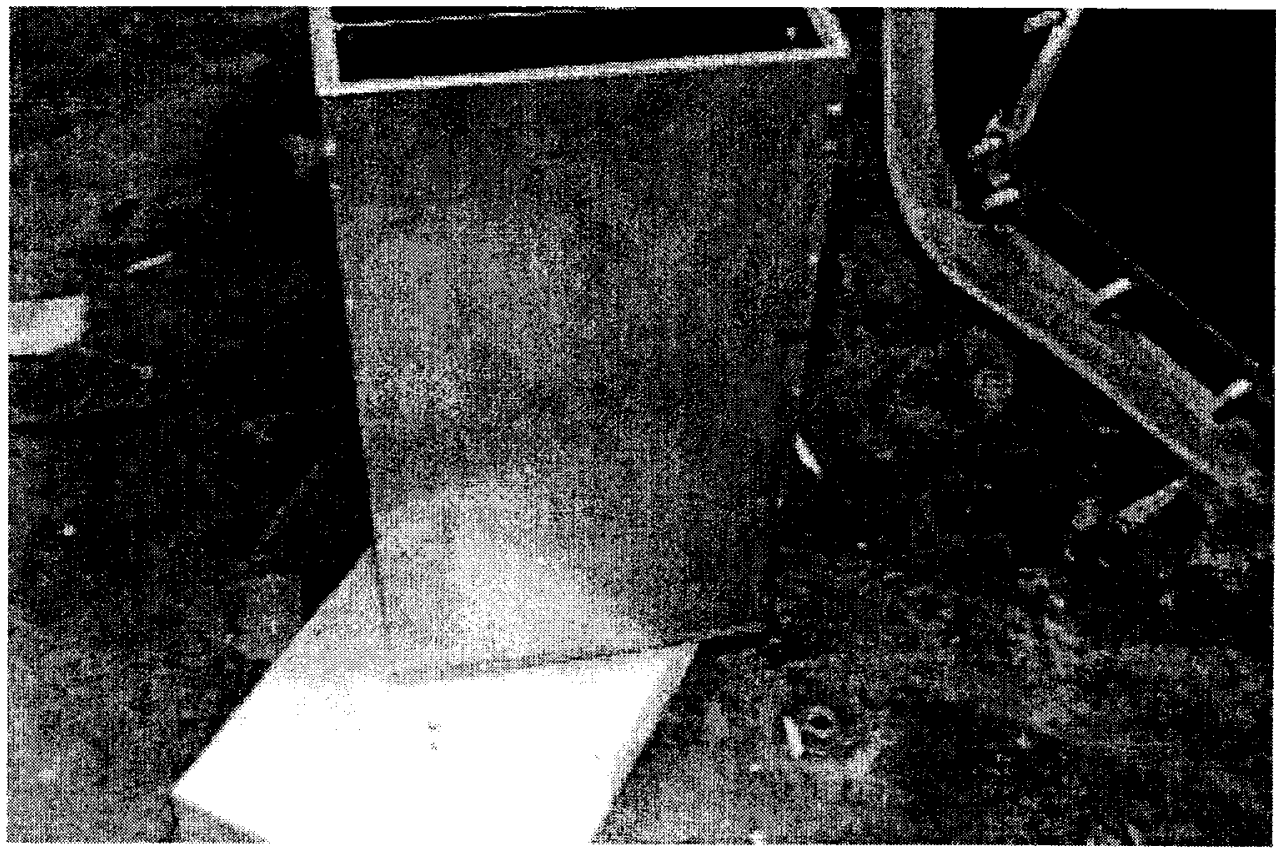

Figure 40. Side-View Close-Up of Pellet Tray Box 
Drop Test Results

for the ABB-2901 Package

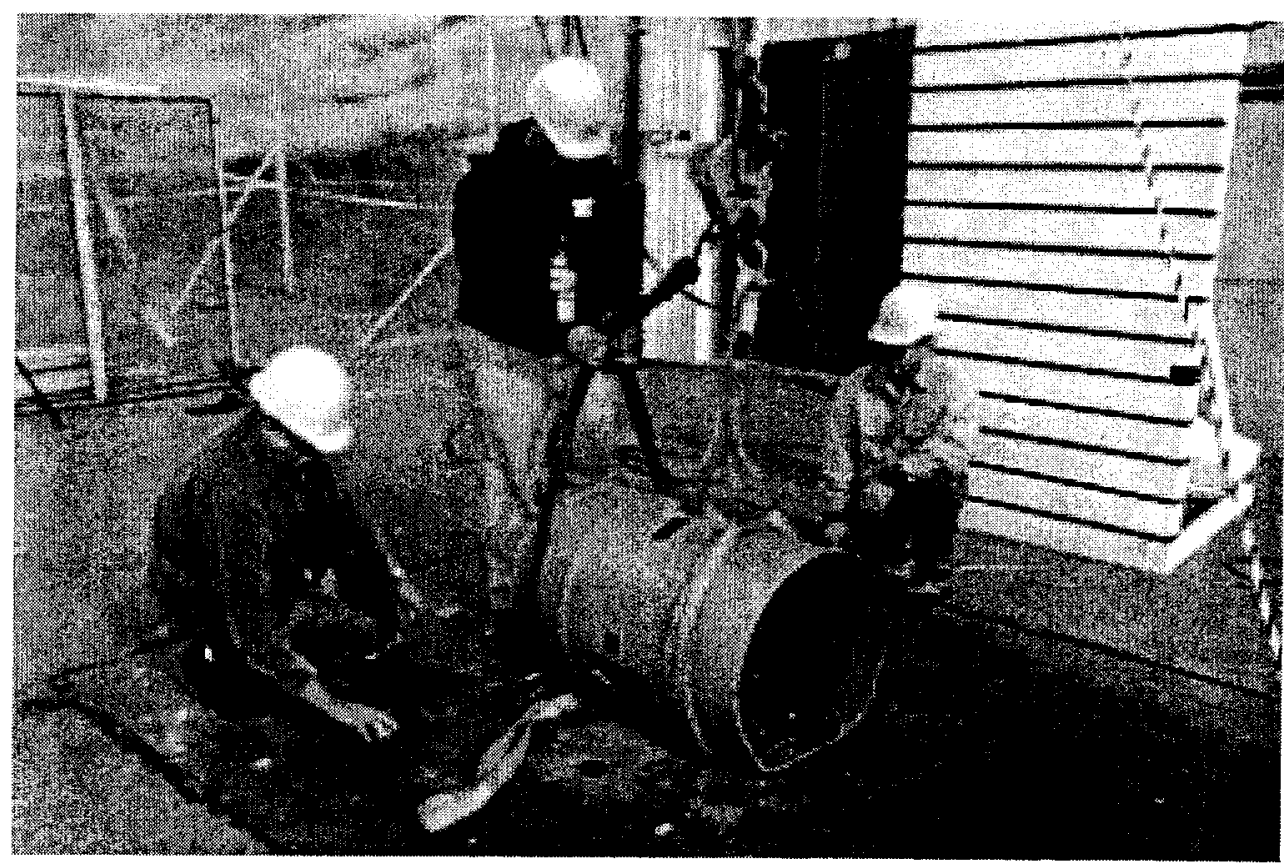

Figure 41. Drum Damage; Wide-Angle View From left, Bruce Clegg (LLNL), Rich Villafana (LLNL), and Jesse Rivera (LLNL) 
Drop Test Results for the ABB-2901 Package 


\subsection{0-ft Free Drop Video Records}

The high-speed video records of the $30-\mathrm{ft}$ drop offer significant insight into the cause and development of the drum lid failure. Therefore, Figures 42 through 49 reproduce some key frames from the video record for discussion and evaluation in this section. The figures present the corresponding side-view and top-view frames of the impacting package and an analysis of each.

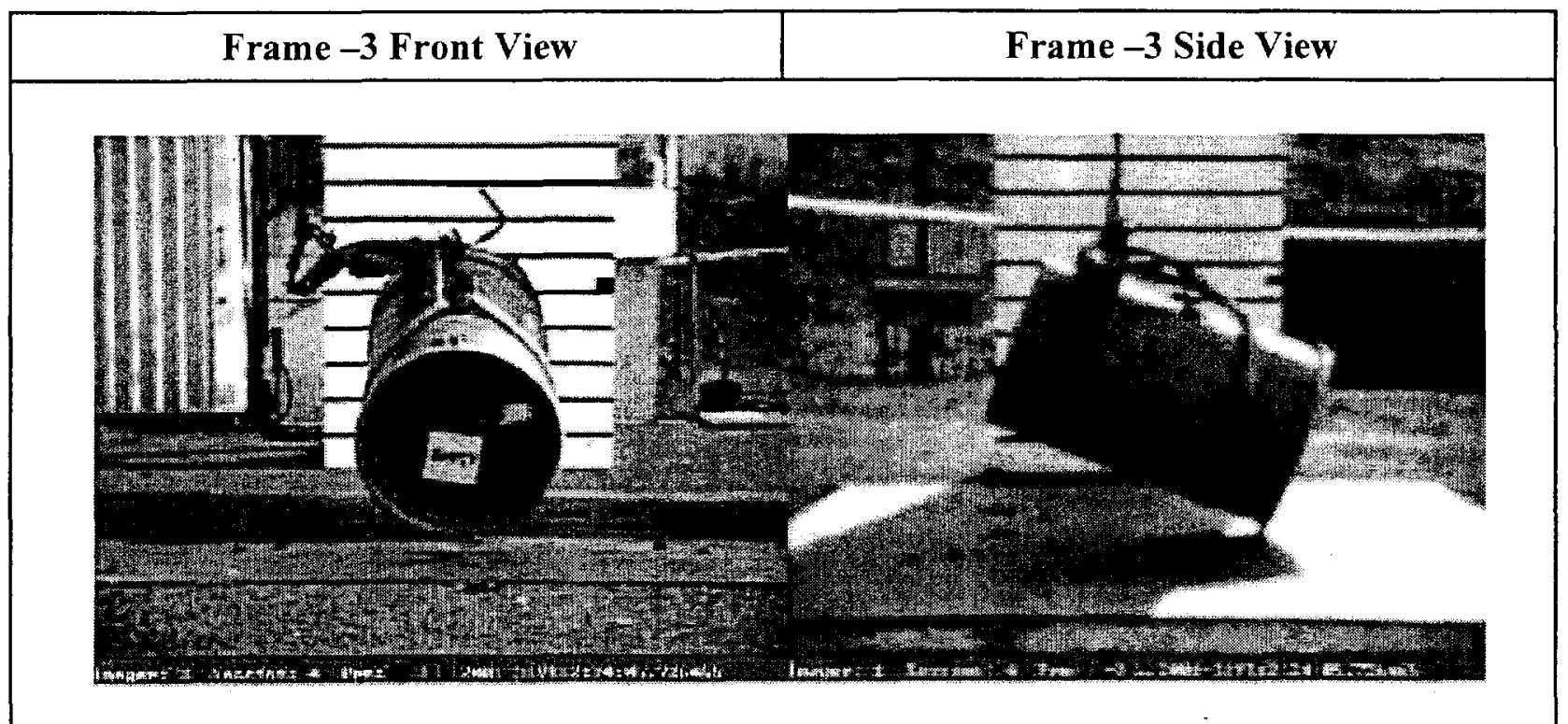

Figure 42. The lowest edge of the drum package was about to hit the unyielding target surface.

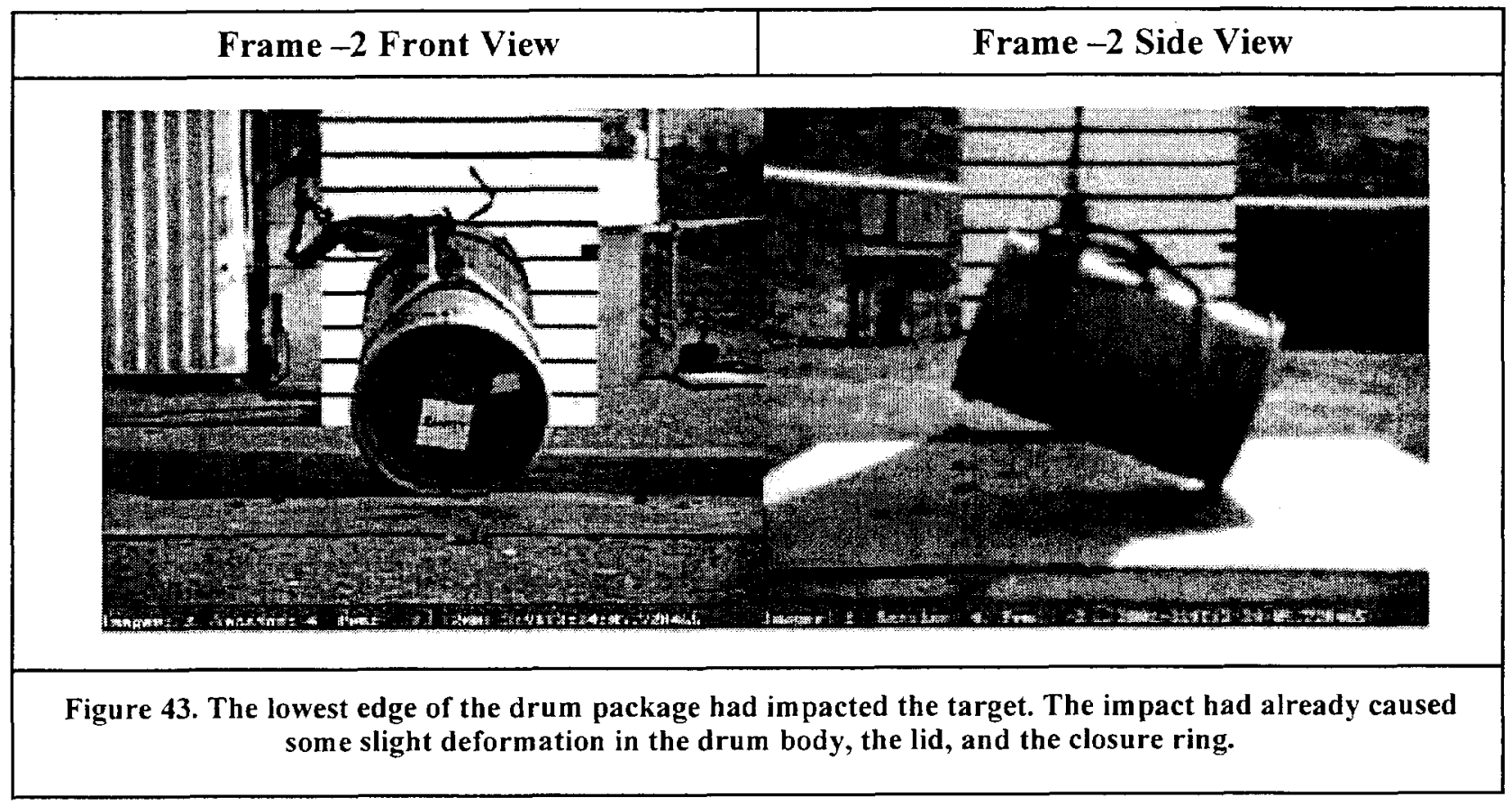



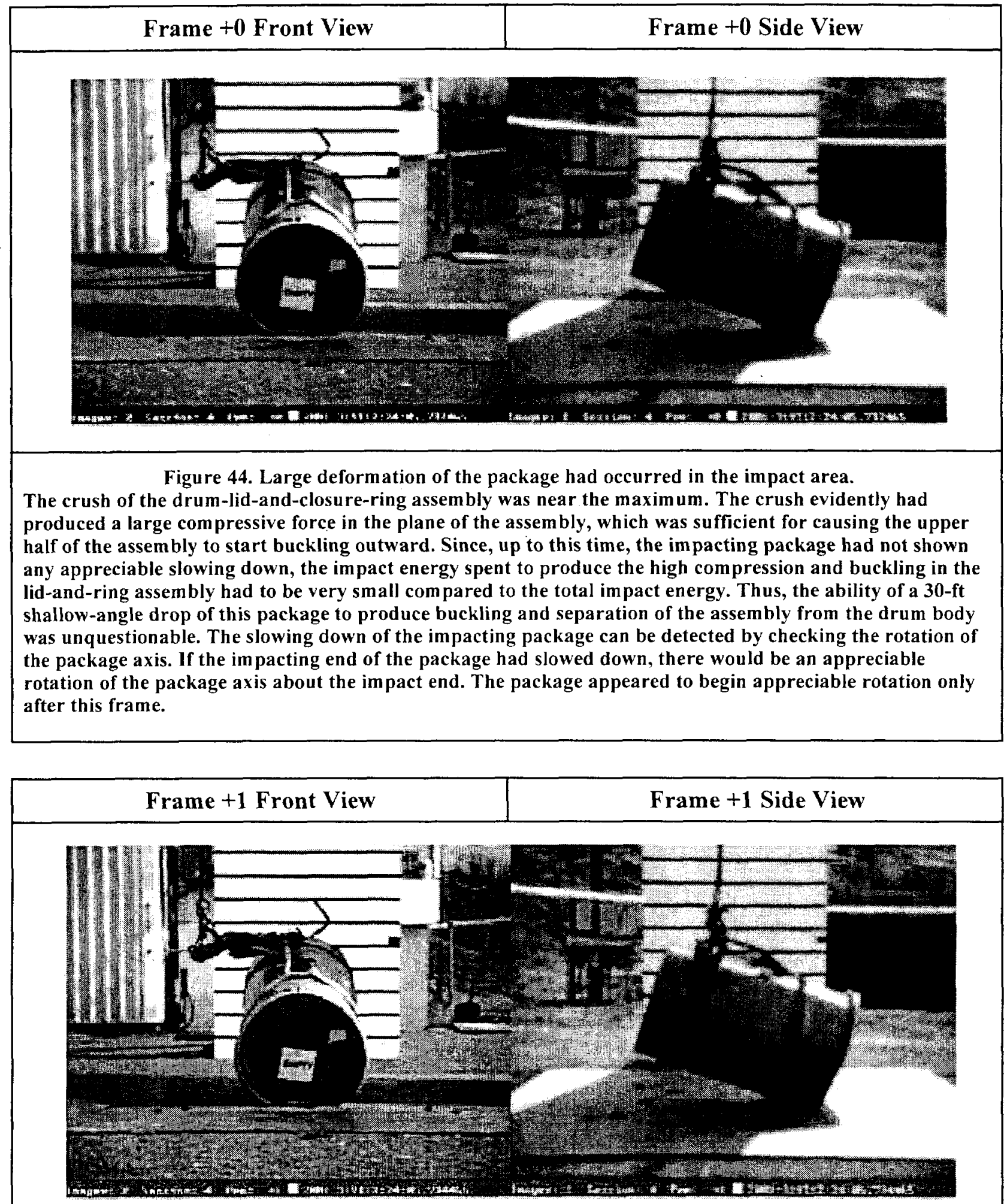

Figure 45. The drum-lid-and-ring assembly began to separate from the drum body. By this time, however, the separation did not appear to have occurred at the top edge of the drum. 


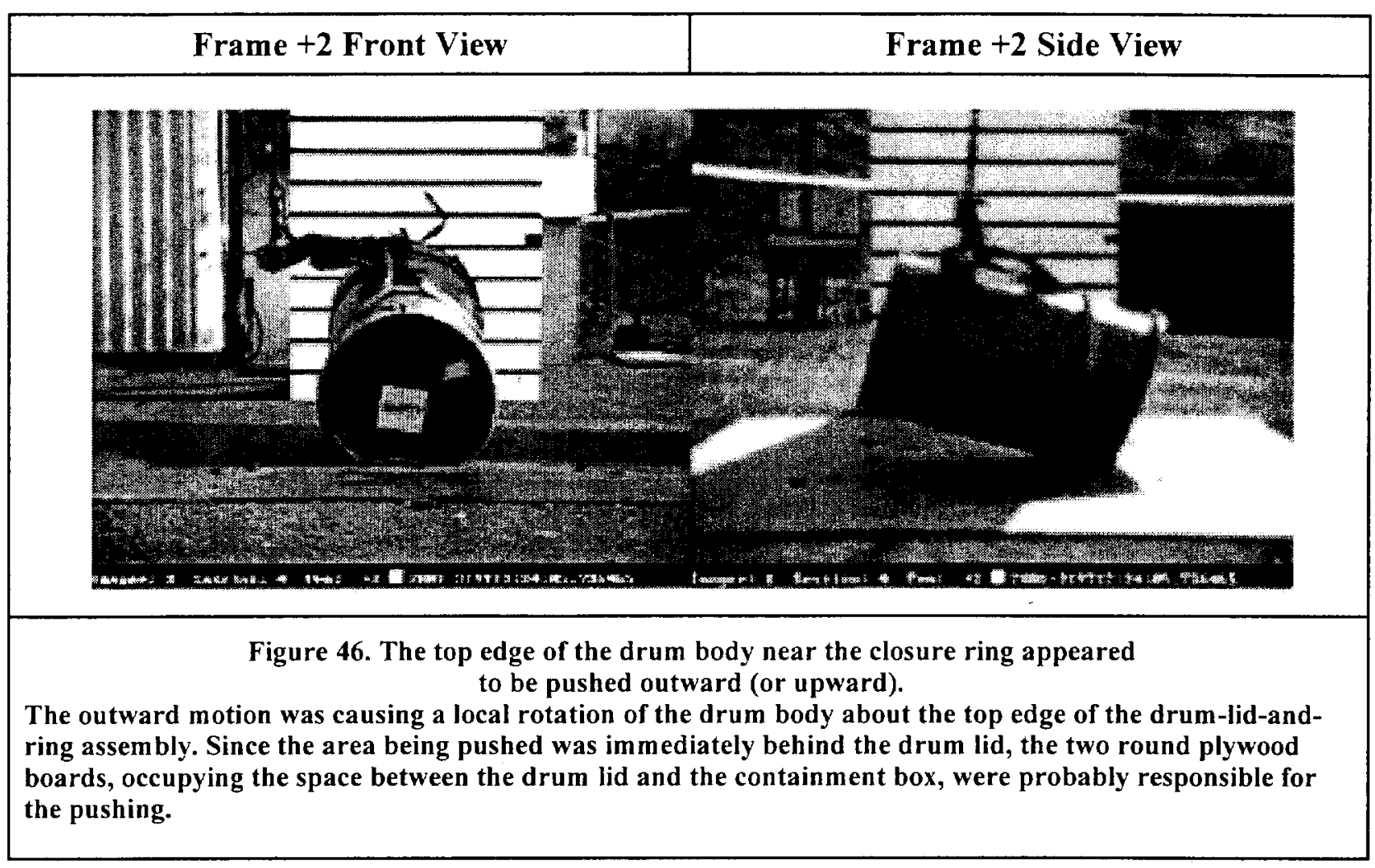




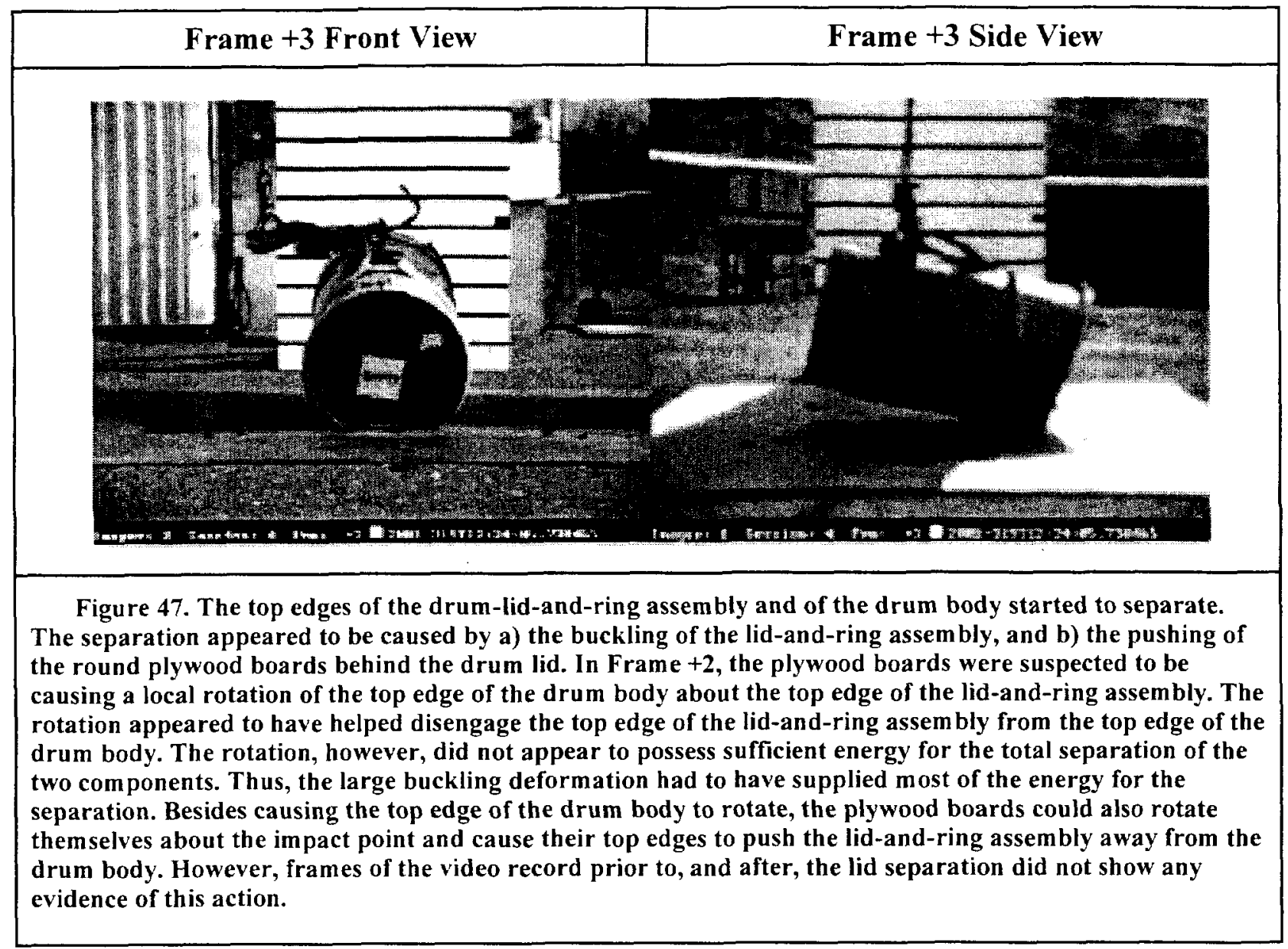

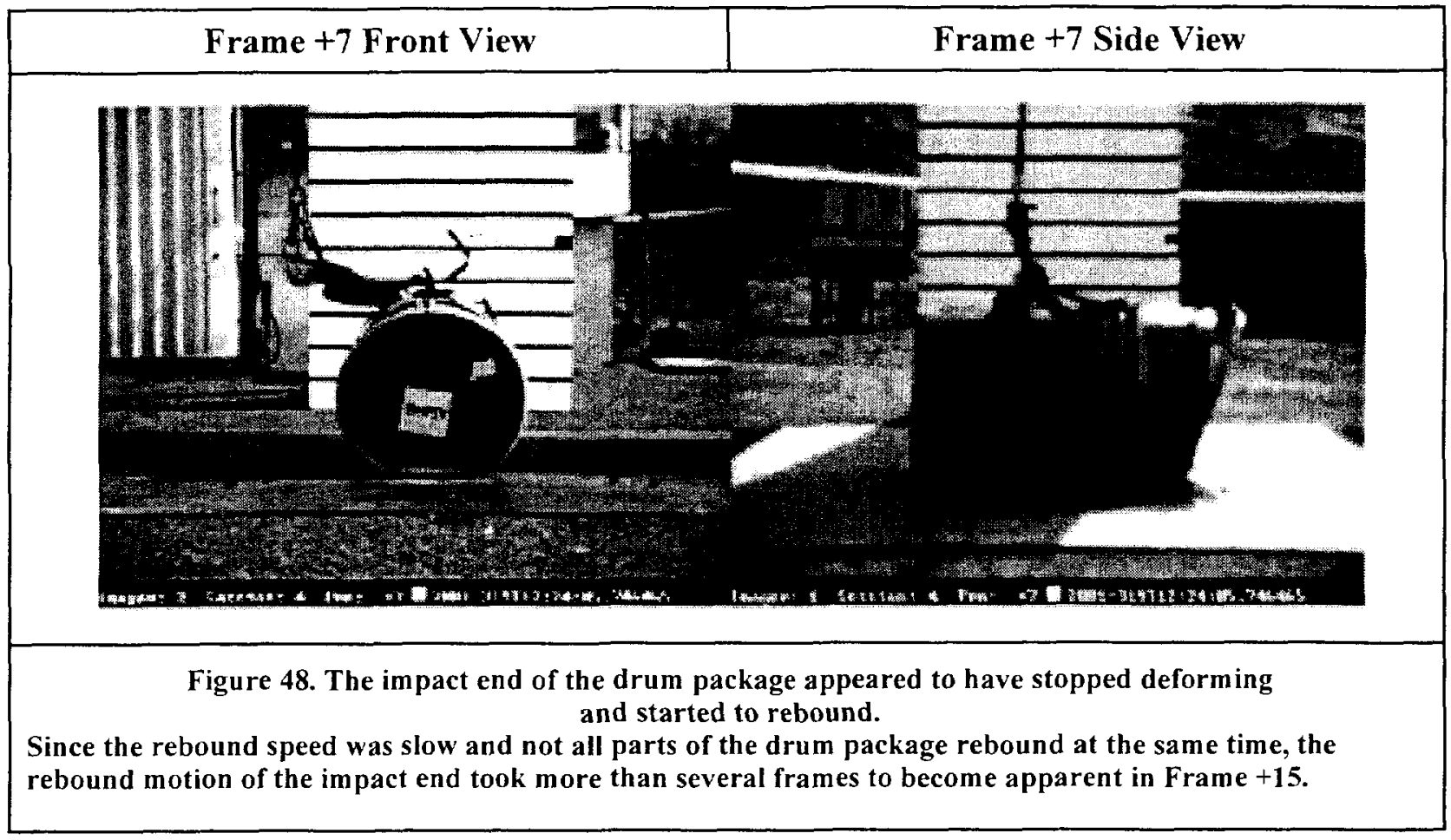




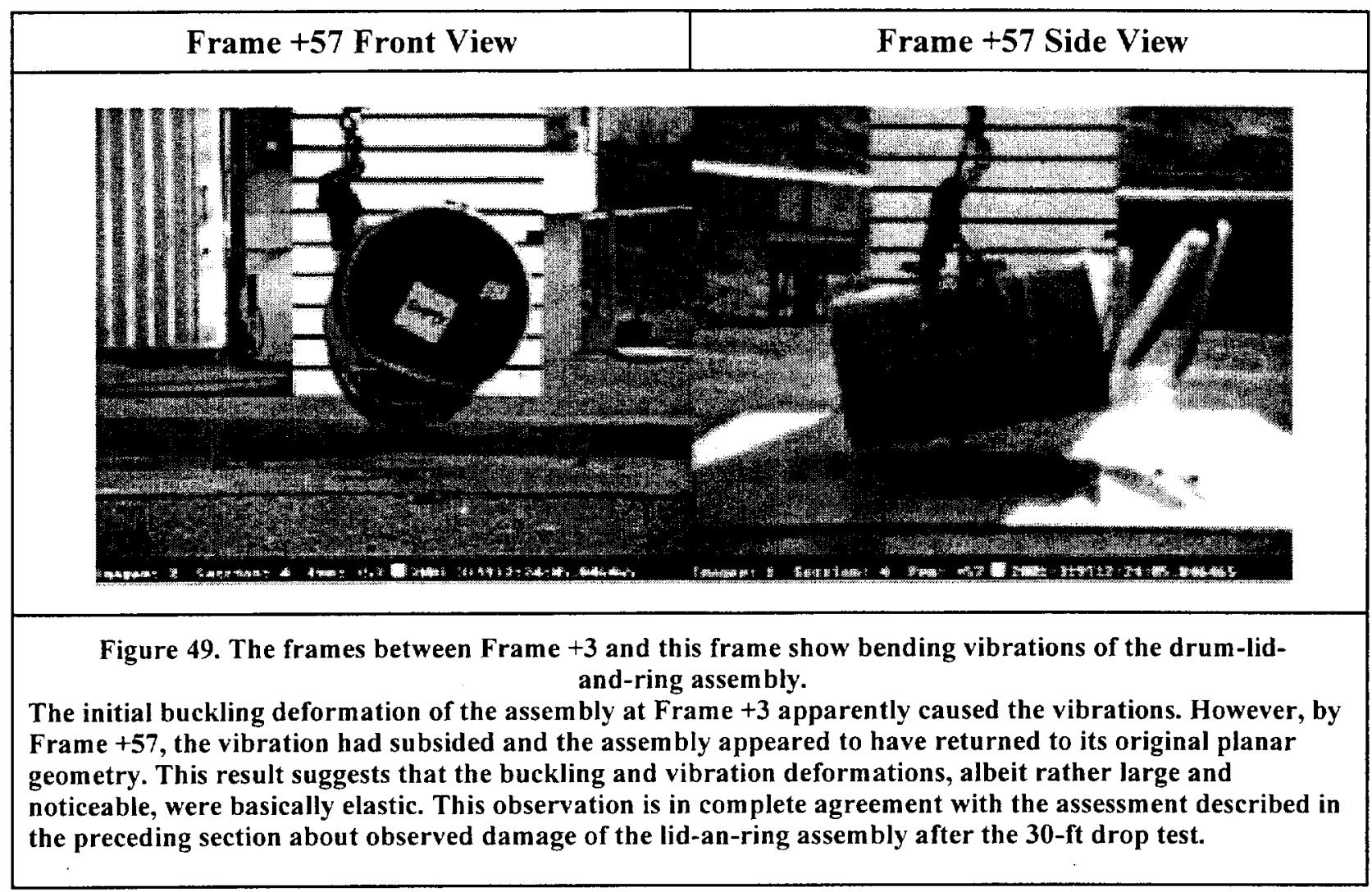




\subsection{Puncture Test}

Since the 30-ft drop was able to create a clear total separation of the drum lid from the drum body, the group of witnessing engineers concurred that the planned puncture test need not be performed. The conclusion that the puncture test need not be performed was reinforced by the fact that the test team turned the damaged drum upside down to demonstrate that the containment box could easily come out of the drum cavity by its own weight (see Figure 50).

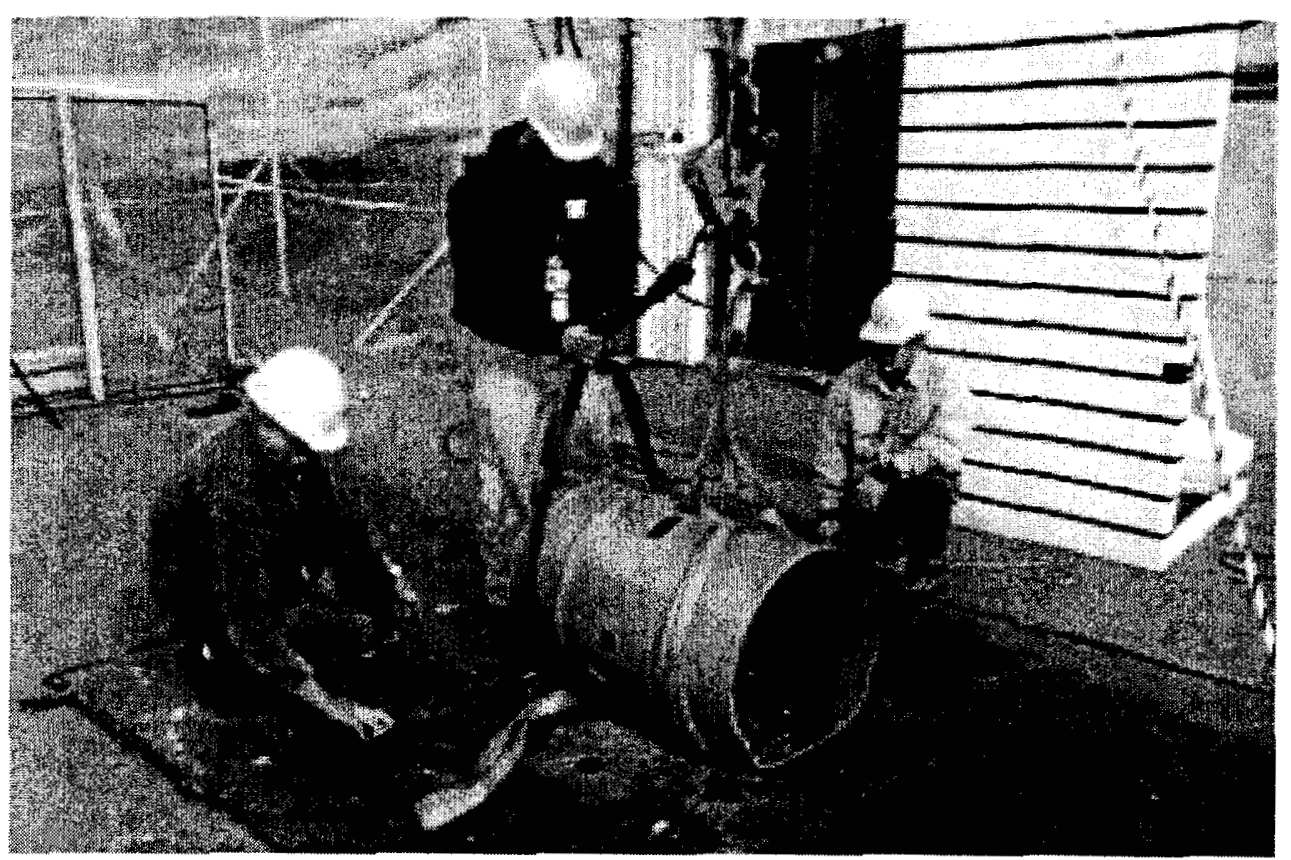

Figure 50. Drum Damage; Wide-Angle View Bruce Clegg (LLNL), Rich Villafana (LLNL), and Jesse Rivera (LLNL) 
Drop Test Results

for the ABB-2901 Package 


\subsection{Summary and Findings}

In summary, the drop test accomplished its mission. Because the lid and closure device separated from the drum body in the $30-\mathrm{ft} 17.5^{\circ}$ shallow-angle drop, the drop test confirmed that the common drum closure with a bolted ring is vulnerable to damage by a shallow-angle drop, even though the closure has been shown to survive much steeper-angle drops. The test program also demonstrated one of the mechanisms by which the shallow-angle drop opens the common bolted-ring drum closure.

The separation of the drum lid and closure device from the drum body was initiated by a large outward buckling deformation of the lid and completed with minimal assistance by the round plywood boards behind the lid. The energy spent to complete the separation appeared to be only a small fraction of the total impact energy. Limited to only one test, the present test program could not explore all possible mechanisms for the closure failure, some of which the test plan has described. The test program was also not intended to develop any quantitative design criteria for preventing drum closure failures. However, despite the limitation, the analyses of the present test results and video records in Section 5 offer valuable qualitative understandings of the shallowangle impact. Following is a summary of the significant findings of this test program.

- Drum closures, using the common bolted-ring closure system, can fail under shallow-angle drop conditions, even though such closure systems have been shown to be resistant to similar failures under steeper-angle drop conditions.

- The shallow-angle drop can create failures of the common bolted-ring closure easier than the steep-angle drop, because, inherent in the impact direction and the closure design, the shallow-angle drop tends to drive the closure components apart, whereas the steep-angle drop tends to crush the components together. The puncture drop and the shallow-angle drop have similar ability, but the 40 -inch puncture drop possesses much less damaging forces than that of the 30-ft shallow-angle drop.

- The shallow-angle drop separates the lid and closure from the drum body by producing an outward buckling deformation of the drum lid, which is so large that the deformation of the drum body cannot match and the closure ring cannot restrain. The shallow-angle drop is also known to damage the drum closure by other means, such as breaking the lug welds of the closure weld.

- The shallow-angle drop's ability to creating closure opening depends on the following factors: the drop orientation, the design detail and quality of the closure components, the package weight, and the integrity of the internal structure of the package. If the internal structure has no integrity, like liquid and powder, even the steep-angle drop can cause closure failures. 
- To ensure that standard bolted-ring drum closures can survive a shallow-angle drop, the following general qualitative rules should be observed:

- The drum-closure components should be quality products made of ductile materials.

- The package should not be too heavy.

- The package internal structure should be impact-absorbent and resistant to disintegration and collapse under high compressive loads. However, a strong internal structure may defeat the purpose of protecting the containment vessel from damage during a free drop.

- To establish a quantitative relationship between the closure integrity and the affecting factors will require more than a few drop tests, even if the study is limited to only one specific package design. For this reason, the present single-drop test cannot offer general quantitative findings about shallow-angle drops of the test drum package. The present test only confirms that shallow-angles drops should be considered in the safety evaluation of drum packages that employ the bolted-ring closure system.

- Since closure failures by the shallow-angle drop usually involve large deformations, geometric discontinuities, and structural instabilities, all of which are sensitive to design details and not amenable to regular mathematical analyses, the shallow-angle-drop evaluation of the drum closure should be conducted by test and on a case-by-case basis. Moreover, the familiarity with the package design and the understanding of the behavior of such packages under impact are essential for developing an adequate test plan.

- The performance of the bolted-ring closure system may well depend on the torque value used to tighten the bolt. Therefore, the SAR of the package should contain the appropriate torque value. The torque value for the present test package was not found in the SAR.

- By nature, the behavior of the bolted-ring closure under the shallow-angle impact can be rather unpredictable. This unpredictability may warrant a larger-than-usual margin of safety for this type of closure design. If the closure cannot be proven to remain closed under shallow-angle impacts, the possibility of the containment vessel being totally exposed should be considered in the evaluation of the package's capability to maintain the sub-criticality, containment, and shielding of the radioactive contents. 


\section{References}

Combustion Engineering, Inc., "Application for Use of Model No. ABB-2901 Fuel Pellet Shipping Package," Certificate of Compliance No. 9274, NRC Docket No. 71-9274, April 8, 1997.

Hagler, L., M.K. Sheaffer, B.L. Anderson, R.S. Hafner, M.K. Witte, "Potential Vulnerability Issues for Drum-Type Packages," published in Lisle Hagler, "Potential Vulnerability Issues for Drum-Type Packages," presented at the ASME PVP Conference, 2000. Proceedings of the ASME Pressure Vessel and Piping Conference, PVP-Vol. 408, pp. 89-95, Seattle, Washington, July $23-27,2000$.

Lewallen, E.E. "Drum and Board-Type Insulation Overpacks of Shipping Packages for Radioactive Materials," E.I. Dupont de Nemours \& Co., Savannah River Laboratory, DP-1292, Aiken, SC, July 1972. (1972)

Title 10, Code of Federal Regulations, Part 71 (10 CFR 71), "Compatibility with the International Atomic Energy Agency (IAEA)," 60 FR 50248, September 28, 1995, as amended.

Towell, Robert H. "Important Features Affecting Thermal Protection Provided by Drum and Fiberboard Packages," Proceedings of the $29^{\text {th }}$ Annual Meeting of the Institute of Nuclear Materials Management, Vol. XVII, Las Vegas, Nevada, 1988. (1988)

Westinghouse Savannah River Corporation, "Safety Analysis Report - Packages, 9972-9975 Packages (U)," WSRC-SA-7, Revision 12, Radioactive Materials Packaging Technology, Savannah River Technology Center, Aiken, SC, June 2001. 
Drop Test Results

for the ABB-2901 Package 


\title{
Appendix A
}

\author{
Drop Test Plan \\ for the \\ Combustion Engineering \\ Model No. ABB-2901 \\ Fuel Pellet Shiping Package
}

Lawrence Livermore National Laboratory

Livermore, CA

October 30, 2001 
Drop Test Plan

for the ABB-2901 Package 


\section{Table of Contents}

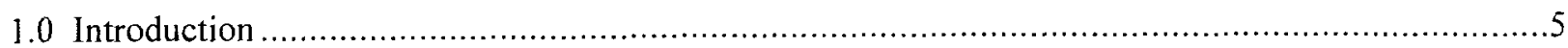

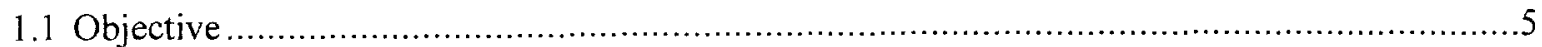

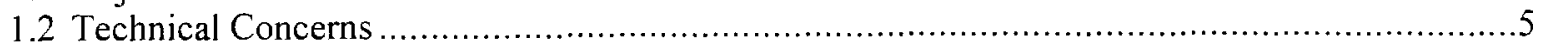

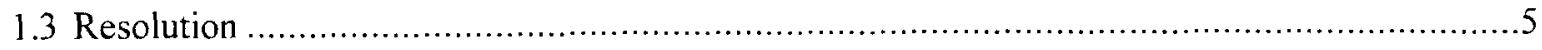

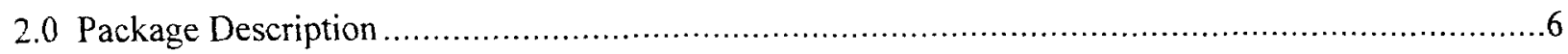

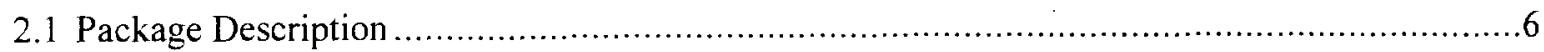

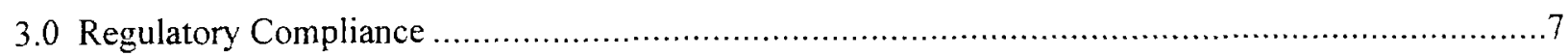

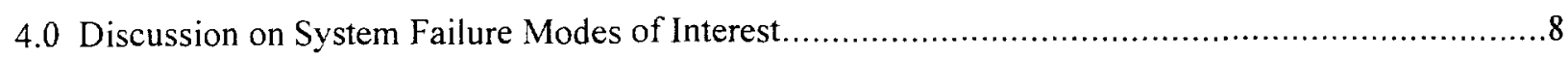

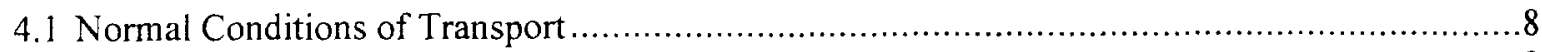

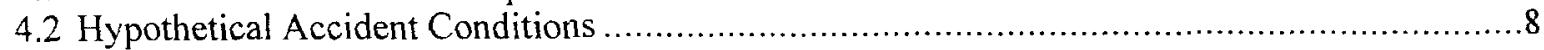

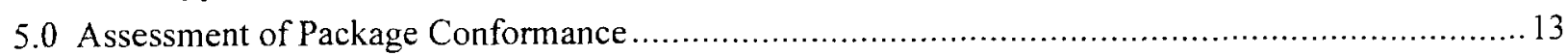

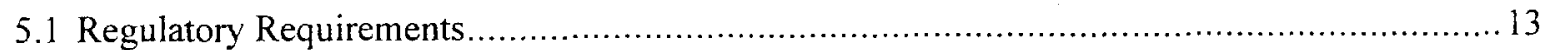

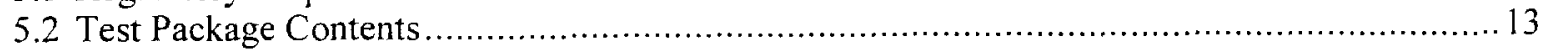

6.0 Condition and Loading Procedures for the Test Specimen ............................................. 14

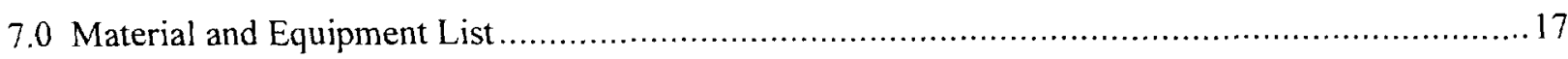

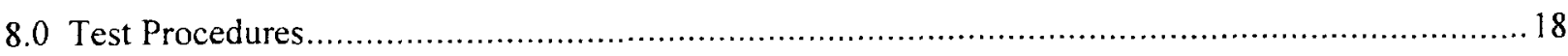

8.1 General 18

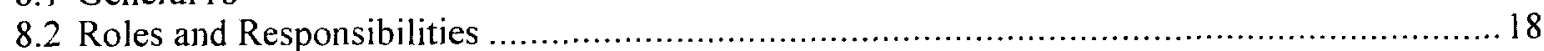

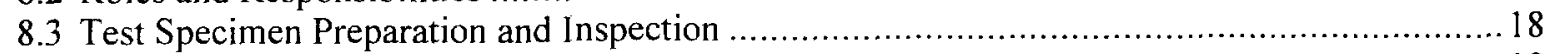

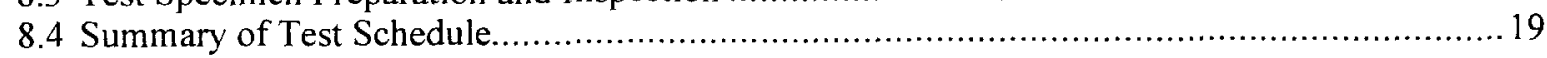

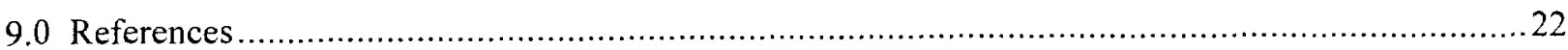

\section{Table of Figures}

Figure A-1. Drop Angle of the Packaging Relative to the Impact Surface ......................................... 12

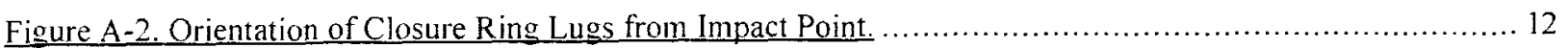

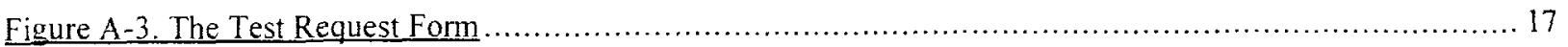

\section{Table of Tables}

Table A-1. ABB-2901 Drum Lid Retention Test Matrix. 
Drop Test Plan

for the ABB-2901 Package 


\subsection{Introduction}

This document describes the test plan for Combustion Engineering's Model No. ABB-2901 No. 71-9274 (Combustion Engineering 1997). This document further describes the test Fuel Pellet Shipping Package (the ABB-2901), NRC Docket package specifications, testing equipment, and testing scenario. In addition, this document provides the appropriate justification for the package orientations for the test specimen, and it provides test worksheets to record key steps in the testing sequence.

\subsection{Objective}

To resolve concerns about the ABB-2901 drum-type overpack lid retention during a low-angle, top-down impact tests, under hypothetical accident conditions (HAC).

\subsection{Technical Concerns}

The failure of two Westinghouse Savannah River Corporation's (WSRC) packagings (WSRC 2001) (i.e., the WSRC-9974 and the WSRC-9975 packagings), during shallow-angle HAC drop tests in the top-down orientation has raised concerns about the vulnerability of all relatively heavy, drum-type packagings, particularly those with bolted ring closures. In particular, currently certified packages whose designs did not consider shallow-angle impact during either HAC testing or analysis may present a risk.

\subsection{Resolution}

Resolution of these concerns requires demonstration of the ability of the ABB-2901 to withstand a drop test, which challenges the closure assembly. The testing proposed consists of a single drop test. The test will be a 9-m (30-ft) drop at $17.5 \pm 2.5^{\circ}$ from the horizontal, with the closure ring lugs $90^{\circ}$ from the impact point. (See Figures A-1 and A-2.)

The 9-m (30-ft) drop test will be followed by a standard $1-\mathrm{m}$ (40-in.) puncture test. Because each test is designed to add to damage inflicted on a specific component or assembly in the preceding test, the exact orientation of the package for the puncture test will be determined after the damage inflicted by the $9-\mathrm{m}$ $(30-\mathrm{ft})$ drop test has been examined. 


\subsection{Package Description}

The ABB-2901 shipping packaging (Combustion Engineering 1997) is designed for shipment of uranium oxide fuel pellets. The package evolved from the UNC-2901 shipping package and is identical to it in all respects except for the configuration (i.e., corrugated trays), in which the fuel pellets are placed into the inner compartment, and the allowable tolerances for the inner compartment. The ABB-2901 fuel pellet shipping configuration was developed primarily to reduce the amount of pellet damage during shipment, as well as to provide the pellets in a configuration compatible with certain pellet-to-rod pushing operations during fuel rod fabrication, thereby minimizing pellet handling.

Based on a Transport Index (TI) of 0.50 , the maximum number of shipping packages per shipment is limited to not more than 100 (i.e., 50/0.50).

\subsection{Package Description}

\subsubsection{Packaging}

The ABB-2901 shipping package consists of a standard steel drum, with a 10 inch square inner compartment centered in the steel drum. The inner compartment is centered by hardboard support rings. Asbestos or ceramic sheet, plywood and Fiberlite insulation provide thermal protection to the inner compartment, which is the radioactive material containment boundary. The inner compartment is fitted with a bolted lid and gasket to assure positive closure.

The ABB-2901 container has a steel insert which holds four boxes of pellets on corrugated trays and is placed into the inner compartment.

\subsubsection{Operational Features}

The ABB-2901 shipping package is of relatively simple design, and does not incorporate cooling systems, shielding, etc.

\subsubsection{Contents of Packaging}

Fuel pellets are shipped in a horizontal orientation on corrugated trays; corrugated trays are not used to ship reject pellets or pieces.

Maximum Enrichment: 5.0 wt.\%

Type Material: Sintered (high fired) uranium oxide fuel pellets ( $\left.\leq 5.0 \mathrm{wt} . \%{ }^{235} \mathrm{U}\right)$, various poison materials, such as Gadolinia, Erbia, B4C, Stainless Steel, or Depleted Uranium $\left(\leq 0.22 \mathrm{wt.} \%{ }^{235} \mathrm{U}\right)$.

Maximum quantity per shipping package:

a) Maximum net weight of fuel pellets: $103.0 \mathrm{~kg}$ (227 lbs)

b) Gross weight of the shipping package, as assembled for shipment, shall not exceed $299.4 \mathrm{~kg}$ (660 lbs). 


\subsection{Regulatory Compliance}

As was noted in Section 1.2, the failure of two of WSRC's packagings (i.e., the WSRC-9974 and the WSRC-9975 packagings) during shallow-angle HAC drop testing raised concerns about the vulnerability of all drum-type packagings, particularly those with a bolted ring closure. Both were relatively heavy, fissile, and Type-B packagings. In the case of the WSRC-9974 packaging, which weighed about $700 \mathrm{lbs}$, the lid came off of the packaging completely, which would have allowed the containment vessels to come out of the packaging. Certification of the WSRC-9974 packaging was not pursued (WSRC 2001). Removal of the lid from a packaging of this design would have been a reportable occurrence under 10 CFR 71.95(a), because there was a clear and significant reduction in the effectiveness of the packaging.

In the case of the WSRC-9975 packaging, which weighed about $400 \mathrm{lbs}$, an opening developed between the lid and the drum body that was some two to three times greater than that allowed for by the applicant. Although it was not clear that this had actually produced a significant reduction in the effectiveness of the packaging, the drum/lid interface was redesigned, and the packaging was later certified

For the ABB-2901 packaging, it is assumed from the outset that these tests will not result in either the containment system being discharged from the drum or the contents escaping from containment or the drum. As was noted in Section 1.1, the primary purpose of these tests is to resolve systemic concerns about relatively heavy, drum-type overpack lid retention questions during top-down, shallow-angle, HAC impact tests. For purposes of these tests, therefore, the primary failure criterion will be defined as the complete separation of the lid from the drum body. A secondary failure criterion can also be defined as the partial separation of the lid from the drum body, if it can be determined that the separation produced will result in a significant reduction in the effectiveness of a drum-type packaging.

The secondary area of interest to be examined is the question of damage to the packaging at the drum lid/body interface, specifically with respect to possible criticality issues and the requirements of 10 CFR 71.59(a)(2). Thus, the testing will also be used to determine if the effective dimensions of the packaging can be decreased sufficiently, or the containment system can be moved sufficiently close to the external surface of the drum, so that two times "N" damaged packages are not subcritical with optimum interspersed hydrogenous moderation, where " $\mathrm{N}$ " is derived from the criticality TI of the package. 


\subsection{Discussion on System Failure Modes of Interest}

The ABB-2901 packaging is based on a typical, drum-type packaging design, that has long had a successful performance reputation under steeper angle HAC drops (i.e., $45^{\circ}$ to $60^{\circ}$ ), which, for many years, was accepted to be the most unfavorable drop orientation. Recently, however, two, relatively heavy, WSRC drum-type packagings failed, with the partial, or complete removal of the drum lid, under relatively shallow-angle drop test conditions (i.e., $15^{\circ}$ to $30^{\circ}$ ). The nominal weights of the two packagings that failed were $182 \mathrm{~kg}(400 \mathrm{lbs})$ and $341 \mathrm{~kg}(750 \mathrm{lbs})$, for the partial lid separation, and the complete lid removal, respectively. The present test program is to evaluate the vulnerability of the ABB-2901 packaging to shallow-angle drops.

\subsection{Normal Conditions of Transport}

Because the concerns described pertain only to Hypothetical Accident Conditions, no Normal Conditions of Transport tests will be performed.

\subsection{Hypothetical Accident Conditions}

Past failures of drum closures like that used on the ABB-2901, which uses the traditional closure ring, indicate that a number of $9-\mathrm{m}(30-\mathrm{ft})$ drop and puncture scenarios can cause the failure:

(1) The impact force generated by a 9-m (30-ft) shallow-angle drop can buckle the drum lid. If the buckled lid bulges away from the drum interior, the action can result in a detachment of the lid from the closure ring and the drum body.

(2) The detachment of the lid can increase significantly if the drum contents slide towards the drum lid at the same time.

(3) If the impact force of a 9-m (30-ft) drop strikes the closure-ring bolt at one of its ends, the impact force can produce a large prying action to break the welds which connect the bolt lug to the closure ring.

(4) Striking the closure-ring bolt in the drum-axis direction, the puncture bar can cause the closure ring and its bolt to rotate about the drum edge and result in ripping the closure ring off the drum lid and body. If the closure ring resists the rotation, the puncture force can produce a large tension in the bolt-lug-to-closure-ring welds to cause a rupture of the welds and a total separation of the closure lid, ring and drum body.

(5) The damage produced by the preceding 9-m (30-ft) drop can relax the pretension of the closure ring and make the ripping off of the closure ring easier.

Obviously, a comprehensive evaluation of all the foregoing possibilities would require more than a single pair of free-drop and puncture tests, although the staff believes that the sliding of the contents is not a concern for the ABB-2901. Thus, in planning the present test program, the challenge is to identify a single set of 
free drop and puncture tests which are most likely to produce the greatest damage to the ABB drum closure. The selected test conditions, which includes a 9-m (30$\mathrm{ft}), 17.5 \pm 2.5^{\circ}$ shallow-angle drop, are shown in Figures A-1 and A-2. This test is to by followed by a standard 1-m (40-in.) puncture test. Current plans for the puncture test call for the striking of the closure-ring bolt and lug assembly, at an angle to be determined after the damage produced by the drop test has been evaluated. The 9-m (30-ft) drop will strike the drum closure edge at a location that is directly under the center of one of the four flat edges of the square fuel-pellet container of the ABB-2901 drum package, and is $90^{\circ}$ from the closure-ring bolt. The staff expects the 9-m (30-ft) drop to cause buckling of the drum lid, and the puncture test to rip off the closure ring or to rupture the bolt-lug-to-closure-ring welds.

In the selection of the $17.5 \pm 2.5^{\circ}$ impact angle for the 9-m (30-ft) drop, the staff took into consideration the following information:

(1) A $17.5 \pm 2.5^{\circ}$ free drop produced the latest lid buckling failure of the WSRC-9975 package drum lid.

(2) At an angle of $17.5 \pm 2.5^{\circ}$, the majority of the impact energy will be devoted to the buckling of the drum lid, and only a small portion of the energy will be used to press the drum lid, closure ring, and drum body closer together. Simplified dynamic analyses conducted by the staff using closed-form solutions and the SCANS computer program (USNRC 1990) indicated that the impact force and momentum in the plane of the drum lid, which can cause buckling of the lid, reaches a maximum value at a drop angle of about $30^{\circ}$. However, at this impact angle the impact force and momentum normal to the drum lid, which can push the drum lid, closure bolt and drum body closer together, is also large. This normal impact force vanishes only at a $0^{\circ}$ impact.

In the selection of the impact location for the $9-\mathrm{m}(30-\mathrm{ft})$ drop, the staff considered the following information:

(1) To detach the drum lid from the closure ring and the drum body, the impact needs to produce a deep indentation into the drum body, so that a large buckling deformation of the drum lid can develop. The large gap and relatively soft plywood located between the drum body and the center of an edge of the square fuel-pellet container will provide the necessary room for developing the required deep indentation and large buckling deformation.

(2) To locate the closure-ring bolt at a location $90^{\circ}$ from the impact point serves two purposes:

(a) The bolt location will act as a node (fixed boundary) for the lid buckling deformation. Thus the bolt location will confine the drum-lid buckling to the bottom half of the drum lid, where the impact force is, in relative terms, higher. 
(b) The bolt is located sufficiently far from the impact point, so that the damage produced by the $9-\mathrm{m}$ ( $30-\mathrm{ft}$ ) drop at the impact point will not prevent the removal of the closure ring by the subsequent puncture test. The impact damage from the 9-m (30-ft) drop will push the drum lid, closure ring and drum body closer together, and may render the separation of the three components in the damaged area more difficult. 
The plywood covers supporting the drum lid of the ABB-2901 appear to be stronger than the Celotex material used for the WSRC-9975 packaging. Therefore, the ABB-2901 drum may be able to survive the shallow-angle 9-m (30-ft) drop without a lid and ring separation. On the other hand, the ABB-2901 appears to have a weaker closure-ring-bolt lug design. Thus the puncture bar test may inflict damage to the ABB-2901 more easily than that which was inflicted to the WSRC-9975.

The specifics for the drop tests to be performed are given below in Table A-1. The drop angle of the packaging relative to the unyielding surface is shown below in Figure A-1. The position of the closure ring lugs and the packaging internals relative to the impact point is shown in Figure A-2. 
Table A-1. ABB-2901 Drum Lid Retention Test Matrix

\begin{tabular}{|c|c|}
\hline 9-m (30-ft) Drop Orientation & Top-Down, $17.5 \pm 2.5^{\circ}$ \\
\hline Lug position & $180^{\circ}$ from Impact Point \\
\hline Package weight & $297.4 \mathrm{~kg}(655 \mathrm{lbs})$ \\
\hline Temperature & Ambient \\
\hline Puncture & $\begin{array}{c}\text { 1-m (40 in.) Drop - } \\
\text { Orientation TBD* }\end{array}$ \\
\hline
\end{tabular}

* Appropriate impact point and angle for the puncture will be determined based on damage caused in the $9-\mathrm{m}(30-\mathrm{ft})$ drop.

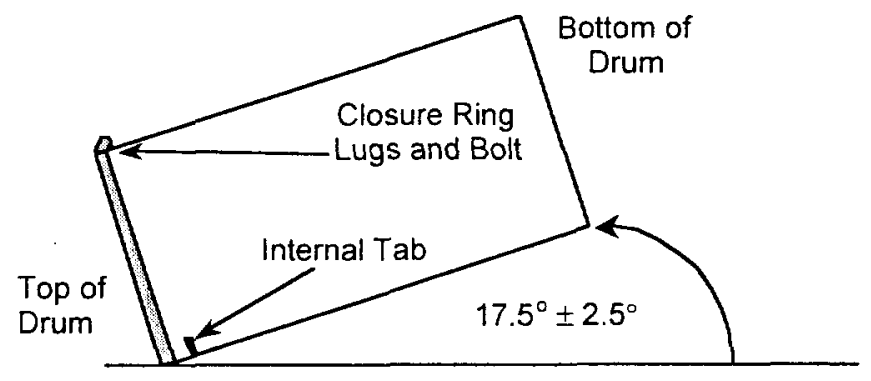

Figure A-1. Drop Angle of the Packaging Relative to the Impact Surface.

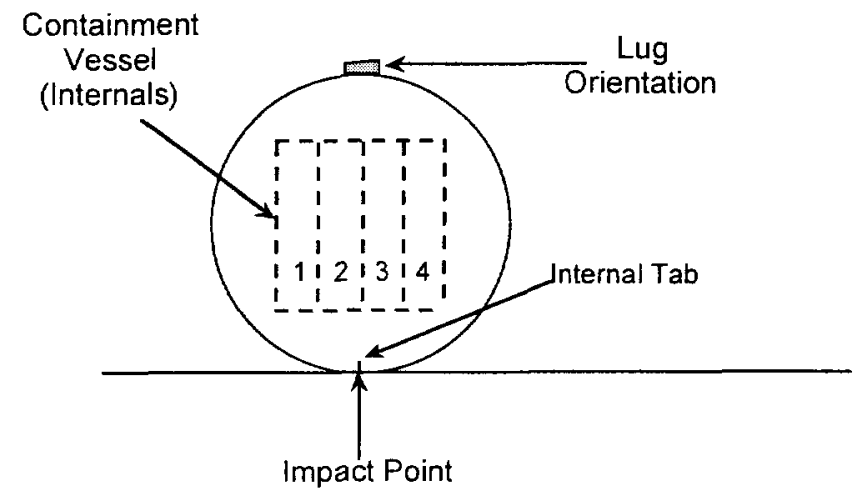

Figure A-2. Orientation of Closure Ring Lugs from Impact Point. 


\subsection{Assessment of Package Conformance}

\subsection{Regulatory Requirements}

5.1.1 Normal Conditions of Transport

Because the concerns described pertain only to Hypothetical Accident Conditions, no Normal Conditions of Transport will be performed.

\subsubsection{Hypothetical Accident Conditions}

Under the requirements specified in 10 CFR 71.95(a), the purpose of these tests is to resolve systemic concerns about relatively heavy, drum-type overpack lid retention questions during top-down, shallow-angle, HAC impact tests. For purposes of these tests, therefore, the primary failure criterion will be defined as the complete separation of the lid from the drum body. A secondary failure criterion can also be defined as the partial separation of the lid from the drum body, if it can be determined that the separation produced will result in a significant reduction in the effectiveness of a generic, drum-type packaging.

The secondary area of interest to be examined is the question of damage to the packaging at the drum lid/body interface, specifically with respect to possible criticality issues and the requirements of 10 CFR 71.59(a)(2). (See Section 3.0.)

\subsection{Test Package Contents}

As was noted above, the ABB-2901 shipping package consists of a standard steel drum, with a 10_ inch square inner compartment centered in the steel drum compartment, centered by hardboard support rings.. The inner container, in turn, has a stainless steel insert that holds four boxes of fuel pellets on corrugated trays.

The fuel pellets themselves are normally shipped in a horizontal orientation on corrugated trays, the maximum net weight of fuel pellets being $103.0 \mathrm{~kg}$ (227 lbs).

In order to simulate the weight of the fuel pellets, steel plates will be used, evenly spaced throughout each of the four boxes. The total weight of the steel plates and spacers will be kept to a maximum of $103.0 \mathrm{~kg}$ ( $227 \mathrm{lbs}$ ), and the maximum gross weight of the package, as assembled for testing, shall not exceed $299.4 \mathrm{~kg}$ (660 lbs). 


\subsection{Condition and Loading Procedures for the Test Specimen}

The ABB-2901 shipping container to be tested is an existing packaging, which was shipped to Lawrence Livermore National Laboratory (LLNL) by Transportation Logistics, Inc., of Bethesda, MD. Its history is totally unknown to the personnel testing the packaging at LLNL. It is assumed that the packaging can be tested, as is, and that the packaging has been maintained in accordance with the appropriate requirements. Accordingly, no special refurbishment of the packaging will be performed prior to the loading, or the testing, of the package.

Package loading will be performed following the generic loading procedures in the Operating Procedures Section of Combustion Engineering, Inc.'s Safety Analysis Report for Packaging, for the ABB-2901 Packaging, with the exception that the loading of the uranium dioxide fuel pellets will be simulated with the loading of surrogate, _-inch-thick steel plates and spacers.

For purposes of completeness, the procedures for loading the ABB-2901 shipping container are listed below, modified appropriately. (Note: With the concurrence of the Test Requestor, the Test Engineer, and the Facility Operator, the details of any of the steps noted below may be modified to fit the actual loading circumstances.)

1) The pellet tray boxes are alternatively loaded with the spacers and surrogate steel plates, and transferred to a scale area where the weights of the boxes is determined by measurement and adjusted to be within the loading limit of 190 pounds (i.e., $86.2 \mathrm{~kg}$ ). From the scale area, the pellet tray boxes are brought to the loading area to await loading.

2) Prior to loading the pellet tray boxes into the shipping package, its ring clamp, outer drum lid, circular wooden top spacer, inner compartment cover and cover gasket are removed. The outer shell of the steel drum is inspected to assure that there are no holes or tears. The shipping pallet, upon which the shipping package rests, is also inspected to assure it is in reasonable condition prior to use (i.e., no bent legs, straps are in place, etc.). Once the shipping package and shipping pallet are determined to be acceptable for use, the corrugated pellet tray boxes of surrogate steel plates can be loaded.

3) Initially, the first loading step is to place a wooden spacer block in the bottom of the inner container. This is followed by the insertion of the heavy steel shelved insert. Although it is removable, the shelved insert is not intended to be removed and inserted on a continuous basis due to its weight. Therefore, following initial assembly, this step only needs to be repeated if the insert has been removed. 
4) The shelved insert contains four locations, which accommodate the corrugated pellet tray boxes. Each of the four boxes is filled with up to eight corrugated pellet trays depending on the type (i.e., diameter) of fuel pellet being shipped. An empty corrugated tray is used over the top layer of fuel pellets as a cover for the stack of pellet trays. A piece of compressible rubber material approximately the size of a corrugated tray is placed on top of the uppermost tray and the box lid is attached to the pellet box. The thickness of the rubber material is listed on the engineering drawings in Appendix 1A [of the SARP]. (See Note 1, on Drawing Number D-5018-8438.) 
5) The four corrugated tray pellet boxes are placed into the steel insert. If fewer than the total number of trays for each pellet diameter are to be shipped in a box, then the void left by any missing trays shall be filled with wood spacers. If there is insufficient material to fill all four locations per insert, for structural reasons, an empty box filled with a wood spacer must occupy the unused locations.

6) After loading of the four corrugated tray boxes into the steel insert is complete, an additional wood spacer block is inserted, which occupies the remaining volume within the inner compartment. Before installing the inner compartment cover gasket, the gasket is inspected for acceptability and replaced if necessary. The inner compartment cover gasket and cover are installed, secured with nuts.

Note 1: The 1/2 13 UNC nuts for the inner containment compartment should be tightened to $35 \mathrm{ft}$. lbs. No specific tightening sequence is specified. When all of the nuts are tightened, verify that all torque values are set to a final value of $35 \mathrm{ft}$. lbs. Following this the circular wooden top spacers, lid and ring clamp are installed thereby sealing the entire package.

Note 2: The orientation of the closure-ring lugs/bolt is to be $180^{\circ}$ from the impact point (see Figure A-2).

Note 3: The closure-ring bolt should be tightened to a final value of $75 \pm 5$-ft-lbs. To verify that the closure force is uniform all-around, the closure-ring should be tapped, all-around, with a leaded hammer, while the closure ring bolt is being tightened.

Note 4: Before final closure, the impact point of the package will be marked with an indelible marker, after final verification that the relative orientations of the package internals are correct. The outside surface of the shipping package is smeared and surveyed, as appropriate. Finally, the loaded package is weighed, to verify that the total package weight does not exceed $660 \mathrm{lbs}$ (i.e., $299.4 \mathrm{~kg}$ ). The package can then be moved to the drop test area.

7) The outside surface of the shipping package is smeared and surveyed. Finally, the shipping package is appropriately labeled, a tamper-proof seal is applied, and the shipping package is removed to a storage area to await shipment or it is loaded directly on the transport vehicle, as appropriate.

8) The ABB-2901 shipping package is loaded, unloaded and transported in a horizontal orientation. 


\title{
7.0 Material and Equipment List
}

\author{
All materials and equipment will be supplied by LLNL's DTED personnel assigned to \\ LLNL's Site 300 . Figure A-3 is a copy of the Test Request.
}

\section{$1+\infty 16041$}

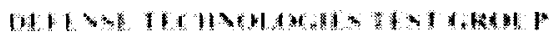

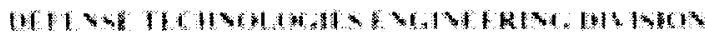

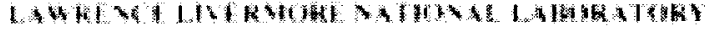

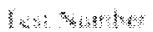

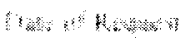

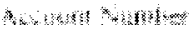 \\ ins \\ $12+1$ \\ Nowhe 2 wa \\ Alation
}

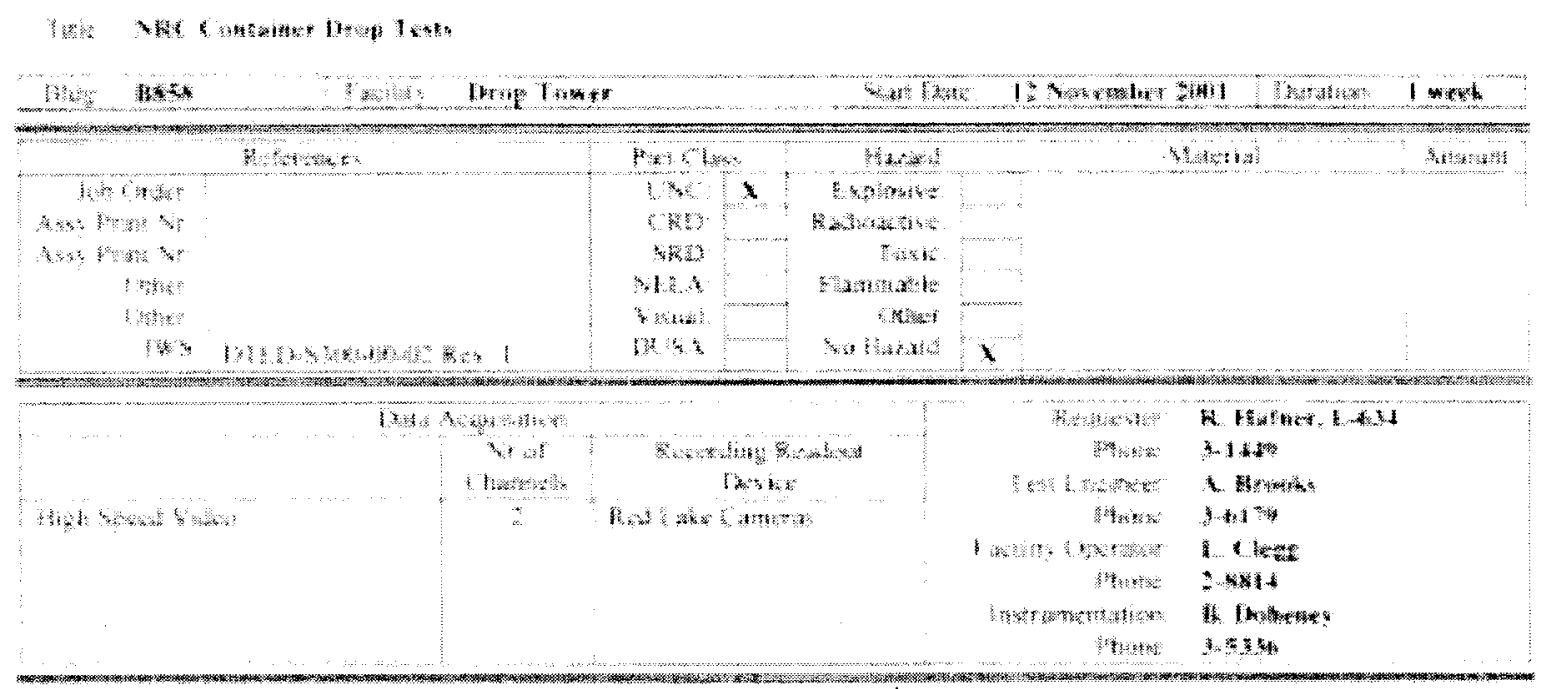

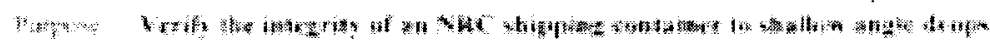

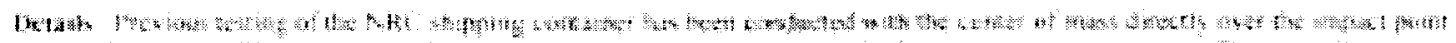

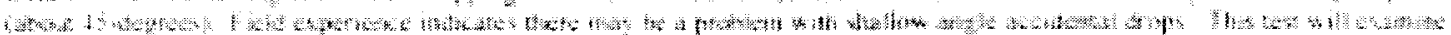

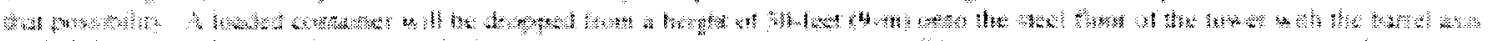

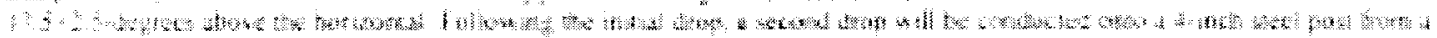

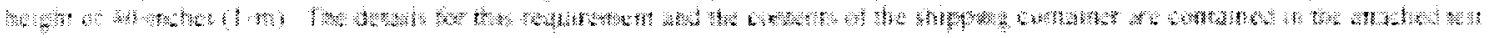

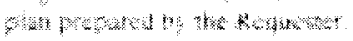

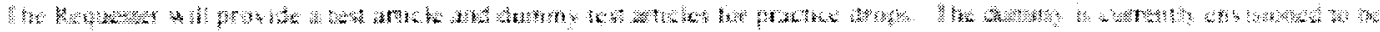

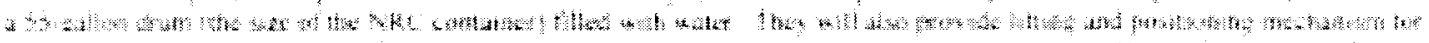

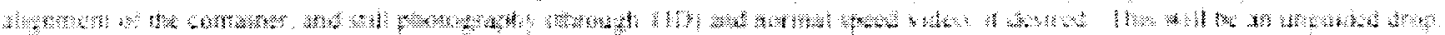

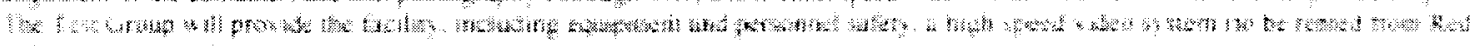

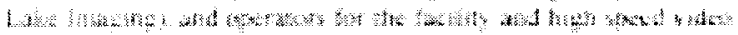

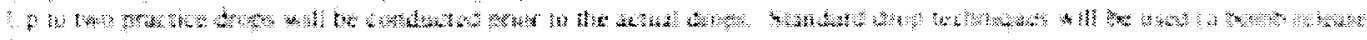
W

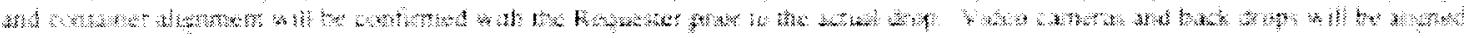

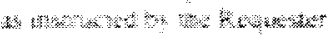

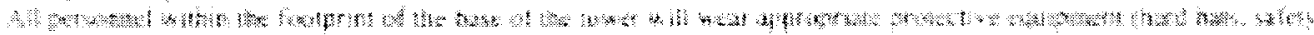

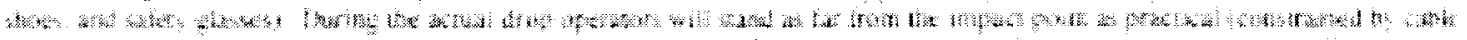

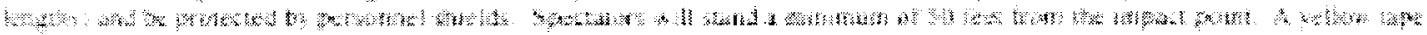

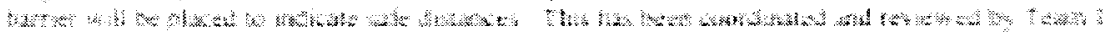

Figure A-3. The Test Request Form 


\subsection{Test Procedures}

\subsection{General}

The specimen is to be tested in the sequence outlined below. Each test has been designed to check the integrity of various components of the package. (See Section 4.0, above.) An assessment of overall integrity of the package can be made based an the cumulative effect of the tests performed on the package.

After completion of the $9-\mathrm{m}(30-\mathrm{ft})$ drop test, the puncture test will follow. The justification and description for the orientation of the puncture test shall be documented.

The tests have the following sequence:

- 9-m (30-ft) Free Drop (10 CFR 71.73(c)(1)):

- Test specimen preparation and inspection

- 9-m (30-ft) free drop test

- Post-test inspection and analysis

- Puncture Drop Test (10 CFR 71.73(c)(3)):

- Test specimen preparation and inspection

- Puncture test

- Post-test inspection

- Post-Test Assessments:

- Final inspections and/or assessments

- Preparation of Final Report

- Test specimen disposition

\subsection{Roles and Responsibilities}

The responsibilities of the groups identified in this plan are:

- Fission Energy and Systems Safety Program (FESSP) personnel from Lawrence Livermore National Laboratory (LLNL) are responsible for the overall development and coordination of this Test Plan.

- DTED personnel from LLNL are responsible for the overall implementation of the tests, to, and including, the implementation of all applicable Integrated Safety Management, and Quality Assurance requirements.

- DTED personnel are also responsible for ensuring that the test and specimen data are measured and recorded throughout the test cycle.

- FESSP personnel are responsible for monitoring the tests and reviewing test data for compliance with regulatory requirements.

\subsection{Test Specimen Preparation and Inspection}

1. Measure and record the weight of the test specimen. 
2. Inspect the test specimen to ensure that the test specimen complies with the requirements on the drawings.

3. DTED personnel, along with FESSP personnel will jointly verify that the test specimen complies with the drawings.

4. Prepare the test specimen for transport to the drop-test tower.

\subsection{Summary of Test Schedule}

This section provides an overall view of the test specimen orientations for each test.

\subsubsection{Normal Conditions of Transport Tests}

No Normal Conditions of Transport Tests are to be conducted under this test plan.

\subsubsection{Hypothetical Accident Conditions Tests}

The first HAC test is the 9-m (30 ft) free drop test, as described in 10 CFR 71.73(c)(1). The schematics shown in Figures A-1 and A-2 illustrate the appropriate orientation for this test.

\subsubsection{9-m (30-ft) Free Drop Test Set-Up}

To set up the package for the 9-m (30-ft) drop test:

1. Measure and record the weight of the test specimen;

2. Place the specimen on the drop test surface;

3. Position the specimen according to the specific orientation as is shown in Figure A-1;

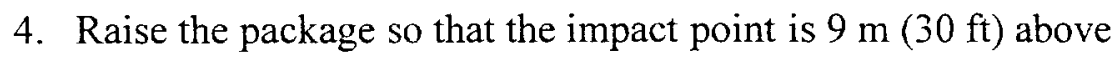
the drop surface;

5. Measure and record the ambient weather conditions, i.e., the ambient temperature, wind speed, wind direction, etc.;

6. Photograph the set-up;

7. Start the video recorders;

8. Drop the package;

9. Stop the video recorders;

10. Record the damage to the package and take a photographic record. 
8.4.2.2 9-m (30-ft) Free Drop Test Assessment

Upon completion of the test, FESSP, DTED, and NRC personnel (as appropriate) team members will jointly take the following actions:

- Review the test execution to ensure that the test was performed in accordance with 10 CFR 71.73(c)(1), IAEA Safety Series $\# 6$, and this test plan.

- Make a preliminary evaluation of the specimen relative to the requirements of 10 CFR 71 and IAEA Safety Series \#6.

- Assess the damage to the specimen to decide whether testing of that specimen is to continue.

- Evaluate the condition of the specimen to determine what changes, if any, are necessary in package orientation in the puncture test to achieve maximum damage.

\subsubsection{Puncture Test}

The follow-up HAC test is the $1-\mathrm{m}$ (40 in.) puncture test, as described in 10 CFR 71.73(c)(3).

The package is dropped from a height of $1 \mathrm{~m}$ (40 in.) onto the puncture billet. This test uses a $40(+)$ in. high puncture billet. The billet meets the minimum height ( 8 in.) required in $10 \mathrm{CFR}$ $71.73(\mathrm{c})(3)$. The specimen has no projections or overhanging members longer than 12 in. that could act as impact absorbers, allowing the billet to cause the maximum damage to the test specimen. The billet is to be bolted to the drop surface used in the drop tests.

The justification for the puncture orientation is the same as the orientation for the $9-\mathrm{m}(30-\mathrm{ft})$ drop test, i.e., if the orientation needs to be changed, the new orientation will be documented and approved with a justification describing how it would be a worst condition than the planned orientation. 


\subsubsection{Puncture Test Set-Up}

NOTE: Because both tests are designed to add to damage inflicted on a specific component or assembly in the preceding test, in this case, the drum/lid interface, it is important that the test specimen maintain its identity throughout the tests, and that the set-up instructions specific to the specimen are strictly followed.

To set up the package for the puncture test:

1. Measure and record the weight of the test specimen;

2. Place the specimen on the drop test surface;

3. Position the specimen according to the orientation that has been decided upon as a result of the decisions following the 9-m (30-ft) drop test, i.e., see Section 8.4.2.2;

4. Raise the package so that the impact point is $1 \mathrm{~m}$ (40 in.) above the edge of the surface of the test billet;

5. Measure and record the ambient weather conditions, i.e., the ambient temperature, wind speed, wind direction, etc.;

6. Photograph the set-up;

7. Start the video recorders;

8. Drop the package;

9. Stop the video recorders;

10. Record the damage to the package and take a photographic record.

The objective of the puncture drop orientation is to continue the damage inflicted on the specimen by the 9-m (30-ft) drop test.

\subsubsection{Puncture Test Assessment}

Upon completion of the test, FESSP, DTED, and NRC personnel (as appropriate) team members will jointly take the following actions:

- Review the test execution to ensure that each test was performed in accordance with 10 CFR 71 and this test plan.

- Make a preliminary evaluation of the specimen relative to the requirements of 10 CFR 71 .

- Assess the damage to the specimen to decide whether testing of the specimen is to continue. 


\subsection{References}

Combustion Engineering, Inc., "Application for Use of Model No. ABB-2901 Fuel Pellet Shipping Package," Certificate of Compliance No. 9274," Revision 0, NRC Docket No. 71-9274, April 8, 1997.

Title 10, Code of Federal Regulations, Part 71 (10 CFR 71), "Compatibility with the International Atomic Energy Agency (IAEA)," 60 FR 50248, September 28, 1995, as amended.

U.S. Nuclear Regulatory Commission, "SCANS (Shipping Package Computer ANalysis System): A Microcomputer Based Analysis System for Shipping Package Design Review," NUREG/CR-4554 (UCID-20674), February 1990.

Westinghouse Savannah River Corporation, "Safety Analysis Report — Packages, 9972-9975 Packages (U)," WSRC-SA-7, Revision 12, Radioactive Materials Packaging Technology, Savannah River Technology Center, Aiken, SC, June 2001. 